\title{
Rural Electric Cooperatives IRP Survey
}

Cynthia Garrick

Garrick \& Associates

Morrison, Colorado

DISTRIBUTION OF THIS DOCUMENT IS UNLIMITED

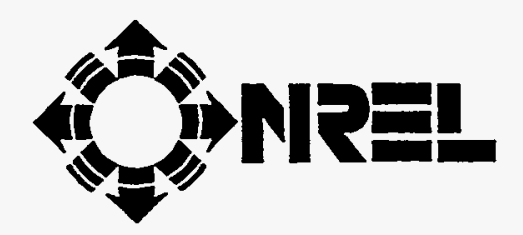

National Renewable Energy Laboratory 1617 Cole Boulevard Golden, Colorado 80401-3393

A national laboratory of the U.S. Department of Energy Managed by Midwest Research Institute for the U.S. Department of Energy under Contract No. DE-AC36-83CH10093 



\section{Rural Electric Cooperatives IRP Survey}

Cynthia Garrick

Garrick \& Associates

Morrison, Colorado

NREL Technical Monitor: Paul Galen

National Renewable Energy Laboratory 1617 Cole Boulevard

Golden, Colorado 80401-3393

A national laboratory of the

U.S. Department of Energy

Managed by Midwest Research Institute

for the U.S. Department of Energy

under Contract No. DE-AC36-83CH10093

Prepared under Subcontract No. AAW-3-13353-01

November 1995 


\section{NOTICE}

This report was prepared as an account of work sponsored by an agency of the United States government. Neither the United States government nor any agency thereof, nor any of their employees, makes any warranty, express or implied, or assumes any legal liability or responsibility for the accuracy, completeness, or usefulness of any information, apparatus, product, or process disclosed, or represents that its use would not infringe privately owned rights. Reference herein to any specific commercial product, process, or service by trade name, trademark, manufacturer, or othenwise does not necessarily constitute or imply its endorsement, recommendation, or favoring by the United States government or any agency thereof. The views and opinions of authors expressed herein do not necessarily state or reflect those of the United States government or any agency thereof.

Available to DOE and DOE contractors from:

Office of Scientific and Technical Information (OSTI)

P.O. Box 62

Oak Ridge, TN 37831

Prices available by calling (615) 576-8401

Available to the public from:

National Technical Information Service (NTIS)

U.S. Department of Commerce

5285 Port Royal Road

Springtield, VA 22161

(703) $487-4650$ 


\section{Acknowledgments}

The extensive information on rural electric cooperative integrated resource planning (IRP) practices and IRP policies presented in this report was made possible by the contributions of the "Advancement of IRP in Public Power" Steering Committee. The efforts of the following committee members are greatly appreciated: Barry Moline of the American Public Power Association, Eric Westman of the Bonneville Power Administration, Rob Church and Mike Oldak of the National Rural Electric Cooperative Association (NRECA), Georg Shultz of the Rural Electrification Administration (REA), Bill Stewart and Kim Ledbetter of Southeastern Power Administration, Jerry Martin of Southwestern Power Administration, Lynn Maxwell of the Tennessee Valley Authority, and Theresa Williams and Randy Manion of Western Area Power Administration.

Special thanks to Georg Shultz, whose cooperation and assistance in the Cooperative IRP Survey were instrumental to the success of the project. NRECA staff and generation and transmission cooperative representatives from NRECA's IRP Technical Advisory Committee also provided key input for the survey.

Several NREL and Garrick \& Associates personnel were key contributors to the Rural Electric Cooperatives IRP Survey. Jan Eckert's (of NREL) perseverance in obtaining information regarding state IRP policies is evident in Appendix B. Jim Garrick's extensive project input and guidance included assisting in survey instrument design and results analysis. 


\section{Summary}

This report presents integrated resource planning (IRP) practices of U.S. rural electric cooperatives and the IRP policies which influence these practices. By indicating the scope and depth of IRP as practiced by this sector of the U.S. electric utility industry, the report will assist the U.S. Department of Energy (DOE) in fulfilling the reporting requirements of Title I, Subtitle B, Section 111(e)(3) of the Energy Policy Act of 1992 (EPAct), which states:

(e) REPORT.-Not later than 2 years after the date of the enactment of this Act, the Secretary (of the U.S. Department of Energy) shall transmit a report to the President and to the Congress containing-(the findings from several surveys and evaluations, including:)

(3) a survey of practices and policies under which electric cooperatives prepare IRPS, submit such plans to $R E A$, and the extent to which such integrated resource planning is reflected in rates charged to customers.

The Cooperative IRP Survey report was developed by the National Renewable Energy Laboratory (NREL) and its subcontractor, Garrick \& Associates, in close cooperation with the National Rural Electric Cooperative Association (NRECA) and the Rural Electrification Administration (REA). ${ }^{1}$ Information from the REA and federal and state agencies and a mail survey of cooperatives were used to complete this report on rural electric cooperative IRP policies and practices. Mail survey responses were received from 47 of the 64 generation and transmission cooperatives (G\&Ts) and 256 of the 859 distribution cooperatives located in the continental United States. These survey responses provide $95 \%$ confidence with a standard error of $\pm 7.4 \%$ for G\&T results and $95 \%$ confidence with a standard error of $\pm 5.2 \%$ for distribution cooperative results. As will be discussed later in this report, the availability of current information regarding IRP rate impacts is limited.

\section{IRP in the Cooperative Sector}

IRP in the cooperative utility sector is not as well understood as it is in the investor-owned utility (IOU) sector. The structure of the cooperative industry-which is characterized by a non-integrated organization, complex relationships between cooperative systems, and consumer ownership and control-results in unique IRP policies and practices.

Rural electric cooperatives (or cooperatively owned utilities) are consumer-owned cooperatives which are incorporated under the laws of the state in which they operate. In 1992, cooperatively owned utilities sold about 7\% of the country's electricity (APPA 1994). These cooperatively owned utilities include 64 G\&Ts and approximately 880 distribution cooperatives. ${ }^{2}$ The G\&Ts are responsible for supplying all of the power required by their member distribution cooperatives (approximately 780 distribution cooperatives are members of a G\&T) and, as such, are vested with power planning and IRP responsibilities. The distribution systems, which provide the electricity to member consumers, participate in some of the G\&Ts' planning activities and implement demand-side options. The distribution cooperatives that are not members of a G\&T-there are about 100-obtain power supplies from other sources (for example, federal power agencies, investor-owned utilities (IOUs), and self-generation).

\footnotetext{
${ }^{1}$ In December of 1994, the REA became the Rural Utilities Service (RUS). The agency is referred to as the REA throughout this document.

${ }^{2}$ Distribution cooperatives located outside of the continental United States (i.e., Alaska and the territories) were not included in the survey.
} 
The structure of the cooperative utility sector must be recognized when interpreting the IRP policy and practice information presented in this report. This includes recognition of complex interrelationships and overlapping IRP responsibilities. For example, survey responses are reported for "super G\&Ts" (G\&Ts that are owned by other G\&Ts) as well as for a number of the G\&Ts (known as "mid G\&Ts") that own them. As a result, there is an apparent "double-counting" of IRP practices in cases where a super G\&T and a mid G\&T for which they have load responsibility both independently report IRP activities. Therefore, despite the uniqueness of each G\&Ts planning responsibilities, the IRP practices of each responding utility should be presented with the understanding that there are overlaps in responsibilities and activities. Further, the cooperative sector includes a number of unique entities, including "paper" cooperatives (G\&Ts that bargain for power, but do not generate or transmit power). Several cooperatives choose to submit a letter to NREL to indicate the uniqueness of their situation rather than to complete the IRP survey questionnaire.

\section{IRP Policies}

More than 20 federal and state agencies have established IRP policies or rules that influence rural electric cooperative IRP practices, and several additional agencies are currently developing IRP policies. The REA, which is the principal source of long-term G\&T and/or distribution facility debt financing for almost all of the nation's cooperatives, has the most influence of any single agency on cooperative resource planning. All REA borrowers must submit two primary documents, power requirements studies and construction work plans, on a routine basis. The REA considers its rules ("General and Pre-Loan Policies and Procedures Common to Insured and Guaranteed Electric Loans") to be an "IRP" requirement for the nation's cooperatively owned utilities. Although REA's requirements reflect various elements of the IRP process, greatest emphasis is placed on load forecasting, demand-side management (DSM), and supply-side activities. With the passage of the 1993 Rural Electric Loan Restructuring Act, REA's authority has expanded in the area of IRP. This act gives the REA the ability to make loans for all types of DSM programs. In the past, the REA could only provide loan funds for load-control equipment. REA now requires an IRP prior to approval of loans that include funds for DSM activities and/or on- or off-grid renewable energy systems.

Federal power agencies are also significant players in cooperative IRP, as cooperatives nationwide purchase over $30 \%$ of their electricity supplies from these federal agencies. Cooperatives that purchase power from the Bonneville Power Administration (BPA) or the Tennessee Valley Authority (TVA) are included in centralized, regional IRPs. In the Pacific Northwest region served by BPA, regional IRP is practiced by the Northwest Power Planning Council under the authority of the Northwest Power Act of 1980. BPA and its public utility customers, including approximately 56 rural electric cooperatives, participate in implementing the regional IRP. The 50 cooperatives that receive all-requirements electric service from TVA participate in TVA's least-cost planning process, which is required by EPAct (Section 113). TVA expects to complete an initial plan by December 1995.

The Western Area Power Administration (WAPA) is currently developing an IRP requirement that will affect approximately 45 cooperative utilities in its 15 -state region. The IRP requirement is mandated by Section 114 of EPAct. WAPA expects to publish a final IRP rule in the spring of 1995. Two of the other federal power agencies, the Southeastern Power Administration (SEPA) and the Southwestern Power Administration (SWPA), use power sales contract articles to promote cooperative IRP practice. SEPA calls its IRP policy "voluntary," and SWPA does not establish a schedule for customer IRP efforts or require customers to submit an IRP to the agency.

More than 300 cooperatives will be affected to some degree by the IRP Standard established by Congress in 1992. EPAct amended the Public Utilities Regulatory Policy Act of 1978 to require "each state 
regulatory authority (with respect to each electric utility for which it has ratemaking authority) and each nonregulated electric utility..." to consider implementation of IRP.

In at least 13 states, cooperatives are required to practice IRP and another 4 states are currently developing IRP requirements. This compares with 29 states that require IOUs to develop IRPs and 9 states that require government-owned utilities (i.e., municipalities and other federal, state, or local government utilities) to develop IRPs. States require IRP of cooperatives by means of legislation and/or rules. Typically, these requirements involve the preparation of 10- to 20-year IRPs every 2 or 3 years. Some public utility commissions (PUCs) have the authority to approve or disapprove cooperative IRPs, while others provide review comments to the utilities for their use. State IRP requirements may affect G\&Ts, distribution cooperatives, or both, depending upon the regulatory authority of the PUC. For example, the Virginia Corporation Commission regulates 13 distribution cooperatives but does not have regulatory authority over G\&Ts. In Minnesota, the IRP policy only applies to the state's four largest G\&Ts. However, these four G\&Ts are owned and controlled by a total of 72 distribution cooperatives that will indirectly be affected by, and involved in, the IRP process.

In 1992, the 900-plus member cooperatives of NRECA adopted an IRP resolution, Continuing Resolution \#53. The resolution emphasizes that rural electric systems must continue to use IRP, and states the need for cooperation and coordination among the various entities involved in IRP.

\section{IRP Practice}

G\&Ts, as power suppliers, are vested with resource planning responsibilities on behalf of their member distribution (and "mid G\&T") cooperatives. Each G\&T's IRP practices reflect its individual situation and the requirements placed upon it by the REA and others. Of the 47 G\&Ts responding to the NREL IRP survey, the majority indicated that they currently conduct all elements of IRP using a range of planning approaches. Load forecasting and public involvement, along with supply- and demand-side resource assessment and risk analysis, are practiced by $74 \%$ to $85 \%$ of responding G\&Ts. The remaining G\&Ts do not have resource planning responsibilities either because this responsibility lies with a "super G\&T" or federal power agencies, or because their function is limited (for example, "paper G\&T"). Environmental and/or social costing and integrated supply- and demand-side resource evaluation are not as widely practiced by G\&Ts, with $60 \%$ to $65 \%$ of respondents reporting inclusion of these IRP elements in their resource planning.

Distribution cooperative IRP practice is best described by the nature and extent of involvement in power supplier IRP activities, as only 14 of the 256 distribution cooperatives responding to the NREL IRP survey prepares an IRP independent of a G\&T or federal power agency. This is consistent with the REA's requirements that a power supply borrower and all member systems coordinate in the development of a system-wide IRP.

The majority of responding distribution cooperatives participate with their G\&T in all IRP elements. This participation is particularly prevalent in the areas of load forecasting, demand-side assessments, and implementation of the resource plan. These aspects of IRP are characterized by greater distributor involvement than is the case for other IRP elements that are more directly tied to the G\&Ts resource planning responsibilities. In addition, many distribution cooperatives also perform various IRP elements on their own, with load forecasting and demand-side assessments being the most common independent activities.

As evidenced by the information presented in this report, IRP in the cooperative sector does not have the same characteristics as the IRP commonly practiced by IOUs. It appears that there is significant opportunity to further understand and develop IRP as it best applies to cooperatives, including enhancing 
IRP analysis and implementation approaches for multitiered generation, transmission, and distribution systems. At the same time, there is ample opportunity for cooperative utilities, and the agencies that influence them, to adopt advanced IRP approaches as part of their ongoing planning processes. 


\section{Contents}

Page

Introduction $\ldots \ldots \ldots \ldots \ldots \ldots \ldots \ldots \ldots \ldots \ldots \ldots \ldots \ldots \ldots \ldots \ldots \ldots$

Integrated Resource Planning $\ldots \ldots \ldots \ldots \ldots \ldots \ldots \ldots \ldots \ldots \ldots \ldots \ldots \ldots$

- Cooperative IRP Survey Approach $\ldots \ldots \ldots \ldots \ldots \ldots \ldots \ldots \ldots \ldots \ldots \ldots \ldots$

Profile of the Cooperative Utility Sector $\ldots \ldots \ldots \ldots \ldots \ldots \ldots \ldots \ldots \ldots \ldots \ldots \ldots \ldots$

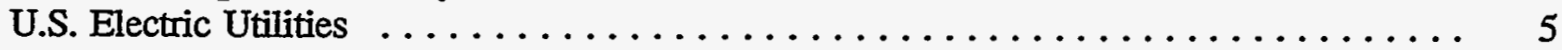

Cooperative Utility Attributes $\ldots \ldots \ldots \ldots \ldots \ldots \ldots \ldots \ldots \ldots \ldots \ldots \ldots \ldots \ldots$

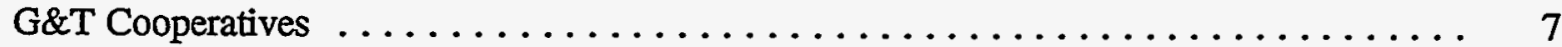

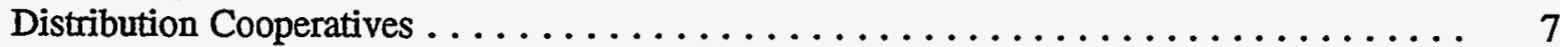

Policies $\ldots \ldots \ldots \ldots \ldots \ldots \ldots \ldots \ldots \ldots \ldots \ldots \ldots \ldots \ldots \ldots \ldots \ldots \ldots \ldots$

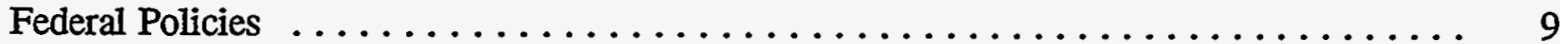

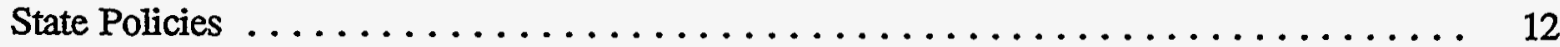

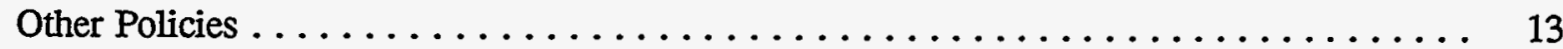

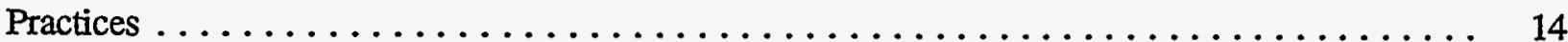

G\&T Cooperative IRP Practices $\ldots \ldots \ldots \ldots \ldots \ldots \ldots \ldots \ldots \ldots \ldots \ldots \ldots \ldots \ldots$

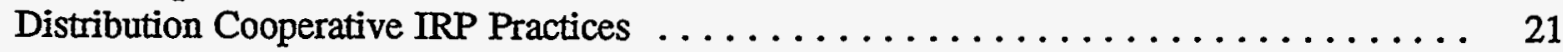

Conclusions $\ldots \ldots \ldots \ldots \ldots \ldots \ldots \ldots \ldots \ldots \ldots \ldots \ldots \ldots \ldots \ldots \ldots \ldots \ldots \ldots$

References $\ldots \ldots \ldots \ldots \ldots \ldots \ldots \ldots \ldots \ldots \ldots \ldots \ldots \ldots \ldots \ldots \ldots \ldots \ldots$

Appendix A: Glossary of Terms $\ldots \ldots \ldots \ldots \ldots \ldots \ldots \ldots \ldots \ldots \ldots \ldots \ldots \ldots$

Appendix B: Federal and State IRP Policies Applicable to Cooperative Utilities $\ldots \ldots \ldots$. . B-1

Appendix C: G\&T Cooperative Survey Instrument $\ldots \ldots \ldots \ldots \ldots \ldots \ldots \ldots$

Appendix D: Distribution Cooperative Survey Instrument $\ldots \ldots \ldots \ldots \ldots \ldots \ldots \ldots$ 


\section{List of Figures}

$\underline{\text { Page }}$

1. Organization of U.S. electric utilities $\ldots \ldots \ldots \ldots \ldots \ldots \ldots \ldots \ldots \ldots \ldots \ldots \ldots$

2. Types of $G \& T$ cooperatives $\ldots \ldots \ldots \ldots \ldots \ldots \ldots \ldots \ldots \ldots \ldots \ldots \ldots \ldots \ldots$

3. G\&T IRP elements: extent of member distribution cooperative involvement $\ldots \ldots \ldots \ldots 15$

4. Load-forecasting methods used by G\&T cooperatives . . . . . . . . . . . . 16

5. Supply-side planning and analysis methods used by G\&T cooperatives $\ldots \ldots \ldots \ldots \ldots$

6. Cost-effectiveness tests used by G\&T cooperatives for demand-side resource evaluation $\ldots 18$

7. Approaches used by G\&T cooperatives to consider environmental and/or social costs $\ldots \ldots 18$

8. Supply- and demand-side integration methods used by G\&T cooperatives . . . . . . . 19

9. Risk analysis methods used by $\mathrm{G} \& \mathrm{~T}$ cooperatives $\ldots \ldots \ldots \ldots \ldots \ldots \ldots \ldots \ldots$

10. Public involvement approaches used by G\&T cooperatives $\ldots \ldots \ldots \ldots \ldots \ldots \ldots$

11. IRP practices of distribution cooperatives $\ldots \ldots \ldots \ldots \ldots \ldots \ldots \ldots \ldots \ldots \ldots \ldots \ldots$

12. Public involvement approaches used by distribution cooperatives $\ldots \ldots \ldots \ldots \ldots \ldots \ldots$

\section{List of Tables}

Page

1. Interpretation of the EPAct Cooperative IRP Requirement $\ldots \ldots \ldots \ldots \ldots \ldots \ldots \ldots \ldots$

2. 1992 Electric Utility Statistics $\ldots \ldots \ldots \ldots \ldots \ldots \ldots \ldots \ldots \ldots \ldots \ldots \ldots \ldots \ldots \ldots \ldots \ldots$

3. IRP Policies Affecting Cooperative Utilities: Type and Applicability . . . . . . . . 10

4. IRP Policies Affecting Publicly Owned Utilities: Required IRP Elements $\ldots \ldots \ldots \ldots$

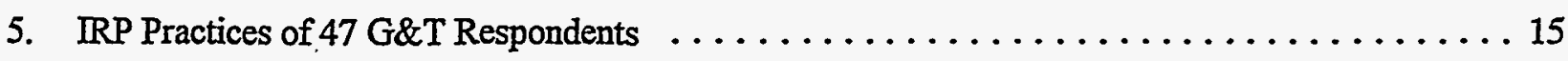





\section{Introduction}

This report summarizes the integrated resource planning (IRP) practices of U.S. rural electric cooperatives and the IRP policies which influence these practices. It was prepared by the National Renewable Energy Laboratory (NREL) and its subcontractor Garrick \& Associates to assist the U.S. Department of Energy (DOE) in satisfying the reporting requirements of Title I, Subtitle B, Section 111(e)(3) of the Energy Policy Act of 1992 (EPAct), which states:

(e) REPORT.-Not later than 2 years after the date of the enactment of this Act, the Secretary (of the U.S. Department of Energy) shall transmit a report to the President and to the Congress containing-(the findings from several surveys and evaluations, including:)

(3) a survey of practices and policies under which electric cooperatives prepare IRPs, submit such plans to REA, and the extent to which such integrated resource planning is reflected in rates charged to customers.

\section{Integrated Resource Planning}

Congress defines IRP as follows:

The term "integrated resource planning" means, in the case of an electric utility, a planning and selection process for new energy resources that evaluates the full range of alternatives, including new generating capacity, power purchases, energy conservation and efficiency, cogeneration and district heating and cooling applications, and renewable energy resources, in order to provide adequate and reliable service to...electric customers at lowest system cost. The process shall take into account necessary features for system operation, such as diversity, reliability, dispatchability, and other factors of risk; shall take into account the ability to verify energy savings achieved through energy conservation and efficiency and the projected durability of such savings measured over time; and shall treat demand and supply resources on consistent and integrated basis. (EPAct of 1992, Section 111[d])

IRP was first introduced in the late 1970s (EPRI 1987) to provide a planning approach that is more adaptable to fundamental changes affecting electric utilities than are traditional methods. These changes include increasing competition; deregulation of electricity generation; greater access to transmission; and increased concern with the environmental consequences of electricity production and use. In addition, there is considerable uncertainty about future load growth, fossil-fuel prices and availability, and the costs and construction lead-times for various resources (Goldman 1989).

As practiced by U.S. electric utilities, IRP typically involves some or all of the following elements:

- Load Forecasting-Estimating future annual electricity use and peak demand requirements, for use in making resource allocation decisions.

- Supply-Side Resource Assessment-Evaluating supply resources for meeting an electric utility's future resource requirements. A supply-side resource assessment may include the examination of a range of resources including purchased power, alternative/renewable resources, life extension and repowering of existing plants, utility construction of power plants, and new or upgraded transmission facilities. 
- Demand-side Resource Assessment-Evaluating demand-side resources for meeting an electric utility's future resource requirements. A demand-side resource assessment may include the examination of peak clipping, valley filling, load shifting, strategic conservation, and strategic load growth.

- Consideration of Environmental and/or Social Costs-Inclusion of various environmental and social costs and benefits, such as those related to air quality or economic development. In addition to the consideration of "internal" costs (for example, compliance with air quality regulations), many utilities consider "externalities" associated with electrical power production and use that are not already incorporated in the price of electric services.

- Integrated Supply- and Demand-side Resource Evaluation-A comparison of supply- and demand-side resources for the purpose of selecting the optimum mix of resources. The comparative evaluation allows equal consideration of both supply- and demand-side resource options.

- Uncertainty/Risk Analysis-Analysis of a variety of possible future conditions and the options available to deal with them. An uncertainty analysis provides information about the relative risks of alternative resource strategies. Its primary purpose is to facilitate better resource planning decisions which reduce risk.

- Public Involvement-A public planning process ensure that a broad range of interests and potential resource options are considered by utility decision-makers and also helps to build consensus about the best resource plan.

After approval by the public utility commission (PUC) or other administrative or regulatory body, for public utilities, the plan is implemented (i.e., resources are acquired). While the plan is in force, the utility monitors changes in its environment and its implementation of the resource plan, and the plan is modified as events and opportunities change over time. While all of the various elements listed above can be incorporated within an IRP process, it is important to note that many IRPs include only a portion of these elements, depending upon a utility's particular situation or the nature of a particular IRP requirement.

\section{Cooperative IRP Survey Approach}

The Cooperative IRP Survey was conducted by NREL and its subcontractor, Garrick \& Associates, in close cooperation with the National Rural Electric Cooperative Association (NRECA) and the Rural Electrification Administration (REA). The overall project approach involved interpreting the EPAct requirement to delineate specific information to be obtained through the survey effort, obtaining this information through primary and secondary research, compiling and analyzing research findings, and presenting findings in this Cooperative IRP Survey report.

The EPAct cooperative IRP survey requirement seeks information in three overall categories: IRP practice, IRP policies, and rate impacts of IRP. Table 1 provides an interpretation of these three components of the EPAct requirement by delineating specific information to be obtained through survey efforts, to the extent practical. 
Table 1. Interpretation of the EPAct Cooperative IRP Requirement

\begin{tabular}{ll}
\hline Information Category & \multicolumn{1}{c}{ Information Needed } \\
\hline IRP practices & - How is IRP being done by cooperative utilities, including the \\
frequency and scope of activity?
\end{tabular}

To the extent practical, the information in Table 1 was obtained through primary and secondary research. Information regarding rural electric cooperative IRP practices, policies, and rate impacts was gathered first from existing sources. Primary data research was then used to obtain additional information not available through secondary sources.

\section{IRP Practices}

The REA provided information regarding IRP practices of generation and transmission G\&T cooperative borrowers. The REA-provided information primarily consists of load forecasting practices, such as forecasting frequency and methods. Appendix $\mathrm{C}$ includes a list of information that was obtained directly from the REA.

The main source of information on IRP practices was a mail survey of G\&T cooperative and distribution cooperatives. NREL and Garrick \& Associates worked closely with NRECA and the REA to design the survey instrument (see Appendices C and D) and to develop the survey sample. The survey sample was stratified into two utility types, G\&T and distribution cooperatives. A 100\% sample of G\&Ts was surveyed, because these utilities have resource planning responsibility for a majority of distribution cooperatives. In addition, a $100 \%$ sample was required to obtain reliable results because there are only 64 G\&T cooperatives in the United States. A statistically valid sample of distribution cooperatives was contacted to reduce the time involvement required from these typically resource-constrained utilities. ${ }^{3}$

The mail survey was designed to achieve a $90 \%$ level of confidence with $\pm 10 \%$ margin of error. Survey responses were received from 47 of the nation's 64 G\&Ts and 256 of the 859 distribution cooperatives

${ }^{3}$ Each of the two utility type subsets was also stratified into six geographic regions so that regional results could be obtained for use in the development of DOE's IRP advancement strategy for publicly and cooperatively owned utilities. Regional results were not analyzed as part of the Cooperative IRP Survey project. 
located in the continental United States. These survey responses provide 95\% confidence with a standard error of $\pm 7.4 \%$ for G\&T results nationwide and $95 \%$ confidence with a standard error of $\pm 5.2 \%$ for distribution cooperative results nationwide.

\section{IRP Policies}

Federal and state agencies with IRP policies that potentially affect cooperatives were also surveyed as part of this effort. Existing and planned policies that apply to cooperatives were identified. For each policy, key information was obtained, including effective date, enabling authority, applicability, and specific requirements. Appendix B presents this key information for all identified federal and state IRP policies that apply to rural electric cooperatives.

\section{Rate Impacts of IRP}

Significant limitations exist related to determining the rate impacts of IRP. EPAct requires the U.S. Department of Energy (DOE) to "...survey...the extent to which such integrated resource planning is reflected in rates charged to customers." Limited information about IRP rate impacts is obtained from NRECA, the REA, and the mail survey effort. This limited information addresses the following questions: "What are the costs associated with IRP development?" and "Is the cost of developing an IRP recovered through rates, and to what extent?" More detailed rate impact information (such as "Are resulting rates higher or lower than they would have been with no IRP?") is not available from any source, primary or secondary. There are two main reasons that this information does not exist. First, cooperatives have not been practicing IRP long enough to have acquired significant resources as a result of the process (i.e., they have not experienced the long-term rate impacts associated with IRP). Second, there is currently no recognized and accepted technique available to perform such an analysis of the rate impacts of IRP.

The findings of the primary and secondary research efforts conducted by NREL and Garrick \& Associates are presented in three sections: Profile of the Cooperative Utility Sector; Policies; and Practices. The first section briefly profiles the cooperative sector of U.S. electric utilities to provide readers with a context for the IRP results presented in the remainder of the report. The policies section presents IRP policies that apply to cooperatives. The practices section summarizes the IRP practices of the nation's rural electric cooperatives, based on information obtained from the REA and from primary research conducted by NREL and Garrick \& Associates. 


\section{Profile of the Cooperative Utility Sector}

There are approximately 950 rural electric cooperatives providing electric service to 25 million Americans in 46 states as well as Puerto Rico, the Virgin Islands, and American Samoa (NRECA 1991a). Rural electric cooperatives are consumer-owned entities established to provide electric service to rural America. These consumer cooperatives are incorporated under the laws of the state in which they operate.

\section{U.S. Electric Utilities}

Figure 1 illustrates the organization of U.S. electric utilities, which include investor-owned utilities (IOUs) and publicly owned utilities. Publicly owned utilities consist of both cooperatively owned and government-owned utilities. Cooperatively owned utilities are rural electric cooperatives and include both G\&Ts and distribution cooperatives. Table 2 presents key 1992 statistics for all U.S. electric utilities, including cooperatives. As indicated in the table, there were 3,236 U.S. electric utilities in 1992 . Of these utilities, cooperatively owned systems accounted for 941 (29\%) of these utilities and sold about $7 \%$ of the nation's electricity during 1992.

\section{Cooperative Utility Attributes}

Cooperatives have a number of attributes which distinguish them from IOUs. These include access to financing from the REA, the lack of a profit motive, consumer ownership and control, and preference access to federal hydroelectricity.

Electric cooperatives are generally financed through the assumption of long-term debt and retained margins. The REA provides cooperatives with access to long-term debt capital at reasonable interest rates for generation, transmission, and distribution facilities. The agency is the principal source of long-term

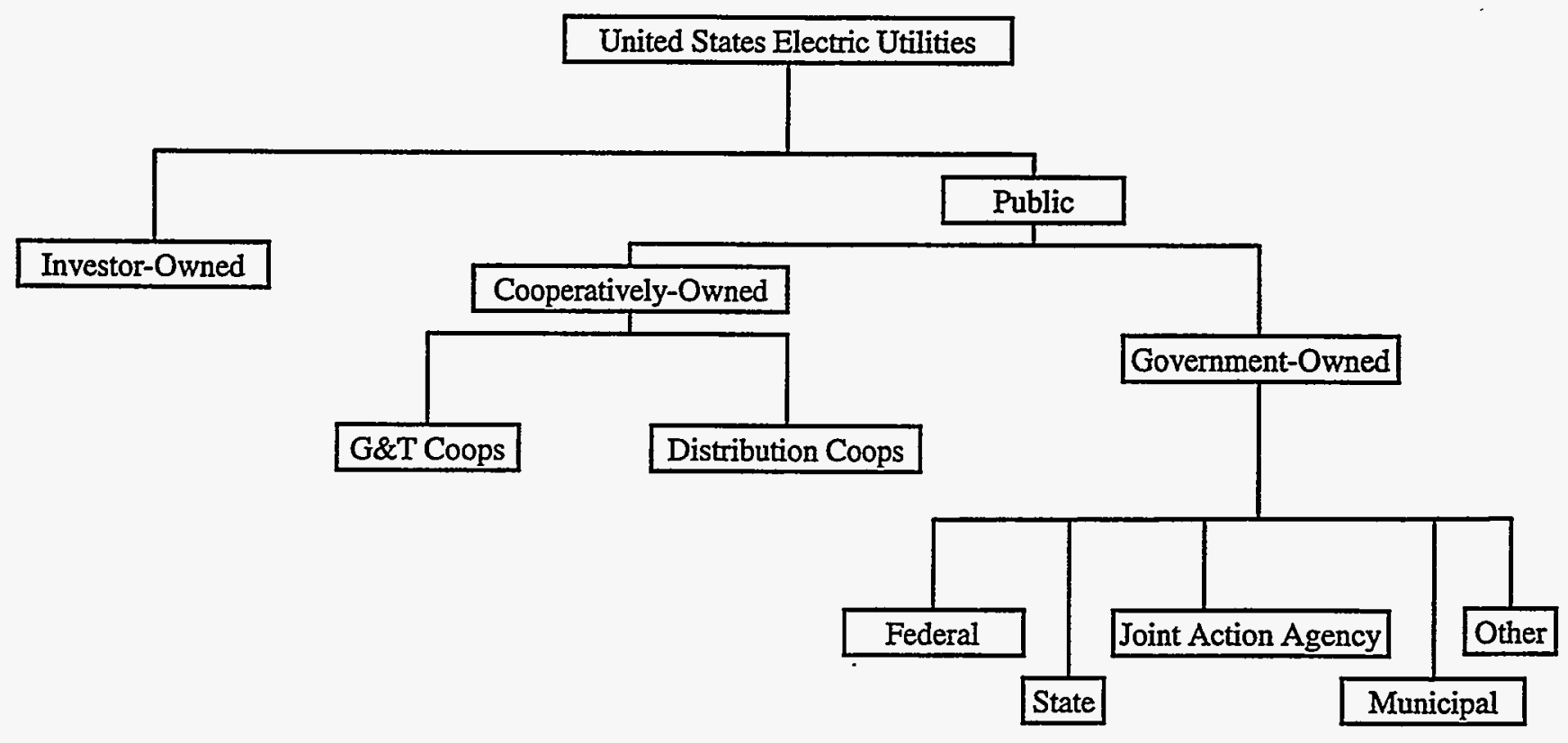

Figure 1. Organization of U.S. electric utilities 
Table 2. 1992 Electric Utility Statistics

\begin{tabular}{|c|c|c|c|c|c|c|c|c|}
\hline \multirow{2}{*}{ U.S. Electric Utilities } & \multicolumn{2}{|c|}{ Number } & \multicolumn{2}{|c|}{ Electric Sales (GWh) } & \multicolumn{2}{|c|}{$\begin{array}{l}\text { Electric Revenues } \\
\text { (in } \$ 1,000 \text { ) }\end{array}$} & \multicolumn{2}{|c|}{ Electric Meters } \\
\hline & Total & Percent* & Total & Percent ${ }^{\star}$ & Total & Percent* & Total & Percent ${ }^{\star}$ \\
\hline $\begin{array}{l}\text { IOUs } \\
\text { Public }\end{array}$ & 261 & $8 \%$ & $2,112,229$ & $76 \%$ & $149,016,218$ & $79 \%$ & $85,789,200$ & $76 \%$ \\
\hline $\begin{array}{l}\text { Co-op-owned- } \\
\text { Gov't-owned }\end{array}$ & $\begin{array}{r}941 \\
2,034 \\
3226\end{array}$ & $29 \%$ & $\begin{array}{r}206,794 \\
444,592 \\
762,615\end{array}$ & $\begin{array}{r}7 \% \\
16 \%\end{array}$ & $\begin{array}{r}14,455,132 \\
25,030,934 \\
\end{array}$ & $\begin{array}{r}8 \% \\
13 \% \\
100 \%\end{array}$ & $\begin{array}{r}11,944,041 \\
15,549,139 \\
113 ? 90390\end{array}$ & $\begin{array}{l}11 \% \\
14 \% \\
100 \%\end{array}$ \\
\hline
\end{tabular}

*Total of individual percentages may not exactly equal $100 \%$ because of rounding.

Source: American Public Power Association. (January-February 1994). Public Power Magazine, Annual Statistical Issue; Vol. 2, No. 1, pp. 72-73. Data reflect 1992 statistics based on Energy Information Administration Forms APPA-860 and APPA-861.

debt financing for almost all of the nation's cooperatives. Other common sources of long-term debt financing are the National Rural Electric Cooperative Financing Corporation and the Banks for Cooperatives.

Prior to 1973, the REA provided access to capital through direct loans. This direct-loan program was terminated in 1973 and replaced by an insured and guaranteed loan program. Under this program, distribution cooperatives typically obtain $70 \%$ of required debt from the REA and the remaining $30 \%$ through supplemental loans from private-sector institutions. This debt is usually secured through a common mortgage and loan contract. G\&Ts obtain their debt financing through the use of an REA loan guarantee. This guarantee is used to obtain financing from either government or private-sector financial institutions. In 1993, the Rural Electrification Loan Restructuring Act modified the interest rates for the REA's insured loan program. Interest rates were changed from a fixed rate of 5\% to a rate tied to the retum for municipal bonds. The loan guarantee program was unchanged.

Cooperative utilities are not-for-profit entities and as such are not motivated by shareholder profits or rate-basing investments. Any revenues received over and above operating expenses and debt service flow back to the consumers in the form of lower rates and/or capital credits, ${ }^{4}$ improved service, and other community contributions. Cooperative utilities are also owned by their member consumers and governed by consumer-elected boards of directors. As a result, many cooperatives are not regulated by state PUCs. The degree of regulation varies from state to state-from no regulation to full regulation.

Cooperative utilities also have greater access than do IOUs to low-cost hydroelectricity marketed by federal power agencies as a result of the preference principal, which specifies that public utilities be given first purchase rights to these power resources. First legislated in 1906, the preference clause has been included in more than 30 national statutes. Although the preference principle has been challenged in the past, it remains important to the operation of many cooperative utilities because it provides access to low-cost power.

Currently, there are more than 60 G\&Ts and close to 900 distribution cooperatives in the United States. The nation's G\&Ts provide all power supplies for their approximately 780 member distribution cooperatives, and these distribution systems provide the electricity to their member consumers. In

\footnotetext{
${ }^{4}$ Capital credits are funds credited to rural electric cooperative members that equate to their ownership equity in the system.
} 
addition, there are approximately 100 distribution cooperatives that are not members of a G\&T and that obtain power supplies from other sources (e.g., federal power agencies, IOUs, and self-generation).

\section{G\&T Cooperatives}

G\&Ts are power suppliers owned by several individual distribution cooperatives. They are governed by boards of directors consisting of representatives from all member distribution cooperatives. In many states, G\&Ts are also regulated by state PUCs. For example, G\&Ts are typically regulated for plant siting, and some states regulate G\&T wholesale rates.

The nation's 64 G\&Ts are responsible for supplying all of the power required by their 780 distribution cooperative members, and do so by generating the power and/or procuring it contractually from public or private utilities. About $44 \%$ of the electricity supplied by the nation's G\&Ts is produced by G\&T-owned plants, while another $33 \%$ comes from federal power sources. The remaining $23 \%$ is purchased from IOUs (NRECA 1990). In 1988, U.S. G\&Ts had a total capacity of more than 30,000 megawatts, including partial ownership in units owned by other utilities. Seventy-five percent of this G\&T-owned plant capacity is coal-fired, $14 \%$ is oil- or gas-fired, $10 \%$ is nuclear, and less than 1\% is hydro (NRECA 1991b).

More than half of the nation's G\&Ts have full G\&T responsibilities. A few of the G\&Ts are referred to as "super G\&Ts" because they are owned by other G\&Ts. Those G\&Ts (that own a super G\&T) are referred to as "mid G\&Ts" and typically have more limited responsibilities than a "regular G\&T." The term "paper G\&T" is used to describe an organization owned by the distribution systems that is legally empowered to generate and transmit but has not done so. Instead, paper G\&Ts bargain for power for their distribution cooperative members (NRECA 1991b). Also, there are a few "other G\&Ts," most of which operate a plant and sell the output to one or more other cooperatives. These G\&Ts do not have any planning responsibilities. As shown in Figure 2, 34 of the nation's cooperatives can be classified as "regular G\&Ts," while the three "super G\&Ts" are owned by 17 "mid G\&Ts." An additional four G\&T are considered "paper G\&Ts" and six can be classified as "other G\&Ts."

\section{Distribution Cooperatives}

Distribution cooperatives are rural electric cooperatives that deliver electricity to residential, agricultural, and other consumers who are generally located in rural areas. Distribution cooperatives are governed by

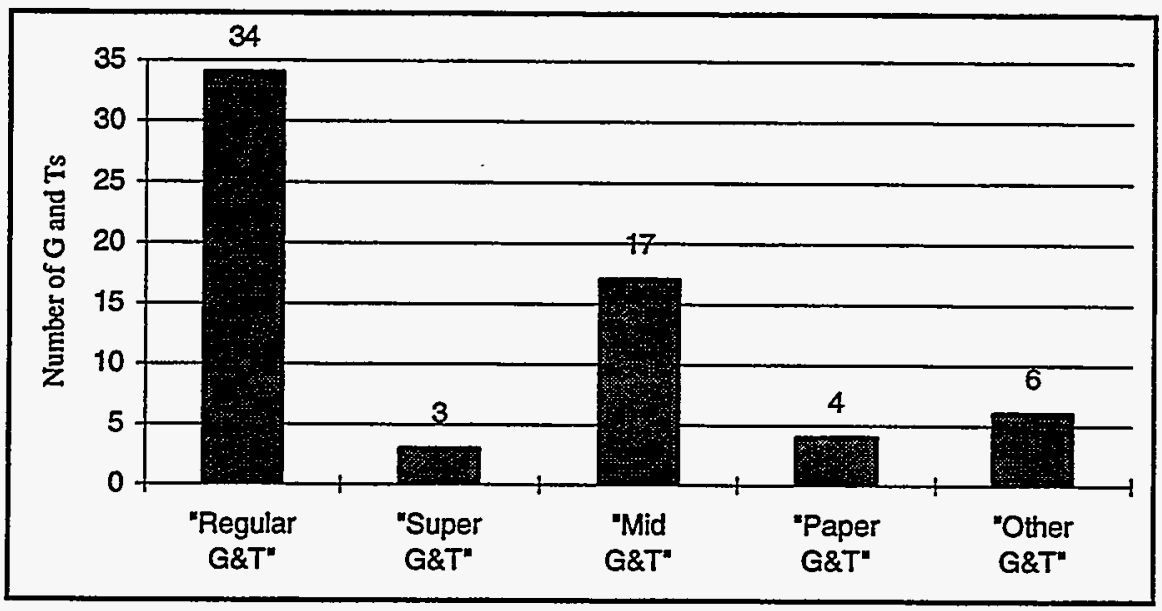

Figure 2. Types of G\&T cooperatives 
boards of directors who are elected by their member consumers. In some states, distribution cooperatives are also regulated by state PUCs. For example, retail rates of distribution cooperatives are subject to regulation in 17 states (NRECA 1990). However, in some of those states, regulation is only applicable to those cooperatives whose consumers have voted for state regulation as a result of concerns about local governance.

In 1990, 889 distribution cooperatives provided electric service in $83 \%$ of the counties in the United States. Distribution cooperatives that are member owners of a G\&T (approximately 780) receive 100\% of their electricity requirements from a G\&T. The nation's remaining "independent" distribution cooperatives (about 100) obtain their power supplies from federal power agencies (for example, the Bonneville Power Administration [BPA] and the Tennessee Valley Authority [TVA]), IOUs, self-generation, or other sources.

The nation's distribution cooperatives are diverse, serving from fewer than 1,000 member consumers to more than 125,000 . Distribution utility plant assets of these cooperatives range from $\$ 1$ million to $\$ 250$ million. The dispersed nature of their territory is illustrated by statistics indicating the average number of consumers per mile of line for various types of utilities. IOUs and municipal utilities, which typically serve urban areas, have an average of 32 and 41 consumers per mile of line, respectively. Distribution cooperatives, which serve predominantly rural areas, have an average of five consumers per mile of line $e^{5}$ (NRECA 1991a). As a result, distribution cooperatives own and maintain more than half the electric distribution lines in the United States, yet they serve only about $10 \%$ of the population.

\footnotetext{
${ }^{5}$ The number of distribution cooperative consumers per mile ranges from fewer than one consumer per mile to more than 30 per mile.
} 


\section{Policies}

More than 20 federal and state agencies have established IRP policies or rules that influence rural electric cooperative IRP practices, and several additional agencies are currently developing IRP policies. Many of these policies apply to cooperatives under state PUC jurisdiction. Other policies apply across a region of the United States, such as a federal power agency's region, or to most cooperatives in the country (in the case of the REA's requirements). One or more of these policies affects practically every cooperative in the United States to one degree or another.

Table 3 lists the various federal, state, and "other" agencies with IRP policies for cooperatives, and also indicates the type of policy (for example, legislation, or rule) and the approximate number of cooperatives to which it applies. Table 4 indicates the IRP elements required by each of the federal, state, and other agencies with IRP policies for cooperative utilities. The required IRP elements indicated in Table 3 are not based on survey input, but rather reflect NREL's and Garrick \& Associates' interpretation of the various federal and state policies.

A concise summary of the various federal, state, and other IRP policies is provided in the remainder of this section. A more detailed discussion of each agency's IRP policy is provided in Appendix B, Federal and State IRP Policies Applicable to Cooperative Utilities.

\section{Federal Policies}

The REA has required all cooperative borrowers to consider both demand- and supply-side resource options since 1992, when the 7 CFR Part 1710, "General and Pre-loan Policies and Procedures Common to Insured and Guaranteed Electric Loans," was published. It is REA's position that the 1710 rule, which requires two primary documents-power requirements studies and construction work plans-to be submitted on a routine basis, provides an "IRP" requirement for approval of all loans. With the passage of the 1993 Rural Electric Loan Restructuring Act, a historical impediment to cooperative IRP has been removed. The act gives REA the ability to make loans for all types of demand-side management (DSM) programs. In the past, REA could only provide loan funds for load-control equipment. In response to the act, the REA published Subpart H-Demand-side Management and Renewable Energy Systems (of the 1710 regulation), which requires an REA-approved IRP prior to approval of loans that include funds for DSM activities and/or on- or off-grid renewable energy systems. The REA specifically requires that a power supply borrower and all member systems coordinate in the development of a system-wide IRP, and that the IRP be approved by the board of directors of the power supply borrower. Virtually all cooperatives are affected by the rule 1710 requirements. The requirements cover both routine reporting and new loan approval policies for G\&T and distribution cooperatives. The only cooperatives that are not subject to these policies and procedures are those few that are not REA borrowers.

Section 113 of EPAct requires the TVA to conduct a least-cost planning process. The agency expects to complete the initial plan in this process by December 1995. TVA, a federal corporation that provides electric power in an area that covers most of Tennessee and parts of Alabama, Georgia, Kentucky, Mississippi, North Carolina, and Virginia, has the utility responsibility for meeting the electric power needs of this region. The agency provides all-requirements electric service to 50 cooperatives. EPAct requires that TVA provide distributors with both an opportunity to participate in the IRP process and with assistance in the planning and implementation of cost-effective energy efficiency options.

The Western Area Power Administration (WAPA) is currently developing an IRP requirement to replace its Guidelines and Acceptance Criteria for the Conservation and Renewable Energy Program. The IRP requirement is mandated by Section 114 of EPAct, which amended Title $I I$ of the Hoover Power Plant 
Table 3. IRP Policies Affecting Cooperative Utilities: Type and Applicability

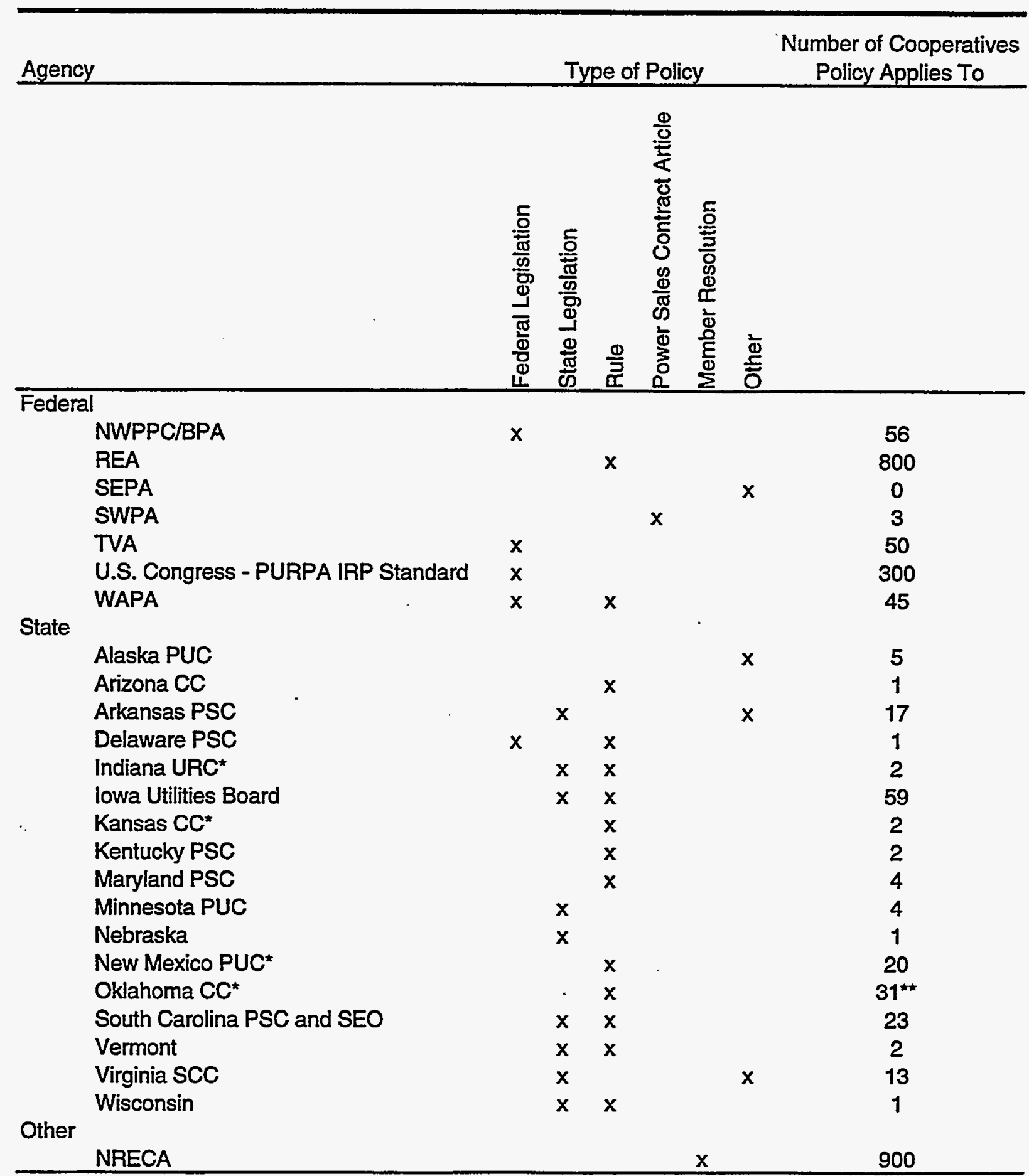

*Proposed policy

**The OCC is currently investigating whether the proposed regulation will apply to all 31 distribution cooperatives. 


\begin{tabular}{|c|c|c|c|c|c|c|c|c|}
\hline Agency & 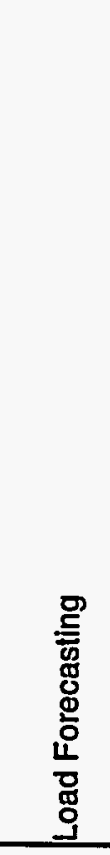 & 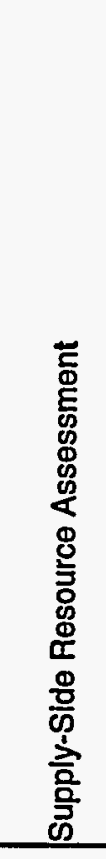 & 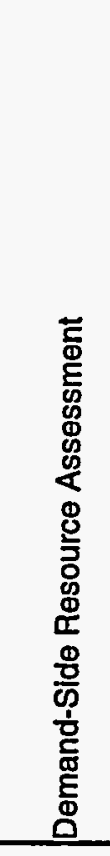 & 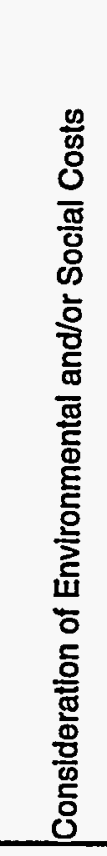 & 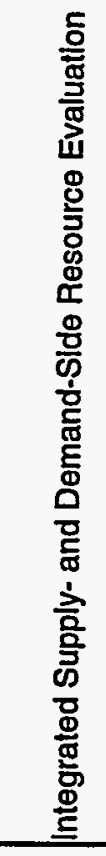 & 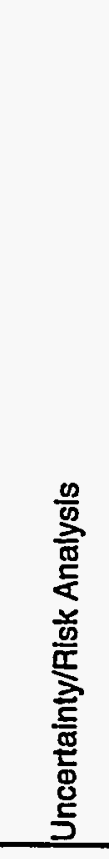 & 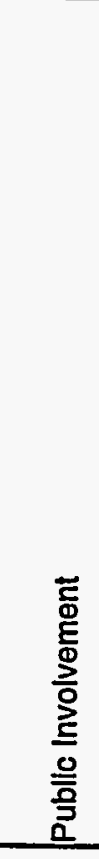 & 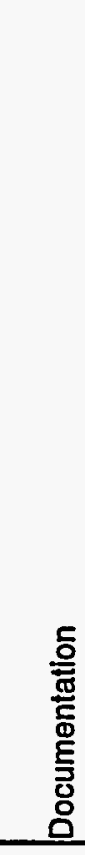 \\
\hline \multicolumn{9}{|l|}{ Federal } \\
\hline NWPPC/BPA & $x$ & $\mathbf{x}$ & $\mathbf{x}$ & $\mathbf{x}$ & $x$ & $x$ & $x$ & $x$ \\
\hline REA & $x$ & $x$ & $x$ & $\mathbf{x}$ & & & & $\mathbf{x}$ \\
\hline SEPA & nla & nla & nla & nla & nla & nla & nla & nla \\
\hline SWPA & & $x$ & $x$ & & $\mathbf{x}$ & & $x$ & \\
\hline TVA & & $\mathbf{x}$ & $x$ & & $\mathbf{x}$ & $\mathbf{x}$ & $\mathbf{x}$ & $x$ \\
\hline U.S. Congress - PURPA IRP Standard & nla & nla & nla & nla & nla & nla & nla & nla \\
\hline WAPA & $\mathbf{x}$ & $\mathbf{x}$ & $x$ & $\mathbf{x}$ & & & $x$ & $x$ \\
\hline \multicolumn{9}{|l|}{ State } \\
\hline Alaska PUC & nla & nla & nla & nla & nla & nla & nla & nla \\
\hline Arizona CC & $x$ & $x$ & $x$ & $x$ & $x$ & $x$ & & $x$ \\
\hline Arkansas PSC & $x$ & $x$ & $x$ & $x$ & $x$ & $x$ & & $x$ \\
\hline Delaware PSC & $x$ & $x$ & $x$ & $\mathbf{x}$ & $x$ & $x$ & & $x$ \\
\hline Indiana URC & tbd & tbd & tbd & tbd & tbd & tbd & tbd & tbd \\
\hline lowa Utilities Board & $x$ & $x$ & $x$ & $x$ & & & & $x$ \\
\hline Kansas $\mathrm{CC}^{\star}$ & tbd & tbd & tbd & tbd & tbd & tbd & tbd & tbd \\
\hline Kentucky PSC & $x$ & $x$ & $x$ & & $x$ & $x$ & & $x$ \\
\hline Maryland PSC & nla & nla & nla & nla & nla & nla & nla & nla \\
\hline Minnesota PUC & $x$ & $x$ & $x$ & $x$ & $x$ & $x$ & & $x$ \\
\hline Nebraska & $x$ & $x$ & $x$ & & & & & \\
\hline New Mexico PUC* & tbd & tbd & tbd & tbd & tbd & tbd & tbd & tbd \\
\hline Oklahoma $\mathrm{CC}^{\star}$ & tbd & tbd & tbd & tbd & tbd & tbd & tbd & tbd \\
\hline South Carolina PSC and SEO & $x$ & $\mathbf{x}$ & $x$ & $x$ & $x$ & $x$ & & $x$ \\
\hline Vermont & $x$ & $x$ & $x$ & $x$ & $x$ & $x$ & $x$ & \\
\hline Virginia SCC & $x$ & $x$ & $x$ & & $x$ & $x$ & & $x$ \\
\hline Wisconsin & $x$ & $x$ & $x$ & $x$ & & & & $\mathbf{x}$ \\
\hline \multicolumn{9}{|l|}{ Other } \\
\hline NRECA & nla & nla & nla & nla & nla & nla & nla & nla \\
\hline
\end{tabular}

*Proposed policy 
Act of 1984 to require that WAPA customers implement IRPs. EPAct states that the IRP requirement is applicable to any WAPA customer who purchases electric capacity (with or without energy) under a long-term firm power service contract, with the possible exception of certain small customers. WAPA serves over 600 long-term firm power customers in 15 western states from Minnesota in the Midwest to California in the West, including approximately 45 cooperative utilities. EPAct also establishes specific penalties for noncompliance by WAPA customers, including rate surcharges and reduced power allocations. EPAct requires WAPA to prepare an environmental impact statement on the development of the IRP rule. IRP rule development and the corresponding Environmental Impact Statement process are in progress. WAPA expects to publish a final IRP rule by spring of 1995.

Two federal power agencies have begun using power sales contract articles to promote customer IRP practice. The Southwestern Power Administration (SWPA) developed an IRP clause for inclusion in all new or updated power sales contracts, which states that "...the customer agrees to the extent practical to perform activities associated with IRP in securing future power resources..." (SWPA 1992). The contract clause does not establish a schedule for customer IRP efforts, nor does it require customers to submit an IRP to SWPA. Since it was developed in 1992, the article has been incorporated into three cooperative customer power sales contracts. The contract article will be added to additional cooperative contracts in 1997, when a number of existing contracts are scheduled for renewal. The Southeastern Power Administration (SEPA) adopted a new power marketing policy for its Cumberland Basin Project that includes an Energy and Economic Efficiency Measures clause to be placed in renewed power sales contracts to encourage IRP. The clause states, "Each customer who purchases Southeastern's power is encouraged to participate in an integrated resource plan that considers both supply and demand side alternatives..." (Federal Register 1993). SEPA anticipates adding this IRP clause to all future contracts.

Congress established an IRP Standard in 1992. Section 111(a) of the EPAct amended Section 111(d)(7) of the Public Utility Regulatory Policy Act of 1978 (PURPA) to require "each state regulatory authority (with respect to each electric utility for which it has ratemaking authority) and each nonregulated electric utility..." to consider implementation of IRP. State regulatory authorities and nonregulated electric utilities must consider the standard within 2 years of its passage (i.e., October 1994) by making public notice and holding a public hearing. Based upon the findings of the hearing, each state commission and nonregulated utility can either implement the IRP standard or decline to implement the standard. Twenty PUCs have full ratemaking authority over cooperatively owned utilities, regulating over 300 cooperatives (Rodgers 1993). In addition, several other state PUCs have limited ratemaking authority over cooperatively owned utilities. The PURPA IRP standard also applies to nonregulated, cooperatively owned utilities over a certain size.

\section{State Policies}

IRP policies for cooperative utilities have been established by at least 13 states. These states require IRP by means of legislation or rules. A few of the IRP policies were developed in the 1970s or early 1980s (Maryland, 1972; Wisconsin, 1975; Virginia, 1978; and Nebraska, 1981). However, most were established in the late 1980 s or early 1990s. Several of the most recently established policies have yet to be implemented by cooperatives. In Arkansas, the state's only G\&T, Arkansas Electric Cooperative (AEC), appealed the Arkansas Public Service Commission's 1992 IRP order on the grounds that the REA already requires AEC to file an IRP. No decision has been reached by the Commission on AEC's appeal.

In Nebraska, the State's Power Review Board prepares a 20-year power supply plan ("IRP") every 5 to 6 years in collaboration with the state $\square$ s utilities, as required by Nebraska statute. State legislatures in Minnesota, South Carolina, Vermont, and Wisconsin have established IRP requirements that apply to cooperative utilities. In South Carolina, the legislative requirement is enforced jointly by the Public 
Service Commission and the state energy office. ${ }^{6}$ The other three state' PUCs have developed rules implementing the IRP legislation. Rules requiring cooperative IRP were also developed by a number of PUCs without legislative mandates.

Typically, states require cooperatives to prepare 10- to 20-year IRP every 2 or 3 years. Some commissions have the authority to approve or disapprove cooperative IRPs, whereas others provide review comments to the utilities for their use. Appendix B provides considerable detail regarding individual state IRP.requirements.

State IRP requirements may affect G\&Ts, distribution cooperatives, or both, depending upon the regulatory authority of the PUC. For example, the Virginia Corporation Commission regulates 13 distribution cooperatives but does not have regulatory authority over G\&Ts. In Minnesota, the IRP policy only applies to the state's four largest G\&Ts. However, these four are owned and controlled by a total of 72 distribution cooperatives that will indirectly be affected by, and involved in, the IRP process.

Four state PUCs are in the process of developing IRP requirements that will apply to cooperative utilities. In Indiana, a rulemaking is in progress (in response to state legislation) to require electric utilities filing for a certificate of need to submit an IRP as part of the hearing process. The forthcoming requirement will apply to two G\&Ts in the state. Two Kansas G\&Ts expect to be required to file triennial IRP plans after the Corporation Commission renders decisions on its proposed rule later this year. The New Mexico PUC is also expected to issue its final IRP rule by the end of 1994, which will affect all of the state's cooperative utilities. In addition, the Oklahoma Corporation Commission is involved in an IRP rule-making process that will apply to cooperatives.

\section{Other Policies.}

In 1992, the 900-plus member cooperatives of NRECA adopted an IRP. resolution, Continuing Resolution \#53. The resolution reads as follows:

Rural electric systems must continue to plan to meet the energy service needs of their members in a manner which effectively. integrates supply-side and demand-side resources. Since integrated resource planning for rural electric systems requires the concerted efforts of member consumers, distribution systems, power suppliers, statewide organizations, and regulatory agencies we urge continued cooperation and coordination in the development of rate design, policies and programs.

We urge all segments of our program to continue to use integrated resource planning to assist in providing reliable electrical services at the lowest overall cost by carefully integrating both supply-side and demand-side resources.

This resolution was developed through the cooperative policy development process, which is summarized in Appendix B.

${ }^{6}$ Electric cooperatives may submit an IRP to the state energy office that complies with the Rural Utilities Service (formerly REA) regulations (S.C. Code No. 58-37-10-B). 


\section{Practices}

This section summarizes the IRP practices of the nation's rural electric cooperatives, based on information obtained from the REA and from primary research conducted by NREL and Garrick \& Associates. It reflects the IRP practices of $47 \mathrm{G} \&$ Ts and 256 distribution cooperatives that responded to the NREL IRP survey.

\section{G\&T Cooperative IRP Practices}

Forty-seven of the nation's 64 G\&Ts responded to the NREL IRP survey. Of these 47, 27 are "regular G\&Ts" with full power-supply responsibilities. All of the nation's "super G\&Ts" responded to the survey, along with 12 of their 17 "mid G\&Ts."7 In addition, 2 "paper G\&Ts" and 3 "other G\&Ts" responded.

Table 5 presents an overview of the IRP practices of the 47 responding G\&Ts. For each of the IRP elements, the table indicates the percentage of G\&Ts that fall into each of the following categories:

- Currently conducts the IRP element

- Starting to perform the IRP element

- Provided an "other" response regarding practice of the IRP eiement

- Does not perform the IRP element

- No answer provided.

As shown in the table, a majority of G\&Ts indicated that they currently conduct all IRP elements. More than $80 \%$ of the G\&Ts report load forecasting and public involvement activities. Seventy-four to $80 \%$ of the G\&Ts report supply- and demand-side resource assessment and risk analysis practice. Environmental and/or social costs are considered by $64 \%$ of the respondents, while $60 \%$ of these utilities report integrated supply- and demand-side resource evaluations.

A limited number of G\&Ts reported that the practice of certain IRP elements is currently under development, but not yet completed. For example, $6 \%$ of respondents indicated that a demand-side resource evaluation process is under development and $9 \%$ responded that the utility is currently developing an integrated approach for evaluating supply- and demand-side resource options. In addition, a few G\&Ts provided "other" responses regarding IRP practices.

As many as $25 \%$ of the 47 G\&Ts reported that they do not practice one or more of the IRP elements listed in Table 5. These include "regular" and "super" G\&Ts with full resource planning responsibilities, as well as "mid," "paper," and "other" G\&Ts with varying degrees of planning responsibility. A number of respondents indicated that they do not directly perform various IRP elements because they are not applicable to the utility. For example, one G\&T indicated that the BPA holds the full-requirements contracts with all of its distribution cooperatives and also prepares the resource plans. Several "mid" G\&Ts indicated that IRP responsibilities are vested in the "super" G\&T. As explained by one respondent, the "super" G\&T "is the power supply cooperative in a three-tiered cooperative system. [The "super" G\&T] has total responsibility for power supply and IRP. The six ["mid"] G\&T members are really just Ts, transmitting cooperatives. They deliver [the "super" G\&Ts] power and energy to 43 distribution cooperatives... ." An "other" G\&T responded to the survey through a brief letter stating that the

\footnotetext{
${ }^{7}$ When both the super G\&Ts and the mid G\&Ts independently reported IRP activities, these IRP practices are "double-counted." However, given the uniqueness of each G\&T's planning responsibilities it is meaningful to present the IRP practices of each responding utility-with the understanding that there are overlaps in responsibilities and activities.
} 
Table 5. IRP Practices of 47 G\&T Respondents

\begin{tabular}{|c|c|c|c|c|c|}
\hline IRP Element & $\begin{array}{l}\text { Currently } \\
\text { Conducts }\end{array}$ & $\begin{array}{l}\text { Starting } \\
\text { to } \\
\text { Perform }\end{array}$ & $\begin{array}{l}\text { Other } \\
\text { Answer }\end{array}$ & $\begin{array}{l}\text { Does Not } \\
\text { Conduct }\end{array}$ & $\begin{array}{c}\text { No } \\
\text { Answer* }\end{array}$ \\
\hline Load Forecasting & $81 \%$ & $0 \%$ & $0 \%$ & $4 \%$ & $13 \%$ \\
\hline Supply-Side Resource Assessment & $79 \%$ & $0 \%$ & $2 \%$ & $15 \%$ & $4 \%$ \\
\hline Demand-side Resource Assessment & $74 \%$ & $6 \%$ & $6 \%$ & $9 \%$ & $4 \%$ \\
\hline Consideration of Environmental and/or Social Costs & $64 \%$ & $2 \%$ & $4 \%$ & $26 \%$ & $4 \%$ \\
\hline $\begin{array}{l}\text { Integrated Supply- and Demand-side Resource } \\
\text { Evaluation }\end{array}$ & $60 \%$ & $9 \%$ & $2 \%$ & $26 \%$ & $4 \%$ \\
\hline Uncertainty/Risk Analysis & $77 \%$ & $0 \%$ & $0 \%$ & $19 \%$ & $4 \%$ \\
\hline Public Involvement & $83 \%$ & $0 \%$ & $0 \%$ & $11 \%$ & $6 \%$ \\
\hline
\end{tabular}

* No Answer" responses include the following: (1) Non-REA borrowers, for whom REA has no loadforecasting records; (2) Several G\&Ts that elected not to provide responses to the IRP survey questions, and instead explained their utility's IRP practices in a letter; and (3) A few cases where individual questions were not answered.

the organization's singular purpose is to own and operate a power plant that provides output to two other cooperatives. The G\&T, which does not own or maintain any transmission or distribution lines, stated that "most of the information requested [in the survey] is not applicable or available."

The involvement of member distribution cooperatives is a key aspect of G\&T cooperative IRP practice, as the member systems both own and govern the G\&Ts. Figure 3 summarizes the extent of member distribution cooperative involvement in each IRP element for the 47 responding G\&Ts. The figure reflects the planning responsibilities of the G\&Ts relative to their member distribution cooperatives. For example, the figure indicates that 38 of the G\&Ts' distribution cooperatives are "very" involved in demand-side assessments and 31 of the G\&Ts' distribution cooperatives are "very" involved in implementing the resource plan. These aspects of IRP are characterized by greater distributor (and end-user) involvement than other IRP elements that are more directly tied to the G\&Ts resource planning responsibilities.

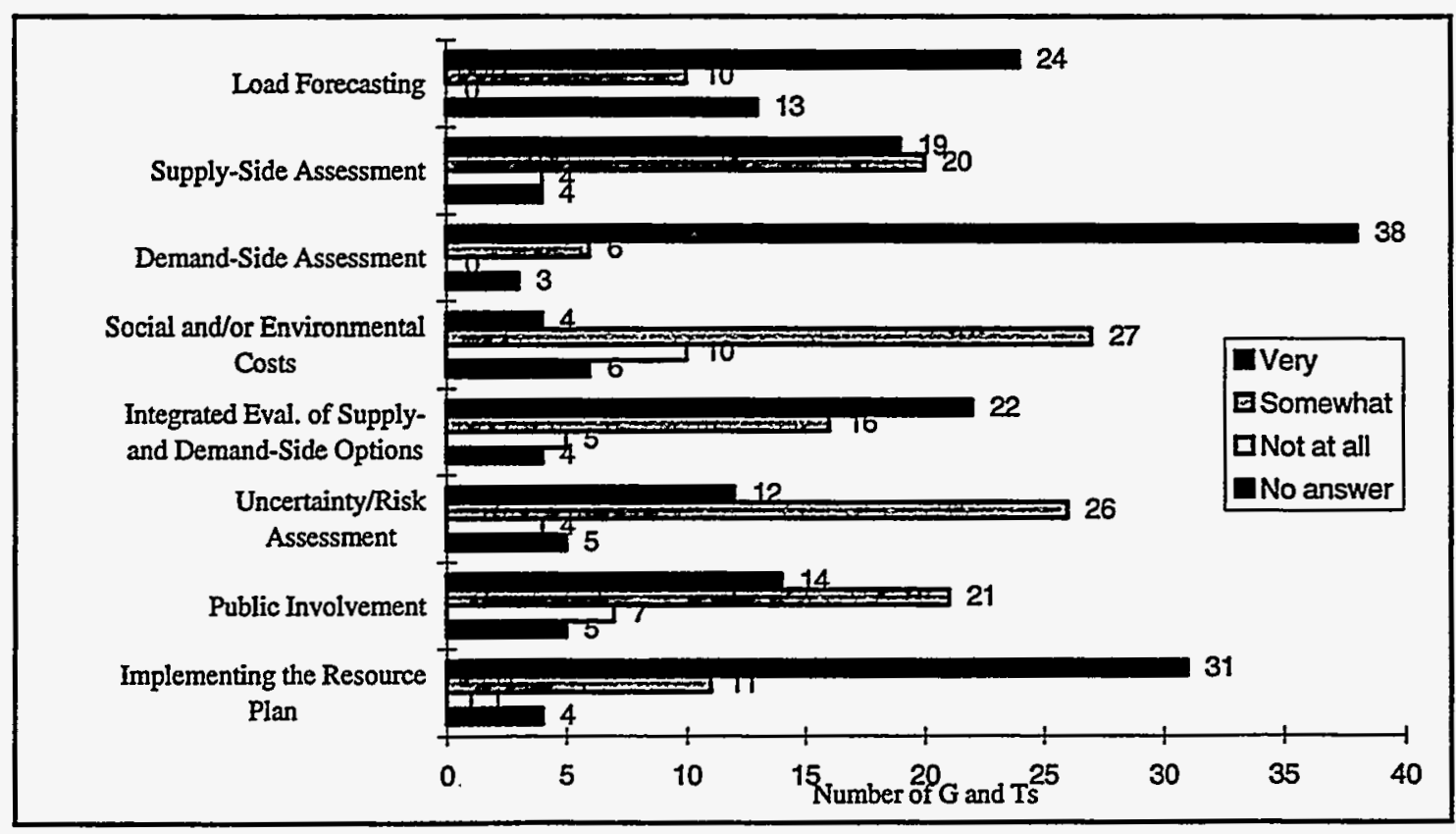

Figure 3. G\&T IRP elements: extent of member distribution cooperative involvement 


\section{Load Forecasting}

Information on G\&T load-forecasting practices was obtained from the REA because the agency's Power Requirements Studies (PRS) requirements drive G\&T load forecasting activity. As indicated in Table 5, $81 \%$ (38) of the G\&Ts responding to the NREL IRP survey prepare load forecasts, while $4 \%$ (2) do not practice load forecasting. These two G\&Ts do not have resource planning responsibility. No load-forecasting information is available from the REA for the remaining six G\&Ts, which include several G\&Ts that are not REA borrowers. Of the $38 \mathrm{G} \& \mathrm{Ts}$ that perform load forecasts, the majority (49\%) prepare forecasts every 2 years. The remainder prepare an annual load forecast (17\%) or prepare a load forecast either every 3 to 4 years (26\%) or every 5 years (9\%). Thirty-five of the 38 G\&Ts develop a range of demand forecasts (for example, high, medium, and low) as part of their load-forecasting activities. Figure 4 presents the forecasting methods used by the $38 \mathrm{G} \& \mathrm{Ts}$ that perform load forecasts. As indicated in Figure 4, practically all of the G\&Ts practice econometric load forecasting and many also use additional forecasting methods.

\section{Supply-Side Resource Assessment}

Thirty-seven of the G\&Ts responding to the NREL IRP survey indicated that they currently conduct supply-side resource assessments. Of the 37 that conduct supply-side resource assessments, 27 (73\%) indicated that they do so on an ongoing basis. Another $21 \%$ perform supply-side assessments annually, while $6 \%$ perform the assessments every 2 years. As illustrated in Figure 5, a variety of methods are used by these $37 \mathrm{G} \& T$ s for supply-side planning and analysis, including levelized bus-bar cost, screening curves analysis, manual evaluation of reliability and cost, automated reliability and cost analysis, and hybrid manual and automated analysis. Many of the G\&Ts use multiple supply-side planning and analysis methods.

In addition to the $37 \mathrm{G} \& T$ s indicating supply-side planning practices, another $10 \mathrm{G} \& T$ s either do not conduct supply-side assessments, did not answer this portion of the NREL IRP survey, or provided an

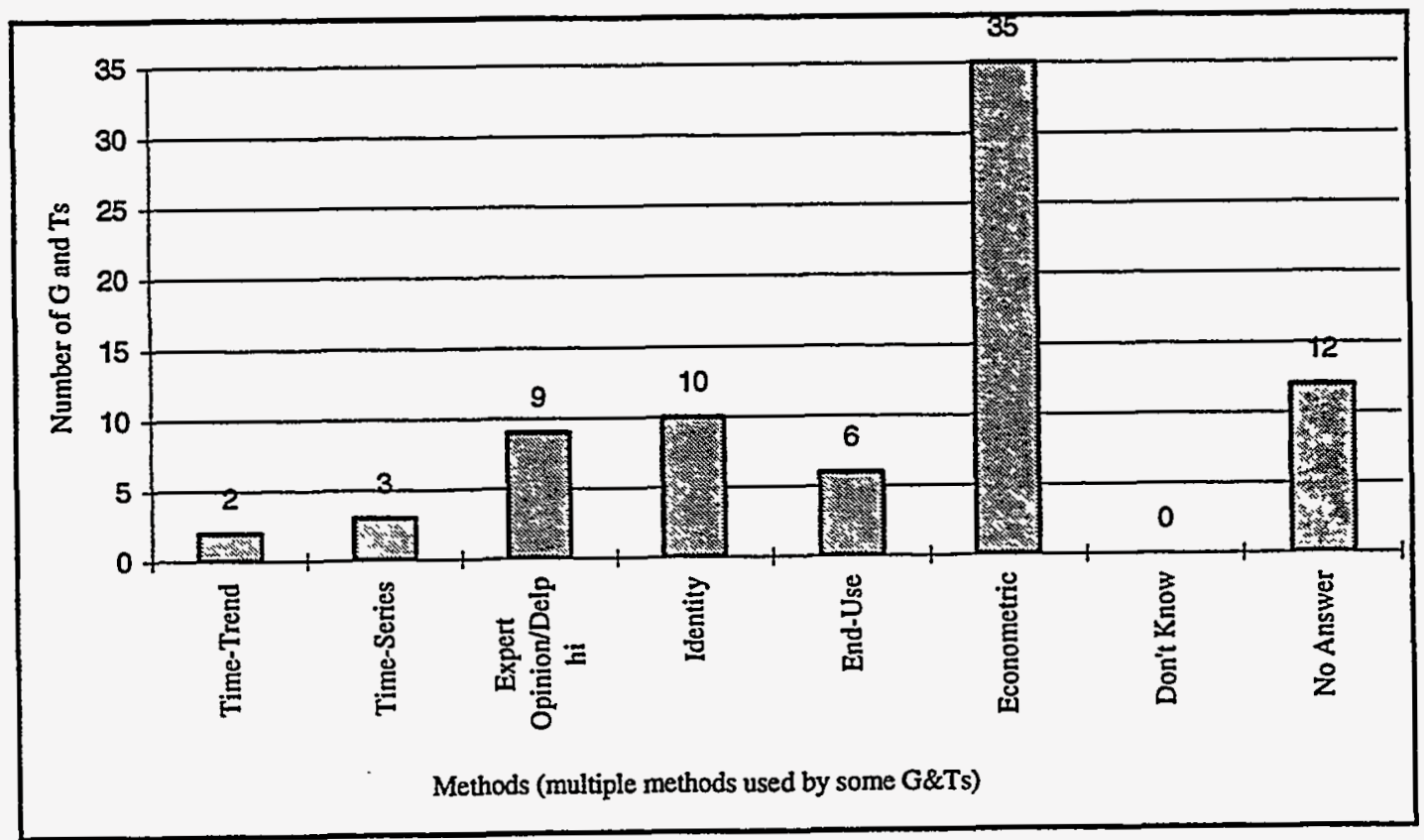

Figure 4. Load-forecasting mèthods used by G\&T cooperatives 


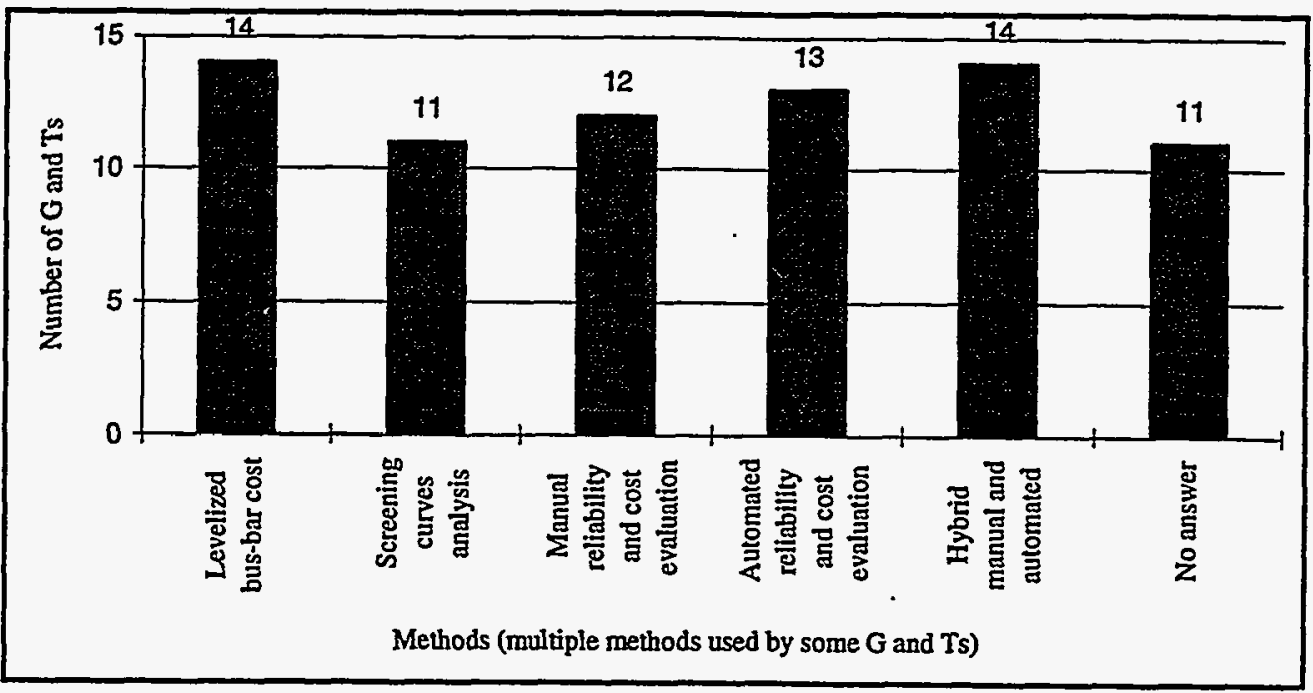

Figure 5. Supply-side planning and analysis methods used by G\&T cooperatives

"other" response. Several "mid" G\&Ts indicated that this responsibility lies with the "super" G\&T from which they purchase power under an all-requirements contract.

\section{Demand-side Resource Assessment}

Seventy-four percent (35) of the G\&Ts responding to the NREL IRP survey reported that they perform demand-side resource assessments. In addition, one G\&T indicated that a "DSM analysis process is currently under development," while another responded that "we are starting with the aid of SWPA." A third stated that "an initial evaluation is underway," while one responded, "[We] have not yet attempted to evaluated demand-side options." Several other G\&Ts indicated that they do not have responsibility for demand-side planning. No demand-side resource assessment information is available for the remaining two G\&Ts.

The majority (23) of the G\&Ts that conduct demand-side resource assessments indicate that they do so on an ongoing basis. Another nine perform demand-side assessments annually, while three perform the assessments every 2 years and one does so every 3 to 4 years. One of the G\&Ts indicated that assessment of demand-side resources is "on-going, [with] major screening [done] every 7 years."

As illustrated in Figure 6, a variety of cost-effectiveness tests are used by the G\&Ts for evaluating demand-side resource options, including the Participant test, the Ratepayer Impact Measure (RIM) test, the Utility Cost (UC) test, the Total Resource Cost (TRC) test, and the Societal test. Most of the G\&Ts use multiple cost-effectiveness tests, with the UC and RIM tests being the most widely utilized.

\section{Consideration of Environmental and Social Costs}

Environmental and/or social costs of various resource options are reportedly considered by $64 \%$ (30) of the G\&Ts responding to the NREL IRP survey. One of the responding G\&Ts is starting to consider this IRP element in response to developing PUC requirements. Twelve G\&Ts do not consider these costs as part of IRP. As illustrated in Figure 7, a variety of approaches are used by the G\&Ts to consider environmental and/or social costs, including the preparation of REA-required Borrower Environmental Reports (BER), qualitative treatment (for example, EIS/listing, and scoring or ranking), use of environmental and/or social adders, and direct quantification or monetization (for example, cost of control 


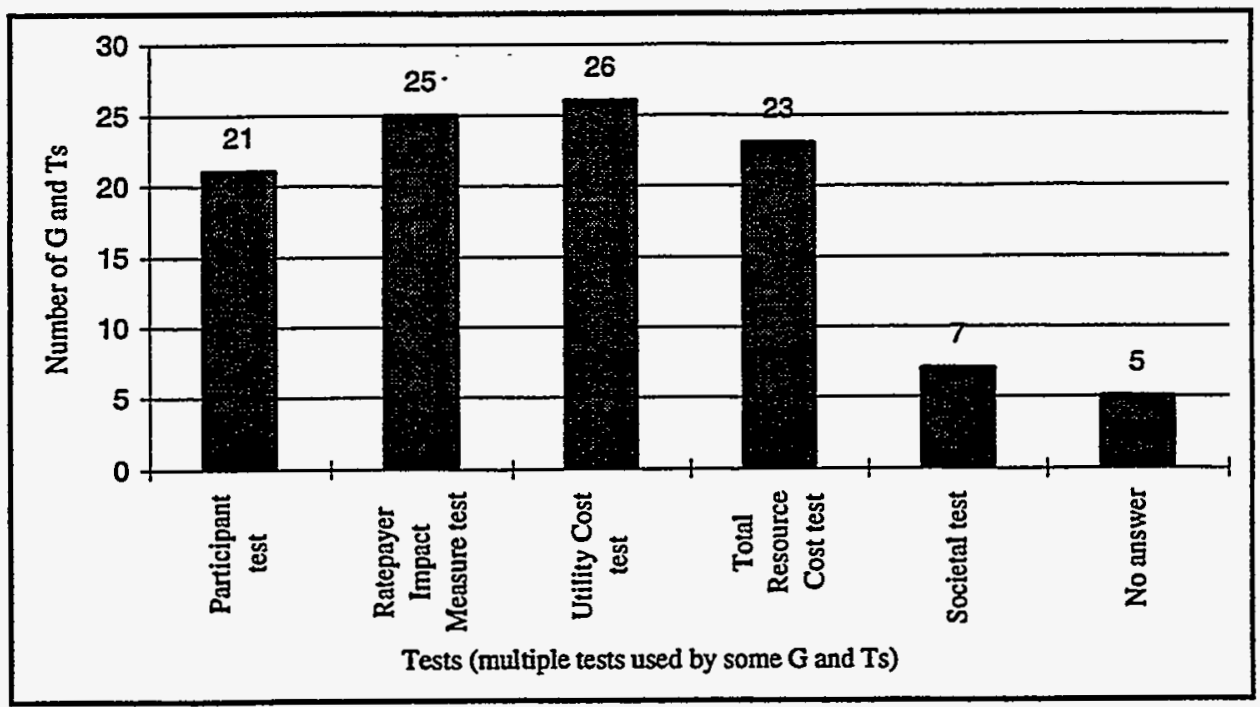

Figure 6. Cost-effectiveness tests used by G\&T cooperatives for demand-side resource evaluation

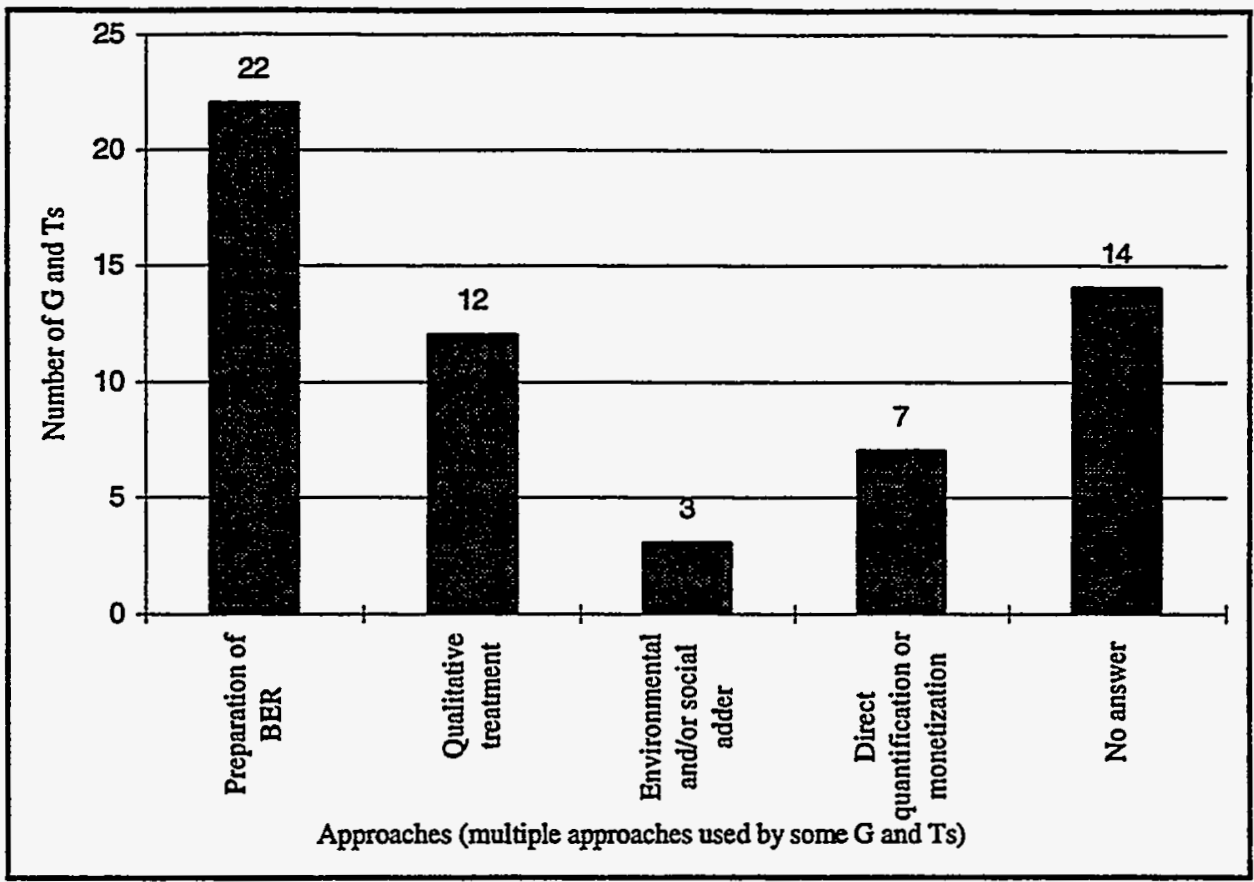

Figure 7. Approaches used by G\&T cooperatives to consider environmental and/or social costs

or damage costing). Many of the G\&Ts use multiple approaches, with preparation of a BER being the most common.

\section{Integrated Supply- and Demand-side Resource Evaluation}

Twenty-eight $(60 \%)$ of the G\&Ts responding to the NREL IRP survey reportedly conduct integrated supply- and demand-side resource evaluations. In addition, four are starting to perform such evaluations. Of these four G\&Ts, the first indicated that it is starting an IRP process with the aid of SWPA and the 


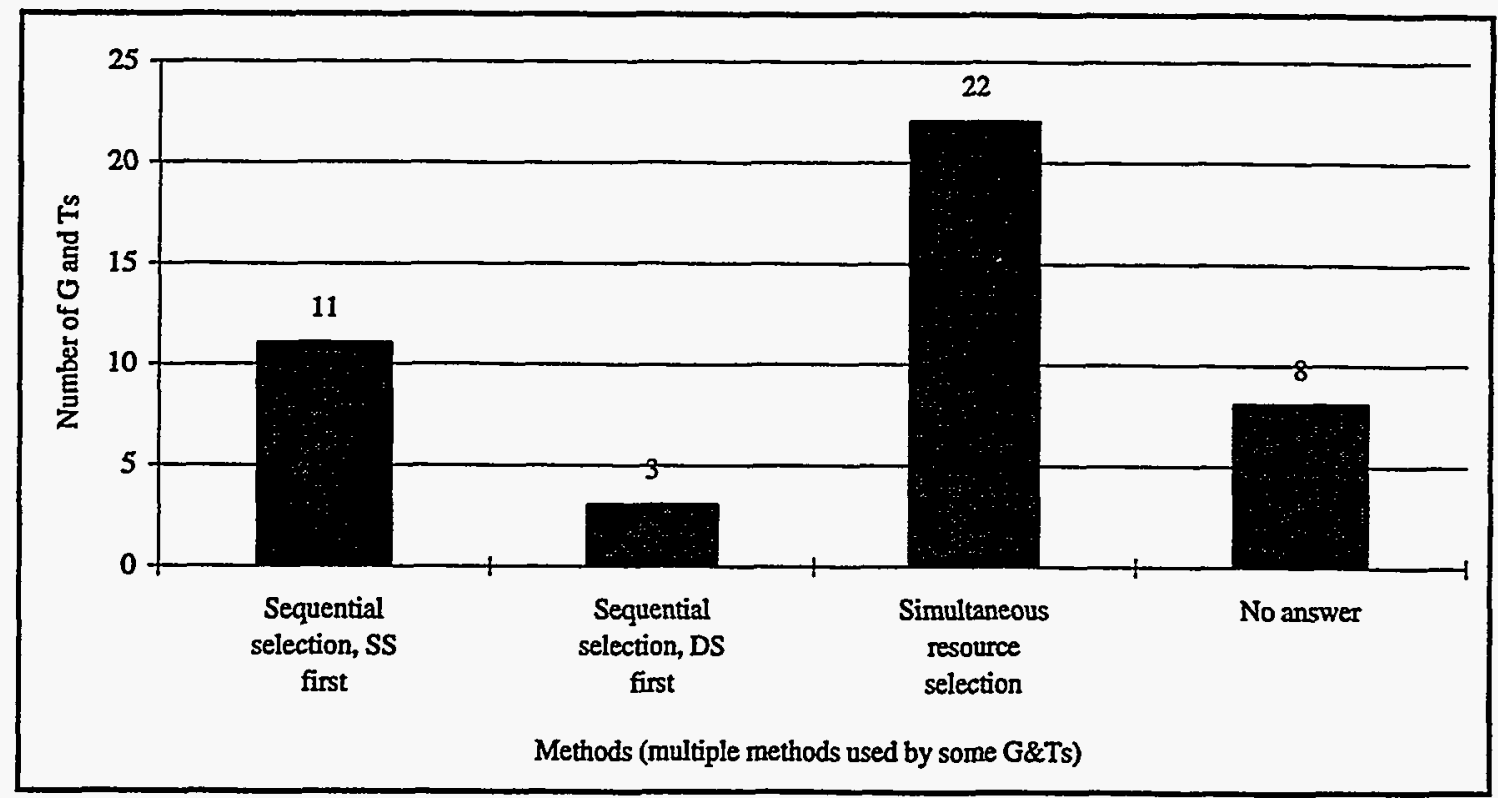

Figure 8. Supply- and demand-side integration methods used by G\&T cooperatives

second is responding to a PUC IRP rule currently under development. The third G\&T indicates that integrated evaluations will be conducted beginning in 1994, while the fourth states that an initial evaluation is under way. Twelve G\&Ts do not perform integrated supply- and demand-side resource evaluations, including a number indicating that they do not have responsibility for this planning function.

Of the 28 that conduct integrated resource evaluations, almost $50 \%$ do so on an ongoing basis and another $30 \%$ perform the evaluations every 2 years. Close to $15 \%$ perform integrated evaluations annually, and a few G\&Ts do so every 3 to 5 years. The supply- and demand-side integration methods used by the $28 \mathrm{G} \&$ Ts are illustrated in Figure 8 . As shown, 22 G\&Ts perform simultaneous supply- and demand-side resource selection, using consistent criteria. Eleven G\&Ts use sequential selection methods and evaluate supply-side options first. Sequential selection methods with demand-side options evaluated first are used by three G\&Ts. The information presented in the figure reflects multiple methods used by a few G\&Ts.

\section{Risk Analysis}

Uncertainty and/or risk analysis is performed by $77 \%$ (36) of the G\&Ts responding to the NREL IRP survey. Another 19\% (9) indicated that they do not conduct IRP risk analyses. As illustrated in Figure 9, a variety of risk analysis methods are used by the G\&Ts, including scenario analysis, sensitivity analysis, portfolio analysis, and probabilistic analysis. Many of the G\&Ts use multiple methods, with sensitivity and scenario analysis being the most common.

\section{Public Involvement}

Thirty-nine (83\%) of the G\&Ts reported public involvement in IRP. Five of the G\&Ts indicated that they do not practice public involvement, including several that reported no responsibility for IRP planning functions. A variety of public involvement approaches are used by the G\&Ts, as illustrated in Figure 10 . 


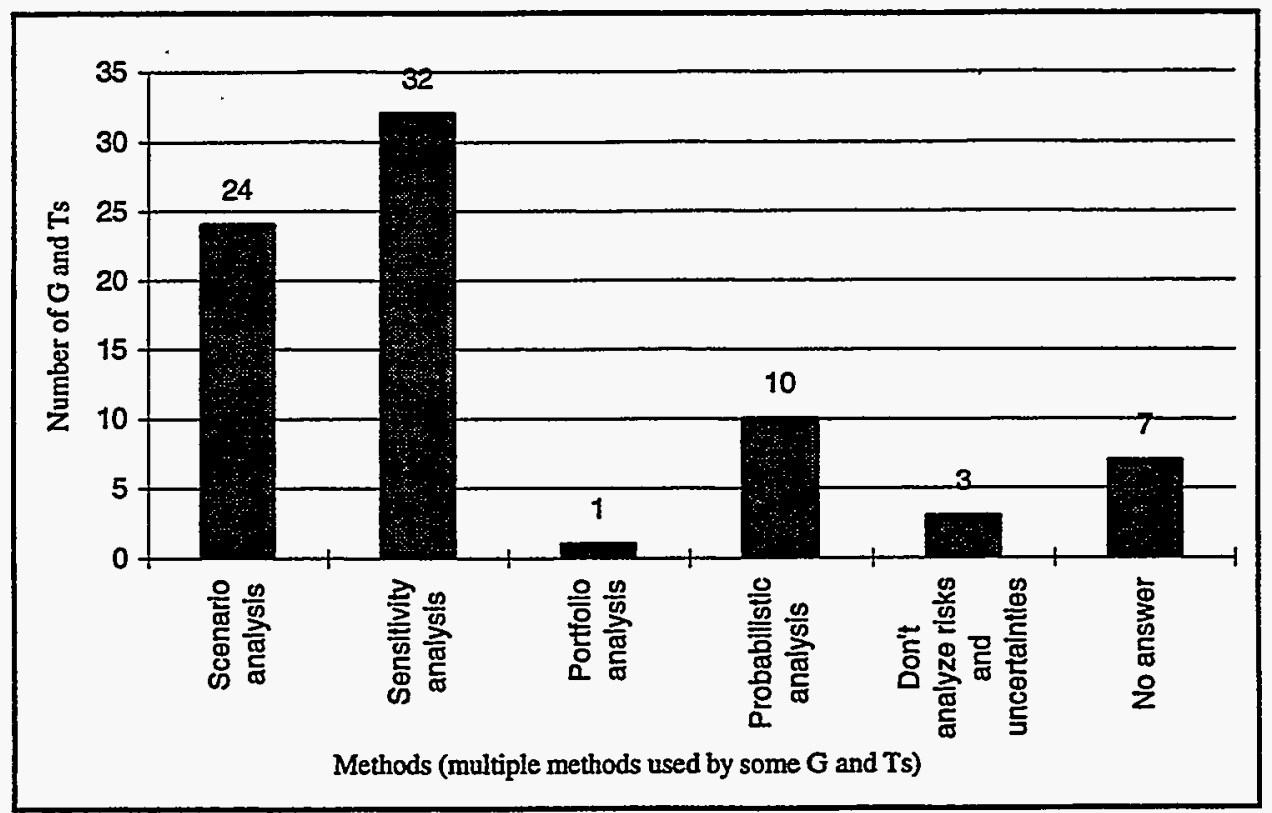

Figure 9. Risk analysis methods used by G\&T cooperatives

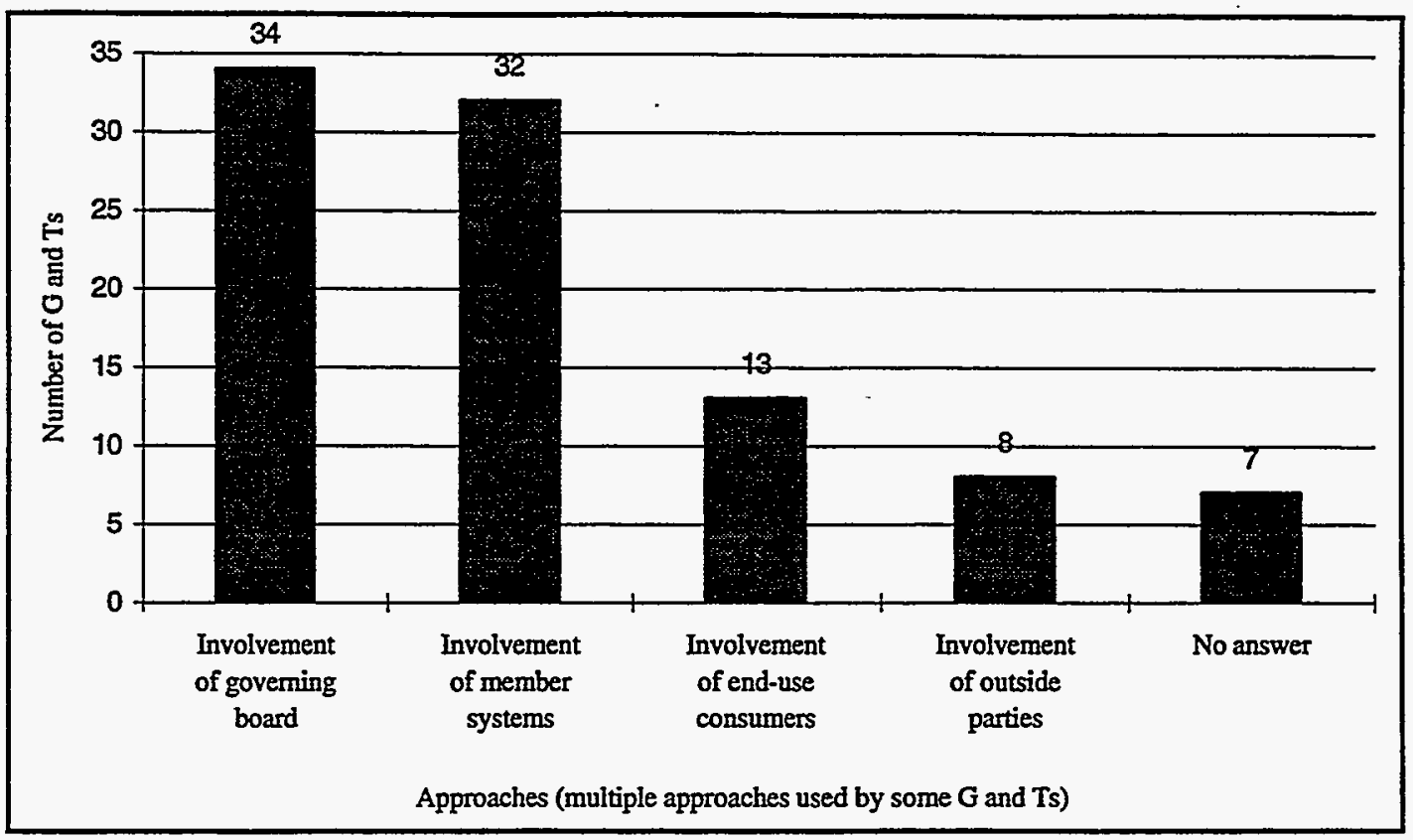

Figure 10. Public involvement approaches used by G\&T cooperatives

These approaches include involvement of G\&T governing boards, member distribution systems, endusers, and outside parties. Most of the G\&Ts use multiple methods, with involvement of G\&T governing boards and involvement of member distribution systems being the most common. 


\section{IRP Costs and Rate Impacts}

The EPAct cooperative IRP survey language requires DOE to "... survey...the extent to which [electric cooperative] integrated resource planning is reflected in rates charged to customers." As discussed in more detail in the introduction to this report, significant limitations exist related to determining the rate impacts of IRP. Currently available information regarding IRP rate impacts is limited to information that addresses the following questions: "What are the costs associated with IRP development?" and "Is the cost of developing an IRP recovered through rates, and to what extent?"

The 47 G\&Ts responding to the NREL IRP survey provided information regarding the cost of their IRP efforts. Information provided includes annual IRP cost (in dollars), number of full-time IRP-related employees, and additional comments. According to respondents, annual G\&T IRP costs range from as little as $\$ 25,000$ per year to as much as $\$ 500,000$, whereas the number of G\&T employees ranges from one-fourth person to five employees. Several G\&Ts emphasized that IRP costs are difficult to establish, as they are not typically separated from overall planning activities.

According to information provided by NRECA and REA representatives, $100 \%$ of all costs associated with IRP development are recovered through G\&T (and, ultimately, distribution cooperative) rates. This is consistent with cooperative ratemaking practices, which pass all costs of utility operation on to ratepayers.

\section{Distribution Cooperative IRP Practices}

Of the 859 distribution cooperatives located in the continental United States, 256 responded to the NREL IRP survey. ${ }^{8}$ Almost $80 \%$ of these distribution cooperatives are full-requirements members of a G\&T. Thirteen percent of the respondents purchase the majority of their power supplies from a federal power agency (for example, BPA, TVA, and WAPA), while the remaining distributors obtain the majority of their power supplies from either an investor-owned utility (IOU) or some "other" source, such as a state power agency or self-generation.

Fourteen of the 256 responding distribution cooperatives indicated preparation of their own IRP, independent of a power supply organization. Three of these distribution cooperatives are members of a G\&T, while the others purchase power from a federal power agency or IOU and/or generate power themselves.

The remaining 242 distribution cooperatives practice resource planning in conjunction with their G\&T or other power supplier. Thus, distribution cooperative IRP practice is best described by the nature and extent of involvement in power supplier IRP activities.

Figure 11 summarizes the IRP practices of the 256 distribution cooperatives responding to the NREL IRP survey. For each of the IRP elements, the figure indicates the number of distribution cooperatives that fall into each of the following categories:

- IRP element is conducted by distribution cooperative (Does their own)

- Distribution cooperative participates with power supplier in conducting the IRP element (Participates with power supplier)

- Distribution system is included in power supplier's practice of IRP element (Power supplier does it)

${ }^{8}$ IRP surveys were sent to a statistically valid sample of the nation's distribution cooperatives. The sample included 591 distribution cooperatives. Over $43 \%$ of these utilities responded to the survey. 


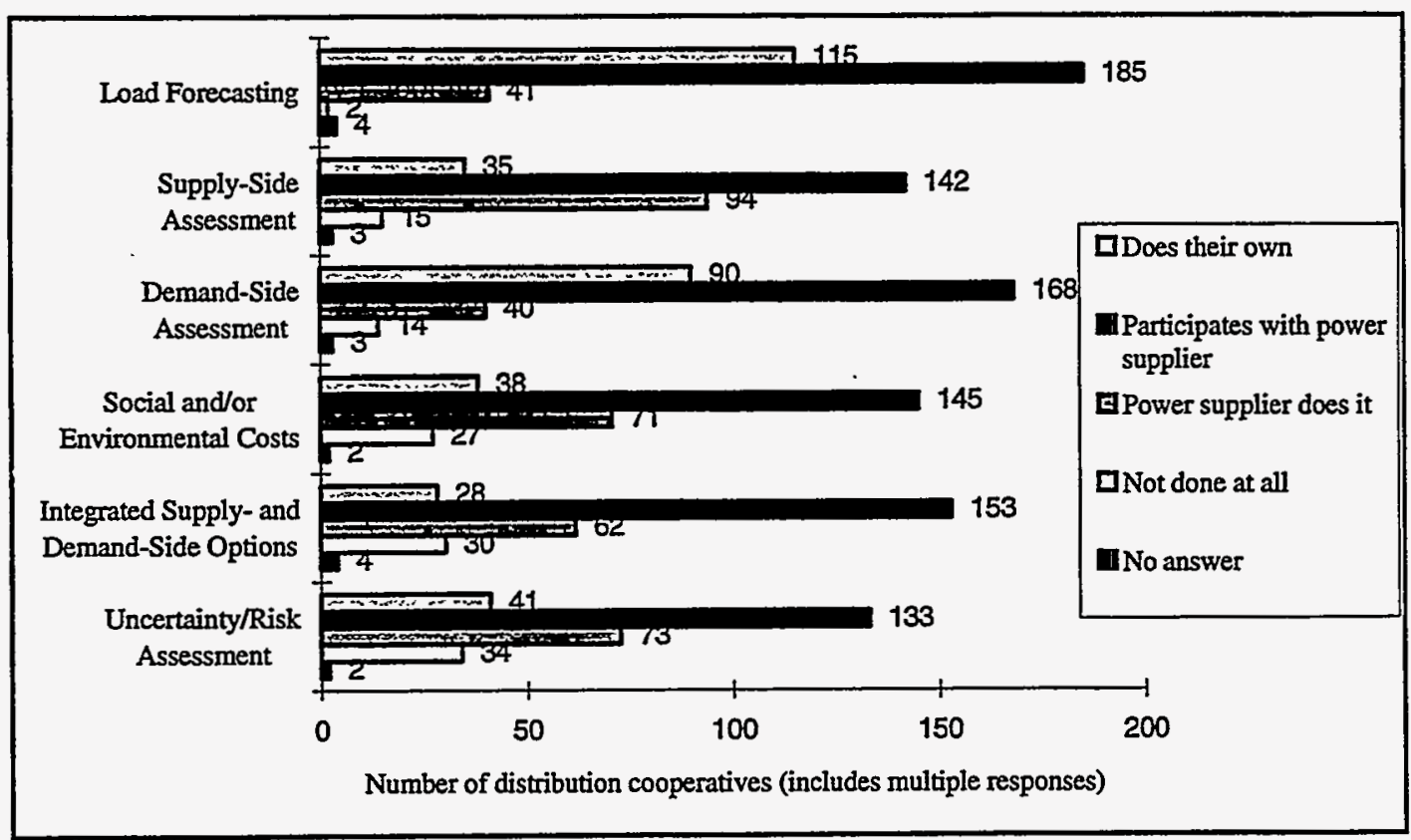

Figure 11. IRP practices of distribution cooperatives

- The IRP element is not practiced by or for the distribution cooperative (Not done at all)

- No answer provided.

As shown in the figure, the majority of the responding distribution cooperatives participate with their power supplier in all IRP elements. Distribution cooperatives participate to the greatest extent with their power suppliers in load forecasting (72\% of distributors participate) and to the least extent in risk analysis (52\% of distributors participate). In addition, many distribution cooperatives also perform various IRP element on their own, with load-forecasting and demand-side assessments being the most prevalent independent activities. Over $100(45 \%)$ of the distribution cooperatives prepare their own, independent load forecasts. Ninety (35\%) of the distributors indicated that they perform their own demand-side resource evaluations.

In many cases, distribution cooperatives are included within IRP efforts performed solely by G\&Ts or other power suppliers. For example, 94 (37\%) of the respondents indicated that their system is included in supply-side evaluations done solely by the power supplier. Risk analysis is the least practiced IRP element-34 distribution cooperatives report no risk assessment activities whatsoever.

Figure 12 indicates the public involvement approaches used by distribution cooperatives as part of resource planning and implementation. As illustrated, 152 (59\%) of the responding distribution cooperatives involves their governing boards in the resource planning and implementation process and 95 (37\%) involve end-use consumers. Twenty-three (9\%) of the distribution cooperatives indicate that outside parties (e.g., public interest groups) are involved. 


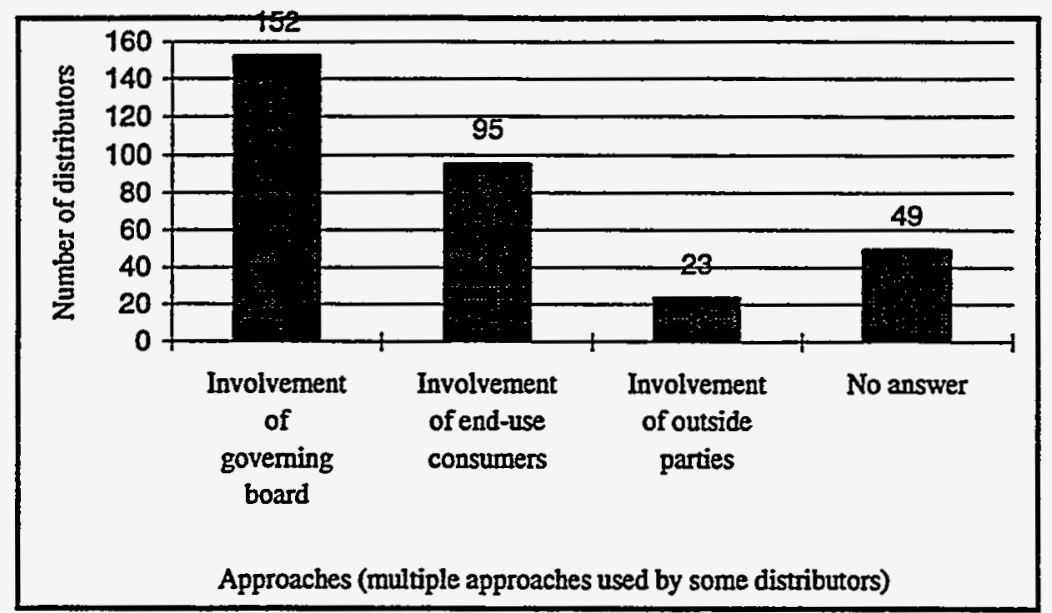

Figure 12. Public involvement approaches used by distribution cooperatives 


\section{Conclusions}

Integrated resource planning is widely practiced in the rural electric cooperative sector. IRP practice in this sector is accomplished by G\&Ts and other power suppliers such as the TVA.

Rural electric cooperative IRP is characterized by participatory involvement from the member distribution cooperatives that own and govern the G\&Ts. Distribution cooperatives are the power suppliers' link to the "customer side of the meter" and their involvement is key to successful implementation of the resource plan. Obtaining consistent support and involvement from member distribution cooperatives can be challenging because each distributor faces different circumstances and has unique needs.

Cooperative utilities are governed by elected boards of directors; however, a number of federal and state agencies also influence cooperatives in the area of resource planning. The REA, which is the principal source of long-term facility debt financing for almost all cooperatives, has the most influence of any single agency on cooperative resource planning. When it becomes final, WAPA's proposed IRP rule will be a driver for cooperative IRP activity in the agency's 15-state region. Cooperatives in 13 states also receive IRP mandates from regulatory commissions. Some cooperatives must satisfy IRP requirements from multiple federal and/or state agencies (for example, from the REA, a Power Marketing Administration, and a state PUC).

The IRP approaches and methods used by cooperatives reflect federal and/or state regulatory influences, as well as each utility's unique situation and needs. For example, a majority of cooperatives consider environmental costs and benefits of various resource options by preparing a BER for the REA to document compliance with the National Environmental Policy Act. Only a limited number of G\&Ts explicitly value environmental factors. Several of these G\&Ts do so at the directive of state regulatory commissions.

The cooperative utility sector-with its nonintegrated organization and complex relationships between cooperative systems-offers unique challenges and opportunities for integrated resource planning and implementation. These challenges and opportunities can be met through the continued development and application of appropriate IRP practices and policies. 


\section{References}

American Public Power Association (APPA). (1994). Public Power Magazine: Annual Statistical Issue, January-February 1994. Volume 2, No. 1, pp. 72-73.

Electric Power Research Institute; Barakat, H.; Chamberlain, Inc., for EPRI. (February 1987). Moving Toward Integrated Resource Planning: Understanding the Theory and Practice of Least-Cost Planning and Demand-side Management. EM-5065.

Federal Register. (1993). Vol. 58, No. 149, August 5, p. 41764.

Garrick \& Associates for National Renewable Energy Laboratory. (June 1994). A Profile of Publicly-Owned Utility Integrated Resource Planning.

Garrick, C.; Garrick, J.; Rue, D. (June 1993). Scoping Study of Integrated Resource Planning Needs in the Public Utility Sector. National Renewable Energy Laboratory.

Goldman, C.; Hirst, E.; and Krause, F. (May 1989). "Least-Cost Planning in the Utility Sector: Progress and Challenges." Washington, D.C.: U.S. Department of Energy; Berkeley, CA: Lawrence Berkeley Laboratory; Oak Ridge, TN: Oak Ridge National Laboratory.

National Rural Electric Cooperative Association. (1990). Rural Electric Sourcebook. Washington, D.C.: National Rural Electric Cooperative Association.

National Rural Electric Cooperative Association (NRECA). (1991a). Facts About America's Rural Electric Systems. Work performed by National Rural Electric Cooperative Association, Washington, D.C.

National Rural Electric Cooperative Association. (January 1991b). The G\&Ts-Power Providers for America's Rural Electric System. Work performed by National Rural Electric Cooperative Association, Washington, D.C.

Rodgers, P. National Association of Regulatory Utility Commissioners. (1993). Utility Regulatory Policy in the United States and Canada.

Shultz, Georg, Chief of Energy Forecasting Branch, REA, IRP information provided for G\&T borrowers as well as frequent telephone input (1994).

Southwestern Power Administration (SWPA). (1992). . Power Sales Contract, Article XII, Integrated Resource Planning. 


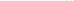




\section{Appendix A}

Glossary of Terms 
Automated Reliability and Cost Evaluation: A supply-side resource assessment method which uses the same process as manual generation planning, but automates the optimization process.

Banks for Cooperatives (BC): Authorized by Congress to lend to rural utilities, BCs lend concurrently with the REA, providing financing in conjunction with the guaranteed loan program which includes refinancing of Federal Financing Bank loans.

Borrowers Environmental Report (BER): A support document required by the REA for loan approval. The BER is used to determine what effect the construction of the facilities included in the Construction Work Plan will have on the environment.

Capital Credits: Funds credited to rural electric cooperative members that equate to their ownership equity in the system.

Consideration of Environmental and/or Social Costs: A component of IRP that involves inclusion of various environmental and social costs and benefits, such as those related to air quality or economic development. In addition to the consideration of "internal" costs (for example, compliance with air quality regulations), many utilities consider "externalities" associated with electrical power production and use, which are not already incorporated in the price of electric services.

Cooperatively Owned Utilities: Rural electric cooperatives, which include both distribution and G\&T cooperatives.

Demand-side Management (DSM): The planning, implementation, and monitoring of those utility activities designed to influence customer use of electricity in ways that will produce desired changes in the utility's load shape. DSM is designed to produce changes in the time pattern and magnitude of a utility's load.

Demand-side Resource Assessment: A component of IRP that involves evaluating demand-side resources for meeting an electric utility's future resource requirements. A demand-side resource assessment may include the examination of peak clipping, valley filling, load shifting, strategic conservation, strategic load growth, and other DSM options.

Direct Quantification: Also referred to as "monetization," this costing approach assigns a monetary value to environmental and/or social costs of various resource options. Two approaches for "costing out" environmental costs include the damage-cost approach and the control-cost approach.

Distribution Cooperatives: Rural electric cooperatives that deliver electricity to residential and other consumers generally located in rural America. Distribution cooperatives are member-owned and were originated in the 1930s to bring power to rural America.

Econometric Forecasting: A load-forecasting method that uses econometric models to explain movements in $\mathrm{kWh}$ sales and $\mathrm{kW}$ peak by looking at the underlying factors or variables such as population, employment, income, weather, appliance ownership, and rates.

End-Use Forecasting: A load-forecasting method that uses end-use models, also called engineering or accounting models, to forecast $\mathrm{kWh}$ sales by counting up $\mathrm{kWh}$ use from each electrical appliance and machine. 
Environmental and/or Social Adder: Use of a percentage adder that either increases the cost of supply-side resources or decreases the cost of demand-side resources. This method uses a simple percentage multiple of the direct cost of the resource option to reflect the cost of environmental harm.

Expert Opinion/Delphi Forecasting: A load-forecasting method that uses information from external sources rather than numerical data. These methods rely on judgment, outside information, and independent forecasts to forecast utility $\mathrm{kWh}$ sales and $\mathrm{kW}$ peak.

Federal Power Agencies: U.S. government agencies that are involved in the generation, transmission, and/or distribution of electricity.

G\&T Cooperatives: "Generation and transmission" cooperatives (also known as power supply cooperatives) are power suppliers owned by several individual rural electric distribution cooperatives. Generally, they are responsible for supplying all of the power needed by their distribution cooperative members and do so by either generating the power or procuring it contractually from public or investor-owned organizations.

Gigawatt-hours (gWh): One million kilowatt-hours.

Government-Owned Utilities: All utilities that are owned by federal, state, or local governments. These utilities can be broken down into five major subcategories: federal, state, municipal, joint-action agency, and other (for example, public utility and irrigation districts).

Identity Forecasting: A load-forecasting method which forecasts $\mathrm{kW}$ peak using separate forecasts of load factor and $\mathrm{kWh}$ sales and definition relationships between them.

Integrated Resource Planning: An approach to utility resource planning that integrates the evaluation of both supply- and demand-side options for providing adequate, reliable, safe energy services at the least cost.

Integrated Supply- and Demand-side Resource Evaluation: A component of IRP that involves a comparison of supply - and demand-side resources for the purpose of selecting the optimum mix of resources. The comparative evaluation allows equal consideration of both supply- and demand-side resource options.

Investor-Owned (Electric) Utilities (IOU): Electric utilities organized as tax-paying businesses usually financed by the sale of securities in the free market, and whose properties are managed by representatives regularly elected by their shareholders.

Joint-Action Agencies: Regional organizations formed by groups of utilities (typically by municipals) to jointly build or finance generation and transmission systems, and share other services.

Levelized Bus-Bar Cost: A supply-side resource assessment method that analyzes generating-unit decisions on a unit basis only, not recognizing how the units may be operated in a power system.

Load Forecasting: A component of IRP that involves estimating future annual electricity use and peak demand requirements, for use in making resource allocation decisions.

Manual Reliability and Cost Evaluation: Also referred to as manual generation planning, a widely used supply-side resource assessment procedure that combines the disciplines of reliability. 
Municipal Electric Utilities (Municipals): Electric utilities that are owned and operated by local governments or municipalities.

National Rural Electric Cooperative Association (NRECA): A nonpartisan and nonprofit organization, owned and controlled by the rural electric systems that make up its membership. NRECA was established as a service organization for its members where activities are coordinated, problems solved, and services shared.

National Rural Utilities Cooperative Finance Corporation (CFC): A self-help financing institution created in 1969 by the nation's rural electric cooperatives out of a need for additional funding for the rural electrification program. CFC serves as the primary source of private financing for the program and supplements financing provided by the REA.

Participant Test: A demand-side resource assessment test that measures the benefits and costs to the customer for participating in a specific DSM program.

Portfolio Analysis: A risk analysis method that involves identification of two or more plans, each keyed to a different set of objectives (for example, environmental quality or financial performance). The different plans are generally subjected to sensitivity analysis and/or probabilistic analysis and the performance of each is compared to the others.

Probabilistic Analysis: A risk analysis method that involves assignment of probabilities to different values of key variables (i.e., by assigning probabilities or drawing a continuous distribution).

Outcomes are then identified that are associated with the different combinations of values for the key factors.

Public Involvement: A component of IRP that involves a public planning process to ensure that a broad range of interests and potential resource options are considered by utility decision makers. It also helps to build consensus about the best resource plan.

Qualitative Treatment of Environmental Costs: This method typically involves assessing externalities by relative degrees of environmental degradation without formally assessing the costs.

Ratepayer Impact Measure (RIM) Test: A demand-side resource assessment test that measures the impacts on customer bills or rates covered by changes in the utility revenues and operating costs as a result of the program.

Rural Electrification Administration (REA): A federal agency that was created to provide loans for rural electrification. It also provides technical assistance where needed to support the security of the loans. (The term REA is often used erroneously as a synonym for the locally owned cooperatives whose growth has been financed with loans from the agency.)

Rural Electric Cooperatives: Consumer-owned utilities established to provide electric service to rural America. (See distribution cooperatives and G\&Ts.)

Scenario Analysis: A risk analysis method that involves constructing alternative futures, each containing internally consistent combinations of key uncertain factors and then identifying suitable combinations of supply- and demand-side resources for each scenarios. The distinguishing feature of scenario analysis is that alternative visions of the future are created first, and then appropriate combinations of resources are identified to fit each future. 
Screening Curve Method: A supply-side resource assessment method that involves plotting the results of the levelized bus-bar analysis on a graph to illustrate total levelized annual cost in dollars per year versus plant capacity factor.

Sensitivity Analysis: A risk analysis method that involves development of a preferred combination of options, often referred to as a plan. Key uncertainty factors are then varied to see how the plan responds to these variations.

Societal Test: A demand-side resource assessment test that is a variant of the TRC test and includes the effects of externalities such as acid rain, excludes tax credit benefits, and may have a different discount rate.

State Power Authorities: State-owned utilities that are involved in the generation, transmission, and/or distribution of electricity.

Supply-side Resource Assessment: A component of IRP that involves evaluating supply resources for meeting an electric utility's future resource requirements. A supply-side resource assessment may include the examination of a range of resources including purchased power, alternative/renewable resources, life extension and re-powering of existing plants, utility construction of power plants, and new or upgraded transmission facilities.

Time-Series Forecasting: A load-forecasting method that involves the extrapolation of historical patterns, not just simple trends.

Time-Trend Forecasting: A load-forecasting method that involves the extrapolation of a historical trend.

Total Resource Costs (TRC) Test: A demand-side resource assessment test that measures net costs of a DSM program as a resource option based on the estimated total costs of the program, including both participant and utility program costs.

Uncertainty/Risk Analysis: A component of IRP that involves analysis of a variety of possible future conditions and the options available to deal with them. An uncertainty analysis provides information about the relative risks of alternative resource strategies. Its primary purpose is to facilitate better resource planning decisions that reduce risk.

Utility Cost Test: A demand-side resource assessment test that measures the net costs of a DSM program as a resource option based on the costs incurred by the utility (including incentives paid out and excluding any net costs incurred by participants). 



\section{Appendix B}

Federal and State IRP Policies

Applicable to Cooperative Utilities 


\section{Contents}

Federal IRP Policies

Northwest Power Planning Council/Bonneville Power Administration . . . . . . . . . . . B-3

Rural Electrification Administration . . . . . . . . . . . . . . . . . . B-5

Southeastern Power Administration . . . . . . . . . . . . . . . . . . B-8

Southwestern Power Administration . . . . . . . . . . . . . . . . . . B-10

Tennessee Valley Authority . . . . . . . . . . . . . . . . . . . . . . . B-12

U.S. Congress-PURPA IRP Standard . . . . . . . . . . . . . . . B-14

Western Area Power Administration . . . . . . . . . . . . . . . . . . B-16

\section{State IRP Policies}

Alaska Public Utilities Commission . . . . . . . . . . . . . . . . . . . . B-19

Arizona Corporation Commission . . . . . . . . . . . . . . . . . . B-20

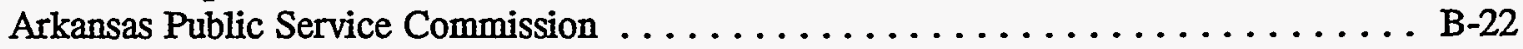

Delaware Public Service Commission . . . . . . . . . . . . . . . . . B-24

Indiana Utility Regulatory Commission . . . . . . . . . . . . . . . . B-26

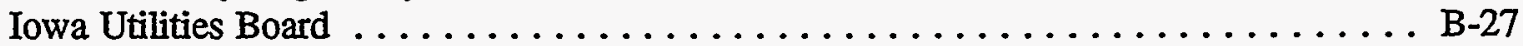

Kansas Corporation Commission . . . . . . . . . . . . . . . . . B-29

Kentucky Public Service Commission . . . . . . . . . . . . . . . . B

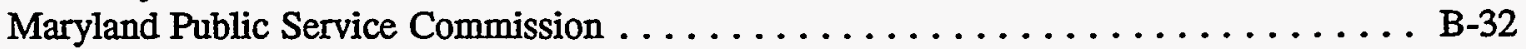

Minnesota Public Utilities Commission . . . . . . . . . . . . . . . . B-33

Nebraska Power Review Board . . . . . . . . . . . . . . . . . . . . . B-34

New Mexico Public Utility Commission . . . . . . . . . . . . . . . . B-35

Oklahoma Corporation Commission . . . . . . . . . . . . . . . B B-36

South Carolina Public Service Commission and South Carolina State Energy Office . . B-37

Vermont Public Service Board . . . . . . . . . . . . . . . . . . . . B-39

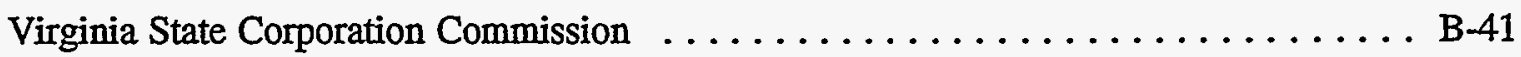

Wisconsin Public Service Commission $\ldots \ldots \ldots \ldots \ldots \ldots \ldots \ldots \ldots \ldots \ldots \ldots$

Other IRP Policies

National Rural Electric Cooperative Association $\ldots \ldots \ldots \ldots \ldots \ldots \ldots$. . . . . . . 
AGENCY:

CONTACT:

SUMMARY OF REQMT:

TYPE OF REQUIREMENT:

ENABLING AUTHORITY:

EFFECTIVE DATE:

APPLICABUITY:

SPECIFIC REQUIREMENTS:
Northwest Power Planning Council/Bonneville Power Administration

Dick Watson, Director of Planning, NWPPC, (503) 222-5161; Mike Bull, Senior Policy Analyst, BPA, (503) 230-3811

In the Pacific Northwest region served by BPA, centralized, regional IRP is practiced by the Northwest Power Planning Council (NWPPC), which is funded through BPA's rates. The NWPPC develops a regional IRP and works with BPA and its public utility customers, the region's six IOUs, and other agencies (for example, PUCs) that help to implement the plan.

Legislation

The Northwest Power Act

1980

The Pacific Northwest regional IRP is developed for the region of Washington, Oregon, Idaho, and western Montana. The BPA, which has direct responsibility for planning and acquiring resources to meet the loads of its customers, implements the plan. The region's other utilities, including IOUs, cooperatives, and municipalities, are encouraged to help implement the regional IRP

- Cooperatively Owned Utilities: BPA serves approximately 56 rural electric cooperatives.

The Northwest Power Act of 1980 authorized the creation of the NWPPC, which was charged with developing a 20-year conservation and electric power plan for the region. The NWPPC, which is funded through BPA's rates, develops a regional integrated resource plan for the Pacific Northwest. The NWPPC adopted its first IRP in 1983, with revisions following in 1986 and 1991.

The council's power plans are characterized by sophisticated methodologies and innovation, including:

- Conservation as a Resource: Through the Northwest Power Planning Act, Congress gave conservation a $10 \%$ system cost advantage over conventional resources.

- Integration: The IRP process includes full integration of demand-side efficiency resources into the planning process. 
- Uncertainty Analysis: The council considers a range of forecasts and possible futures to develop a least-cost strategy that accounts for the effects of risk. The council's ISAAC (Integrated System for the Analysis of Acquisitions) model allows in-depth evaluation of risk mitigation strategies.

- Public Participation: The Northwest Power Planning Act requires the NWPPC to actively involve the public in its planning activities. The council's open public process allows widespread opportunities for participation, comment, and review as its plans are developed.

- Action Plan: This plan explicitly delineates how the IRP will be implemented during the first few years after the plan is adopted. The action plan is critical to achievement of plan goals, and provides a means of tracking progress and identifying problems.

- Implementation: Unlike a utility that implements its own IRP, the council's regional power plan is implemented by over 120 electric utilities in the region. The NWPPC works with BPA, the region's IOUs, and other agencies. (for example, PUCs) in the implementation of the plan.

The centralized, regional planning practiced by the NWPPC and BPA are consistent with the BPA's charter, which requires it to meet the future electric needs of its customers. The agency's active role in planning and development of the region's future power facilities includes development of a biannual "Resource Program" (or BPA-specific IRP) to determine the specific resources BPA will require over the next 10 years to meet loads and to help implement the Northwest Power Plan adopted by the NWPPC. Development of the Resource Program is a collaborative effort involving customers and outside interests in determining how much power will be needed and which resources to acquire. BPA's Area Offices also develop Local Conservation Plans and work with individual customers to implement the plans. 


\section{AGENCY:}

CONTACT:

SUMMARY OF REQMT:

TYPE OF REQUIREMENT:

ENABLING AUTHORITY:

EFFECTIVE DATE:

\section{APPLICABLITY:}

SPECIFIC REQUIREMENTS:
Rural Electrification Administration ${ }^{9}$

Georg Shultz, Chief of Energy Forecasting Branch, Electric Staff Division, (202) 720-1920

Subpart $H$ of the REA's General and Pre-loan Policies and Procedures Common to Insured and Guaranteed Electric Loans requires an IRP for approval of loans that include funds for DSM and renewable energy activities. In addition, it is the REA's position that its General and Pre-loan Policies and Procedures, which require all borrowers to consider both demand- and supply-side resource options, provide an "IRP" requirement for approval of all loans.

Rule

Department of Agriculture, Rural Electrification Administration, 7 CFR Part 1710, General and Pre-loan Policies and Procedures Common to Insured and Guaranteed Electric Loans.

The REA has required borrowers to consider both demandand supply-side resource options since 1992, when the Part 1710 requirements were originally published. Subpart $\mathrm{H}$ of Part 1710 (which provides an explicit IRP requirement for approval of loans that include funds for DSM and renewable energy activities) was published on January 4 , 1994.

Part 1710 is applicable to all existing and future REA borrowers. While its primary focus is on policies and procedures for acquisition of new REA loans, it includes routine reporting requirements for existing REA borrowers.

- Cooperatively Owned Utilities: Virtually all cooperatives are affected by the 1710 requirements. The requirements cover both routine reporting and new loan approval policies for G\&T and distribution cooperatives. The only cooperatives that are not subject to these policies and procedures are those limited few that are not REA borrowers.

The specific IRP requirements are delineated in Part 1710 of the REA's General and Pre-loan Policies and Procedures Common to Insured and Guaranteed Electric Loans (most recently published in the Federal Register on January 4, 1994). This rule requires two primary documents, power

\footnotetext{
${ }^{9}$ In December of 1994, the REA became the Rural Utilities Service (RUS).
} 
requirements studies and construction work plans, to be submitted on a routine basis:

- Power Requirements Study (PRS): Provides borrower and REA with an understanding of the borrower's system loads, the factors influencing these loads, and valid estimates of future loads. It provides a basis for projecting $\mathrm{kWh}$ sales and revenues, and for engineering estimates of plant additions required to accommodate future loads.

- Construction Work Plan (CWP): Specifies and documents the capital investments required to serve a borrower's planned new loads, improve service reliability and quality, and service the changing needs of existing loads. As part of the CWP, the REA requires that the construction or purchase of additional generating capacity by a power supply (G\&T) or distribution borrower be supported by comprehensive project-specific engineering and cost studies. These studies must include:

comprehensive economic present value analyses of the costs and revenues of the available self-generation, load management, energy conservation, and purchased power options, including assessments of service reliability and financing requirements and risk. (1710.253[b])

The REA requires coordination between power supply borrowers and their members in the preparation of their respective PRSs.

Two additional support documents required for loan approval are long-range financial forecasts and borrower's environmental reports:

- Long-Range Financial Forecasts: The REA encourages borrowers to maintain on a current basis a long-range financial forecast, which should be used by a borrower's board of directors and manager to guide the system toward its financial goals.

- Borrower's Environmental Report (BER): This document is used to determine what effect the construction of the facilities included in the construction work plan will have on the environment.

As a result of the 1993 Rural Electric Loan Restructuring Act, the REA now has the ability to make loans for all 
types of DSM programs. (Prior to that time, REA could only provide loan funds for load-control equipment.) Subpart H-Demand-side Management and Renewable Energy Systems, of the current 1710 regulation, requires an REA-approved IRP prior to approval of loans that include funds for DSM activities and/or on- or off-grid renewable energy systems. ${ }^{10}$ REA specifically requires a power supply borrower and all member systems to coordinate in the development of a system-wide IRP, and that the IRP be approved by the board of directors of the power supply borrower. Further, if a distribution borrower desires a DSM or renewable energy loan from the REA, it is required to use the overall system IRP prepared by its power supplier as the IRP submittal to the REA. The REA indicates the rationale for such coordination:

...DSM activities and renewable energy activities must be coordinated among all parties to insure that the activities of one member do not jeopardize the financial integrity or loan security of any other member or that of the power supply borrower. (1710.355[b][1])

${ }^{10}$ The IRP requirement currently only applies for approval of DSM and renewable energy loans (i.e., not for supply-side loans), as this is the extent of the authority granted to the REA under the 1993 Rural Electric Loan Restructuring Act (which expanded the agency's DSM/renewables authority and required updating of related loan approval policies and procedures). 
AGENCY:

CONTACT:

SUMMARY OF REQMT: ${ }^{11}$

TYPE OF REQUIREMENT:

ENABLING AUTHORITY:

EFFECTIVE DATE:

APPLICABHLITY:

SPECIFIC REQUIREMENTS:
Southeastern Power Administration

Al Pless, Energy Efficiency/IRP Program, (706) 213-3846;

E.B. Crenshaw, Power Marketing, (706) 213-3837

SEPA has adopted a Power Marketing Policy for the agency's Cumberland Basin Project that includes an Energy and Economic Efficiency Measures clause for inclusion in the project's renewed power sales contracts.

Power marketing policy; Power sales contract article

Power Marketing Policy for the agency's Cumberland Basin Project

The Cumberland Basin Power Marketing Policy was adopted in 1993. It will be implemented through power sales contract articles within each Cumberland Basin customer's renewed power contract. These contracts are under negotiation; however, the execution dates are undetermined.

The contract article will be included in power sales contracts that are currently under negotiation for the 10 customers of SEPA's Cumberland Basin Project.

- Cooperatively Owned Utilities: The contract article will apply to six cooperatives that receive power from SEPA's Cumberland Basin Project as well as the TVA, which distributes SEPA power to its 160 distributors (including 50 cooperatives). ${ }^{12}$

SEPA also plans to include an Energy and Economic Efficiency Measures clause in all future renewed power sales contracts to encourage IRP.

The Energy and Economic Efficiency Measures clause reads as follows:

\footnotetext{
${ }^{11}$ SEPA's IRP "requirement" is actually a voluntary IRP policy.

${ }^{12}$ TVA is required by Section 113 of the Energy Policy Act of 1992 to conduct a least-cost planning program. Section 113(e) of the act also states that TVA is not subject to any requirement that might arise out of TVA's electric power transactions with SEPA.
} 
Each customer who purchases

Southeastern's power is encouraged to participate in an integrated resource plan that considers both supply and demand side alternatives. It is recognized that some Southeastern customers are members of a power supply organization that does resource planning for their customers (i.e., power supply cooperatives and joint action agencies). Where a customer, or a power supply organization that does resource planning for a Southeastern customer, is responsible to a regulatory body or another Government agency for an integrated resource plan, the customer will make a copy of such integrated resource plan available to Southeastern. All Southeastern customers shall agree to encourage the efficient use of energy by ultimate customers.

It is SEPA's policy to accept IRPs submitted to the REA by its cooperative customers. 
AGENCY:

CONTACT:

SUMMARY OF REQMT:

TYPE OF REQUIREMENT:

ENABLING AUTHORITY:

EFFECTIVE DATE:

APPLICABILITY:

SPECIFIC REQUIREMENTS:
Southwestern Power Administration

Jerry Martin, Energy Conservation Officer, 581-7516

SWPA has developed an IRP clause for inclusion in all new or updated power sales contracts, which states that "...the customer agrees to the extent practical to perform activities associated with IRP in securing future power resources... ." The contract clause does not establish a schedule for customer IRP efforts, nor does it require customers to submit an IRP to SWPA.

Power sales contract article

Article XII, Integrated Resource Planning

1992

To date, Article XII has been incorporated into 16 customer power sales contracts. The contract article will be added to a significant number of additional contracts in 1997, when a number of existing contracts are scheduled for renewal.

- Cooperatively Owned Utilities: SWPA's IRP clause currently applies to three cooperatives.

The integrated resource planning article reads as follows:

In order to encourage the process of comparing supply and demand options as a mechanism for meeting future electrical power requirements, the customer covenants and agrees to the extent practicable to perform activities associated with Integrated Resource Planning (hereinafter, IRP) in securing future power resources. Such activities shall include the analyses of both supply-side and demand-side measures in order to evaluate the full range of applicable alternatives for satisfying future load requirements. Such activities shall treat supply-side and demand-side resources on a consistent and integrated basis and shall provide for the inclusion of public participation appropriate to the customer. In analyzing supply and demand resource options, the customer shall consider all direct and 
quantifiable net costs for an energy resource over its available life, including the cost of production, transportation, utilization, waste management, and compliance with environmental laws. The customer further agrees to furnish nonproprietary information relative to its IRP activities as may be requested periodically by Southwestern and agrees that such information may be furnished by Southwestern to its other customers in order to promote the IRP process for Southwestern's marketing region. Completion of IRP activities, which are required of the customer by a state or another Federal agency, shall be acceptable to Southwestern as compliance with this Article.

The contract clause does not establish a schedule for customer IRP efforts, nor does it require customers to submit an IRP to SWPA. 
AGENCY:

CONTACT:

SUMMARY OF REQMT:

TYPE OF REQUIREMENT:

ENABLING AUTHORITY:

EFFECTIVE DATE:

APPLICABILITY:

SPECIFIC REQUIREMENTS:
Tennessee Valley Authority

Dr. Lynn Maxwell, Manager of Resource Planning, (615) 751-2539

The Energy Policy Act of 1992 requires TVA to conduct a least-cost planning process. It also requires that TVA provide distributors with both an opportunity to participate in the process and with assistance in the planning and implementation of cost-effective energy efficiency options.

Legislation

Section 113 of the Energy Policy Act of 1992

EPAct passed in October of 1992. TVA expects to complete the initial plan in its process by December 1995 .

The requirement applies specifically to TVA, a federal corporation that provides electric power in an area that covers most of Tennessee and parts of Alabama, Georgia, Kentucky, Mississippi, North Carolina, and Virginia. TVA has the utility responsibility for meeting the electric power needs of this region.

Cooperatively Owned Utilities: TVA provides allrequirements electric service to 50 cooperatives, whose needs are addressed by the agency's plan.

EPAct directs that TVA shall:

employ and implement a planning and selection process for new energy resources which evaluates the full range of existing and incremental resources (including new power supplies, energy conservation and efficiency, and renewable energy resources) in order to provide adequate and reliable service to electric customers of the Tennessee Valley Authority at the lowest system cost. (Section 113[b][1])

A number of requirements are delineated for the planning and selection process, including:

- Accounting for diversity, reliability, dispatchability, and other factors of risk

- Consistent and integrated treatment of demand- and supply-side resources 
- Participation of TVA distributors in the planning process, including obtaining recommendations for cost-effective energy efficiency opportunities, rate structure incentives, and renewable energy proposals

- Verification of energy savings achieved through energy conservation and efficiency.

Before the selection and addition of a major new resource, the Act requires TVA to provide an opportunity for public review and comment and to report on this in an annual report to the President and Congress. The Act also directs TVA to provide appropriate assistance to distributors in the planning and implementation of energy efficiency and renewable energy programs. Such assistance could involve education and information dissemination, and technical and financial assistance.

The EPAct requirements serve to reinforce TVA's long-term commitment to a least-cost energy planning process. The agency has been preparing long-range planning documents for supply and demand resources since the early 1980s. The agency also developed one of the nation's largest conservation programs during the late 1970s. In response to EPAct, TVA has initiated the development of a 25-year energy strategy involving power distributors, industries, and the public. The IRP process began in January of 1994 and will be completed within 2 years. 
AGENCY:

CONTACT(S):

SUMMARY OF REQMT:

TYPE OF REQUIREMENT:

ENABLING AUTHORITY:

EFFECTIVE DATE:

APPLICABILITY:
U.S. Congress-PURPA IRP Standard

Andrew Krantz, DOE; Paul Galen, IRP Policy Analyst, NREL, (202) 484-1090

Section 111 of the Public Utilities Regulatory Policy Act (PURPA) requires each state regulatory authority and each nonregulated electric utility to consider implementation of integrated resource planning.

Legisiation

Section 111(d)(7) of PURPA, as amended by Section 111(a) of EPAct

The IRP standard was added to PURPA (1978) by EPAct (1992).

The IRP standard applies to "each state regulatory authority (with respect to each electric utility for which it has ratemaking authority) and each nonregulated electric utility... ."

- Cooperatively Owned Utilities: Twenty PUCs have full ratemaking authority over cooperatively owned utilities (Arizona CC, Arkansas PSC, Delaware PSC, D.C. PSC, Florida PSC, Indiana URC, Kentucky PSC, Louisiana PSC, Maine PUC, Maryland PSC, Michigan PSC, New Hampshire PUC, New Mexico PUC, Oklahoma CC, Rhode Island PUC, Texas PUC, Vermont PSB, Virginia, West Virginia, and Wyoming PSCs). Over 300 cooperatives are regulated by these agencies (Rodgers 1993). In addition, several other state PUCs have limited ratemaking authority over cooperatively owned utilities. For example, cooperatives in Alaska and Kansas can vote to opt out of state regulation. The PURPA IRP standard also applies to large, nonregulated cooperatively owned utilities.

SPECIFIC REQUIREMENTS:

PURPA Section 111 states that:

each state regulatory authority...and each nonregulated electric utility shall consider each standard established by subsection (d) and make a determination concerning whether or not it is appropriate to implement such standard to carry out the purposes of this title. 
The IRP standard reads as follows:

(7) Integrated Resource Planning-Each electric utility shall employ integrated resource planning. All plans or filings before a State regulatory authority to meet the requirements of this paragraph must be updated on a regular basis, must provide the opportunity for public participation and comment, and contain a requirement that the plan be implemented.

State regulatory authorities and nonregulated electric utilities must consider the standard within 2 years of its passage (i.e., October 1994) by making public notice and holding a public hearing. Based upon the findings of the hearing, each state commission and nonregulated utility can either implement the IRP standard or decline to implement the standard. 
AGENCY:

CONTACT:

SUMMARY OF REQMT:

TYPE OF REQUIREMENT:

ENABLING AUTHORITY:

EFFECTIVE DATE:

APPLICABILITY:
Western Area Power Administration

Theresa Williams, Director of Energy Services, (303) $275-1730$

WAPA is currently developing an IRP requirement to replace its Guidelines and Acceptance Criteria for the Conservation and Renewable Energy Program. In 1992, the Energy Policy Act amended Title II of the Hoover Power Plant Act of 1984 to require that WAPA customers implement IRPs.

\section{Legislation}

Section 114 of the Energy Policy Act of 1992

To be determined. EPAct requires WAPA to prepare an environmental impact statement (EIS) on the development of the IRP rule. IRP rule development and the corresponding EIS process are in progress. WAPA expects to publish a final EIS and final IRP rule by spring of 1995 .

EPAct states that the IRP requirement is applicable to any WAPA customer who purchases electric capacity (with or without energy) under a long-term firm power service contract, with the following caveats:

- WAPA may establish different regulations for certain small customers (i.e., those with total annual sales or usage of $25 \mathrm{GWh}$ or less, and which are not members of a joint-action agency or G\&T with power-supply responsibility) (Section 202[b]). WAPA is considering the establishment of different regulations for approximately 80 customers that fit the EPAct-defined small-customer criteria.

- If a customer or group of customers is implementing IRP in response to other federal, state, or other initiatives, WAPA is directed to accept such a plan as fulfillment of Title II if the plan substantially complies with the requirements. (Section 204[c])

As proposed by WAPA, long-term firm power customers could submit IRPs individually or jointly with other purchasers who have common interests (for example, power supplier and distribution members). WAPA serves over 600 long-term firm power customers, including approximately 400 public utilities ${ }^{13}$ in 15 western states

\footnotetext{
${ }^{13}$ In addition to some 400 public utilities, WAPA serves approximately 200 other customers, including IOUs, state agencies, and other federal agencies.
} 


\section{SPECIFIC REQUIREMENTS:}

from Minnesota in the Northeast to California in the Southwest. The following provides a breakdown of the number of public utilities served by WAPA.

- Cooperatively Owned Utilities: ${ }^{14}$ Approximately 45 cooperative utilities purchase electric capacity from WAPA under a long-term firm power service contract. These include about $20 \mathrm{G \& T}$ and some 25 distribution cooperatives. Numerous additional distribution cooperatives receive WAPA power through the $20 \mathrm{G} \& \mathrm{Ts}$ served by WAPA.

EPAct amends Title II of the Hoover Power Plant Act to require that:

Within 1 year after the enactment of this section, the Administrator shall, by regulation, revise the Final Amended Guidelines and Acceptance Criteria for Customer Conservation and Renewable Energy Programs published in the Federal Register on August 21, 1985...to require each customer purchasing electricity under a long-term firm power service contract with the Western Area Power Administration to implement, within 3 years after the enactment of this section, integrated resource planning in accordance with the requirements of this title. (Section 202[a])

EPAct establishes seven minimum criteria for WAPA's approval of customer IRP submittals. These are:

1. Load forecasting

2. Demand- and supply-side resource assessments

3. Use of "least-cost options" to provide reliable electric service to retail consumers

4. Minimization of adverse environmental effects of new resource acquisitions

5. Full public participation in plan preparation and development

\footnotetext{
${ }^{14}$ The number of cooperatives served by WAPA is taken from Statistical Appendix to the 1993 Annual Report, Western Area Power Administration.
} 
6. 2- and 5-year action plans

7. Validation of predicted performance in order to determine whether plan objectives are being met.

In addition, EPAct establishes specific penalties for noncompliance by WAPA customers, including rate surcharges and reduced power allocations. The act also directs WAPA to provide technical assistance to customers related to conducting and implementing IRPs. Such assistance may include education and information dissemination, and technical and financial assistance. The act directs WAPA to give priority in providing technical assistance to customers that have limited capability to conduct IRP. (Section 203)

The EPAct requirements serve to reinforce WAPA's long-term commitment to customers' efficient use of energy. In 1981, WAPA published its "Customer Guidelines and Acceptance Criteria (G\&AC)," which required all customers signing new firm power contracts to develop conservation and renewable energy programs. This requirement became federal law in 1984 with the passage of Title II of the Hoover Power Plant Act. As part of a required review of the G\&AC provisions, WAPA proposed an Energy Planning and Management Program in 1991, which would link the agency's power resource allocations with long-term energy planning and Western's customers' efficient energy use through the preparation IRPs. Since the inception of its Energy Services program in 1981, WAPA has offered a wide variety of services to support its customers' energy efficiency, renewable energy, and IRP efforts.

WAPA's implementation of the EPAct requirements is subject to the provisions of the National Environmental Policy Act (NEPA). The NEPA process, which supersedes the EPAct legislation, is currently driving the schedule associated with development of WAPA's IRP rule. 
AGENCY:

CONTACT:

SUMMARY OF REQMT:

TYPE OF REQUIREMENTS:

ENABLING AUTHORITY:

EFFECTIVE DATE:

APPLICABILITY: 4
Alaska Public Utilities Commission

Don Baxter, Utility Engineer Analyst 4, (907) 276-6222; fax (907) 276-0160

Utilities submit IRPs on a case-by-case basis. For example, utilities requesting authorization of new plant construction must file 20-year IRP plans. No updates are required unless the plans include a DSM component.

Certificate of public convenience and necessity; power sales contract

U-91-98 (certificate of public convenience and necessity); U-92-11

February 1993

The informal IRP requirement could be applied to all electric utilities under the commission's jurisdiction.

- Cooperatively Owned Utilities: The measure could be applied to approximately one G\&T co-op, two combined generation/distribution cooperatives, and two distribution cooperatives, subject to their vote.

SPECIFIC REQUIREMENTS:

Only one utility has had cause to submit an IRP plan to the commission (Docket No. U-92-11). A consulting firm prepared the plan and followed the general IRP guidelines developed by Oak Ridge National Laboratory. 
AGENCY:

CONTACT(S):

SUMMARY OF REQMT:

TYPE OF REQUIREMENTS:

ENABLING AUTHORITY:

EFFECTIVE DATE:

APPLICABILITY:

SPECIFIC REQUIREMENTS:
Arizona Corporation Commission (CC)

David Berry, Chief of Economics and Research, (602) 542-0742; fax (602) 542-2129

The Arizona CC requires all electric utilities that have generation resources to file 10-year (most utilities submit 20-year) IRP plans every 3 years.

Rule

Arizona Administrative Code R142-701 et seq. (Sections 701-704)

January/February 1989

This regulation applies to all electric utilities under the jurisdiction of the commission which operate or own generating facilities.

- Cooperatively Owned Utilities: One cooperative, the Arizona Electric Power Cooperative, is subject to the regulation. Distribution cooperatives are exempt from filing.

The specific IRP requirements are delineated in Regulation R14-2-701 et seq. (nine pages). Annual filings of historical data must include demand- and supply-side data (Sections $703 \mathrm{~A}-\mathrm{B}$ ), including detailed data on demand for the previous 10 years and on supply for the previous year.

Triennial IRPs must include the following:

- Demand and supply forecasts: Sections 703 C-D indicate data and analysis requirements to be included in a 10-year demand and supply forecast, including the levels of disaggregation of forecast information, and the documentation required.

- Uncertainty analyses (Section $703 \mathrm{E}$ )

- Integrated resource plan: Section $703 \mathrm{~F}$ of the regulation requires the development of least-cost plans for meeting forecasted electricity demand. The plan shall take into account the supply, demand, and uncertainty analyses required in Sections 703 C-E, provide documentation of supply- and demand-side conditions, costs, and discount rates used, and include a 3-year action plan.

An Externalities Prioritization Working group evaluated and prioritized 17 externalities to be considered by utilities 
in their 1995, 1998, and post-1998 IRPs. The group also recommended that (1) utilities perform a carbon tax risk assessment in lieu of monetizing global climate change in their 1995 IRPs, and (2) a utility consider a Nuclear Disaster Plan and Release of Radioactivity if a utility includes a nuclear plant in its IRP prior to 1998. In addition, the group selected five Life-Cycle Stages to be included in the 1995 IRP (resource extraction, construction, operation, transportation, and retirement) The Working Group recommended that certain causes listed by the LifeCycle Stages be considered in determining the costs of externalities in the 1995 and 1998 planning cycles. 
AGENCY:

CONTACT:

SUMMARY OF REQMT:

TYPE OF REQUIREMENT:

ENABLING AUTHORITY:

EFFECTIVE DATE:

APPLICABILITY:

SPECIFIC REQUIREMENTS:
Arkansas Public Service Commission

Diana Brenske, Manager, Electric Division, (501) 682-5656

The IRP guidelines require that the Arkansas Electric Cooperative Corporation (AECC) submit triennially a 20-year forecast and corresponding resource plan, and a 3 -year action plan. In addition, every 6 months after the approval of a 3-year action plan, AECC must file a progress report of the actions taken and expenditure incurred to implement the plan.

State legislation; commission orders (separate docket number assigned to each utility affected)

Utility Environment and Economic Protection Act, Arkansas Code Ann. 23-18-501 et seq. and 23-3-401 et seq.; Docket No. 92-229-U (AECC) (not rule-making docket)

1973 (amended in 1977); August 28, 1992 (Docket No. 92-229-U)

The commission issued separate IRP guidelines for three of Arkansas' four investor-owned utilities, and excused the fourth because it served only 3,000 customers in Arkansas and was already subject to Kansas and Missouri IRP filing requirements.

- Cooperatively owned utilities: The policy affects all of Arkansas' cooperatively owned utilities with the exception of one distribution cooperative, Farmer's Electric Cooperative, which is not a member. AECC, a 16-member distribution cooperative and the only G\&T in the state, has contested the commission's IRP order on the grounds that the REA already requires AECC to file an IRP. The commission is currently considering AECC's position.

The specific IRP requirements are delineated in the commission's Guidelines for Arkansas Electric Cooperative Corporation. The triennial IRP plan must include the following:

- Development of a 3-year action plan describing the utility's short-term resource acquisition plans that includes technical documentation (Section 2)

- Energy and demand forecasts (Section 3): Forecasts must include historical (for 10 preceding years) and forecasted (base year and 20 succeeding years) analyses 
based on disaggregated end-use methods. (If other models are used, the utility must provide a justification of the model design and an explanation of the variables used.) Each energy and demand forecast must include an analysis of the sensitivity of results to the major assumptions and estimates used in preparing the forecast, and contingency plans based on base-case, high-, and low-growth scenarios.

- Identification and screening of existing and potential resources (Section 4): The commission requires assessments of existing supply- and demand-side resources, a determination of the adequacy of the existing transmission and distribution systems to meet projected loads over a minimum of the following 10 years, and a description of potential new generation, transmission, and distribution facilities. In addition, the utility must develop and screen a set of demand-side program designs for possible inclusion in the preferred and alternative resource plans.

- Development of Integrated Resource Plans (Section 5): IRPs must include resource plans to meet a range of demand forecast scenarios and objectives (including minimizing rates and customer bills, maximizing environmental protection, and maximizing penetration of DSM resources), assessments of multiple combinations of potential demand- and supply-side resources, a risk and uncertainty analysis for each plan, and a 3-year action plan. 
AGENCY:

CONTACT(S):

SUMMARY OF REQMT:

TYPE OF REQUIREMENT:

ENABLING AUTHORITY:

EFFECTIVE DATE:

APPLICABILITY:

SPECIFIC REQUIREMENTS:
Delaware Public Service Commission

Melinda Carl, Public Affairs, (302) 739-4333;

fax (302) 739-4849

The commission requires its jurisdictional utilities to file 10-year IRPs every 2 years. However, the commission does not have the authority to require these utilities to implement their IRPs.

Legislation; rule

PURPA Section 111 (d)(7) - (d)(9); Regulation Docket Nos. 29 and 35 (affects cooperative)

1978 (PURPA); February 22, 1994 (Rule)

Delaware IRP regulations affect the state's one IOU and distribution cooperatives that provide retail electric service to consumers/members. The IRP guidelines allow distribution cooperatives to submit the most recent IRP of their power supply cooperative, supplemented with details on the reporting cooperative's specific characteristics and DSM planning.

- Cooperatively Owned Utilities: One distribution cooperative, Delaware Electric Cooperative, is subject to the regulation. Delaware Electric is the state's only cooperative and is a member of Old Dominion Electric Cooperative in Virginia.

The commission requires that the following be included in an IRP:

- Load and energy forecasting: Section II outlines standards and minimum reporting requirements for peak demand and energy forecasts, including historical (for the previous 10 years) and forecasted (for the following 15 years) information to be provided.

- Demand-side resource analysis: Section III indicates minimum reporting requirements for describing and evaluating existing and potential DSM programs.

- Supply-side resource analysis: Section IV of the regulation requires the utility to report on existing generation, transmission, and purchased energy resources, and potential supply-side options. The utility must consider environmental abatement and control costs in its analyses of existing and potential supply-side resources. 
- Generation reliability plan: Section V indicates the minimum requirements for reporting on the utility's generation reliability plans, which should include information on actual (for the past 10 years) and forecasted (for the following 15 years) reserve margins, the costs and benefits of alternative levels of generation reliability, and an assessment of reliability using multiple performance measures.

- Integrated analysis of demand- and supply-side options: Section VI specifies minimum requirements for reporting on the utility's integrated resource options, which include implementation schedules, revenue requirements, and average system rates for each option discussed.

- Uncertainty analysis (Section VII)

- Near-term action plan: Section VIII of the regulation requires the utility to submit a 4-year action plan with documentation. 
AGENCY:

CONTACT:

SUMMARY OF REQMT:

TYPE OF REQUIREMENT:

ENABLING AUTHORITY:

EFFECTIVE DATE:

APPLICABILITY:

SPECIFIC REQUIREMENTS:
Indiana Utility Regulatory Commission

Bradley Borum, Assistant Chief Economist, (317) 232-2304; fax (317) 232-6758

Indiana state law requires electric utilities to petition the commission for a certificate of public convenience and necessity prior to the construction, purchase, or lease of a power plant. The commission has interpreted the law to require utilities to do least-cost planning. As a result, all electric utilities filing for a certificate of need must submit an integrated resource plan as a part of the hearing process. The proposed IRP rules indicate that 20-year plans must be submitted every 2 years.

Legislation; rule (in process)

Certificate of Need Statute, Indiana Code 8-1-8.5; and Rulemaking (in process)

To be determined. Rule making is in process.

The proposed IRP rules would be applicable to all electric utilities subject to the requirements of IC 8-1-8.5.

- Cooperatively Owned Utilities: Two G\&Ts are subject to the legislative requirement. These are Hoosier Energy Rural Electric Cooperative, Inc., and Wabash Valley Power Association, Inc.

In August 1990, the commission sought public comment by releasing a statement of issues regarding integrated resource planning. In June 1993, the commission published a proposed rule covering IRP documentation, DSM cost recovery, and bidding for new resources. Comments were received throughout the fall of 1993. Revised proposed rules appeared in the Indiana Register during the summer of 1994 . The commission is currently taking comments received on the revised proposed rules under advisement. 
AGENCY:

CONTACT(S):

SUMMARY OF REQMT:

TYPE OF REQUIREMENTS:

ENABLING AUTHORITY:

EFFECTIVE DATE:

APPLICABILITY:

SPECIFIC REQUIREMENTS:
Iowa Utilities Board

Gordon Dunn, (515) 281-7051; fax (515) 281-5329

The Iowa Utilities Board requires that a utility application for electric generation certificate of public convenience use and necessity be accompanied by least-cost planning information. ${ }^{15}$

Legislation; rule

Iowa Code, Chapter 476 A; Iowa Administrative Code 199:24

1983 (revised in 1990); 1983 (revised in 1991)

This regulation applies to all utilities planning to construct or significantly alter generating facilities of $25 \mathrm{MW}$ or more.

- Cooperatively owned utilities: All of Iowa's 59 distribution cooperatives (and their G\&Ts) are subject to this regulation.

Iowa Administrative Code 199, Chapter 24 requires that an application for certificate of public convenience, use, and necessity include the following:

- General information on the utility, and the proposed site and facility (Section 24.4[1])

- Supply-side resource assessment: In Section 24.4(3a), the commission requires utilities to provide detailed information on all operating generating units and all other sources of electricity available to serve the participating utilities' service area (for example, installed generating capacity, primary fuel types and sources for each unit, the projected retirement date, and total $\mathrm{kW}$ and $\mathrm{kWh}$ available).

- System operating information: Section $24.4(3 b, 3 c)$ outlines system information requirements which include historical data (for the 10 preceding years) on the system load level, customer consumption in each customer class,

\footnotetext{
${ }^{15}$ In compliance with the Energy Policy Act of 1992, the Iowa Utilities Board is investigating whether Iowa rules constitute integrated resource planning. The Board has conducted a hearing and the state's utilities are awaiting a decision.
} 
and capital costs and operation and maintenance expenses.

- System forecast: Section 24.4(4) provides data requirements for forecasting system capabilities. These include descriptions of projected installed generating capacity for the projected life of the facility, other sources of electricity available to supply participants' service territories, existing and planned DSM programs, an analysis of the new facility's impact on the demand for electricity, and a discussion of the forecasting methodology used.

- An evaluation of the economic feasibility of the proposed facility: Section 24(5) provides data requirements for assessing the cost-effectiveness of the proposed facility, including estimated minimum, maximum, and expected cash inflows and outflows, a graphical present value profile, and a discussion of alternative sources of power generation.

- Forecast of environmental, social, and economic impacts: Section 24.4(6) indicates that the utility must conduct an analysis of the effects that the construction, operation, and maintenance of the proposed facility might have on the surrounding social, economic, and natural environments.

- Discussion of site selection methodology (Section 24.4[7])

- Informational meeting (Section 24.7[476A]): Prior to filing an application, the commission requires the utility to hold a public meeting in the county of the proposed site for the facility. The purpose of the meeting is to provide a public forum for discussing the proposed facility and its siting, and for the utility to respond to questions or concerns raised by members of the community. 
AGENCY:

CONTACT:

SUMMARY OF REQMT:

TYPE OF REQUIREMENT:

ENABLING AUTHORITY:

EFFECTIVE DATE:

APPLICABILITY:

SPECIFIC REQUIREMENTS:
Kansas Corporation Commission

John Cita, Chief Economist, Economics Section, (913) 271-3155; fax (913) 271-3354

The commission has proposed an IRP rule that requires triennial IRP plans to be filed by jurisdictional utilities.

Rule (proposed)

Docket \#180,056-U (in process)

To be determined. The commission opened IRP Docket $\# 180,056-U$ in January 1992. At present, commission staff are developing revised proposed rules for commission consideration.

The proposed rule will apply to essentially all electric utilities under commission jurisdiction.

- Cooperatively Owned Utilities: Two G\&Ts will be subject to the regulation. These are Sunflower Electric Power Corporation and Kansas Electric Power Cooperative, Inc. Distribution cooperatives are not subject to the IRP rule.

The proposed IRP rule requires that triennial IRP plans include the following:

- Load forecasts, supply-side and demand-side resource evaluations, and consideration of environmental externalities (some of this language may be deleted from the final rule)

- Construction of two IRP plans. One using the total resource cost (TRC) test as the decision-making criteria, the other using the social cost (SC) test. Utilities have the option of selecting a "preferred plan," which may be equivalent to either the TRC or SC plan, or a mixed average of the two.

- Uncertainty and risk analysis

- Public involvement through implementation of a collaborative process (this provision may be refined as the collaboratives begin to take shape)

- Four-year action plan describing how the preferred IRP plan will be implemented

- A method for data collection and resource evaluation. 
AGENCY:

CONTACT:

SUMMARY OF REQMT:

TYPE OF REQUIREMENT:

ENABLING AUTHORITY:

EFFECTIVE DATE:

APPLICABILITY:

SPECIFIC REQUIREMENTS:
Kentucky Public Service Commission

Michael Alexander, Economist, (502) 564-3940

The Kentucky PSC requires its six largest jurisdictional utilities to file 15-year IRPs every 2 years.

Rule

Regulation 807 KAR 5:058

December 18,1990 . The first utility filings were submitted starting in September of 1991.

This regulation applies to all electric utilities under commission jurisdiction, with the exception of distribution companies with less than $\$ 10,000,000$ in annual revenues and distribution cooperatives organized under KRS Chapter 279. (Section 1, [1])

- Cooperatively Owned Utilities: Two G\&Ts are subject to the regulation. These are the Big Rivers Electric (with 4 member distribution cooperatives) and the East Kentucky Power Cooperative (with 18 member distribution cooperatives).

The specific IRP requirements are delineated in Regulation 807 KAR 5:058 (13 pages). The biennial IRP must include the following:

- Plan Summary: Section 5 of the regulation indicates the minimum contents for a summary of the utility's outlook for load growth and the resources planned to meet that growth.

- Summary of Significant Changes: Section 6 of the regulation indicates that any IRP (subsequent to the initial IRP) shall include a summary of significant changes from the last plan (for example, changes in load forecasts, resource plan, assumptions, or methodologies).

- Load Forecasts: The commission provides detailed loadforecasting requirements in Section 7 of the regulation, including historical (for base year and 4 preceding years) and forecasted (for 15 years) information to be provided, level of disaggregation of forecasting information, and forecasting documentation to be included in the plan.

- Resource Assessment and Acquisition Plan: Section 8 of the regulation requires development of a plan to provide for an adequate and reliable supply of electricity to meet 
forecasted electricity requirements at the lowest possible cost. The plan shall consider the potential impacts of selected, key uncertainties and shall include assessment of potentially cost-effective resource options. The commission requires consideration of a range of demandand supply-side resource options as part of the plan.

- Financial Information: The commission requires inclusion of financial information (for example, revenue requirements, discount rate, and average system rates) as specified in Section 9 of the regulation.

- The regulation does not require formal commission approval of utility IRP submittals. The informal review process consists of staff-level reviews that culminate in a staff report to each utility. The report provides suggestions and recommendations to the utility for subsequent filings. 
AGENCY:

CONTACT(S):

SUMMARY OF REQMT:

TYPE OF REQUIREMENT:

ENABLING AUTHORITY:

EFFECTIVE DATE:

APPLICABILITY:

SPECIFIC REQUIREMENTS:
Maryland Public Service Commission

Mary Beth Tighe, Director of Integrated Resource Planning, (410) 767-8024; fax (410) 333-6086

The Maryland commission requires utilities providing retail electric service in the state to submit 15-year IRPs annually.

Rule

Annotated Code of Maryland, Article 78, Section 59 A-B

1972

This regulation applies to all electric utilities under the commission's jurisdiction providing retail electric service in Maryland.

- Cooperatively Owned Utilities: Four cooperatively owned utilities are subject to this regulation. These are A\&N Electric Cooperative, Choptank Electric Cooperative, Somerset Rural Electric Cooperative, and Southern Maryland Electric Cooperative, Inc.

The commission has not adopted detailed IRP requirements. However, in preparing for its annual 10-year plan, the commission requires that utilities provide specific data on long-range capacity and resource needs in addition to filing IRPs. These include:

- Sales and load forecasts with documentation

- A short-term implementation plan: The commission requires a detailed plan for implementing the utility's long-range integrated resource plan over the next 5 years.

- A strategy for reacting to future uncertainties

- Demand- and supply-side resource assessments; discussion must include utility consideration of renewable energy resources.

- Consideration of environmental externalities. 
AGENCY:

CONTACTS:

SUMMARY OF REQMT:

TYPE OF REQUIREMENT:

ENABLING AUTHORITY:

EFFECTIVE DATE:

APPLICABILITY:

SPECIFIC REQUIREMENTS:
Minnesota Public Utilities Commission

Janet Gonzalez, Supervisor, Energy Unit (612) 296-1336;

fax (612) 297-7073, and Betsy Engelking, (612) 296-1337;

fax (612) 297-7073

The Minnesota commission requires that utilities submit 15-year IRPs every 2 years.

Legislation (public utilities)

Minnesota Laws Chapter 356, Statute 216B.2422

August 1, 1993 (legislative requirement)

The IRP legislation affects all public utilities generating 100,000 or more $\mathrm{kW}$ of electric power and serving, directly or indirectly, 10,000 retail customers. Federal power agencies are unaffected.

- Cooperatively Owned Utilities: The legislation affects Minnesota's four largest G\&Ts. These are Cooperative Power Association (17 member distribution co-ops), United Power Association (15 member distribution coops), Minnkota Power Cooperative (12 member distribution co-ops, 6 in Minnesota), and Dairyland Power Cooperative (28 member distribution coops, 4 in Minnesota).

The specific IRP requirements are delineated in Minnesota Rules Part 7843.0100-0600. The biennial plan must include the following:

- Energy and peak demand forecasts for the next 15 years (Section 7843.0400 Subpart 1)

- A resource plan for meeting the service needs of customers for the forecast period (Section 7843.0400 Subpart 2)

- Resource options for meeting customer service needs when existing resources are inadequate (Section 7843.0400 Subpart 3): This section specifies, at a minimum, the types of resource options that must be considered (ranging from new generating facilities of various types and sizes and with various fuel types to utility-sponsored conservation programs). For those options the utility deems most viable, the utility must evaluate the availability, reliability, cost, and socioeconomic and environmental effects. Utilities must include technical documentation for the plan. 
AGENCY:

CONTACT:

SUMMARY OF REQMT:

TYPE OF REQUIREMENT:

ENABLING AUTHORITY:

EFFECTIVE DATE:

APPLICABILITY:

SPECIFIC REQUIREMENTS:
Nebraska Power Review Board

Gary Gustafson, Director, Nebraska Power Review Board, (402) 471-2301; fax (402) 471-3715

Nebraska Power Review Board requests all electric utilities, under the auspices of the Nebraska Power Association, to collectively prepare a 20-year IRP ("Power Supply Plan") every 5-6 years.

Legislative

Nebraska Statute 70-1023 to 70-1027; Laws 1981, LB 302

1981

The legislation requires that the Nebraska board prepare a long-range power supply plan for the State. The board has the authority to request that "a representative organization," the Nebraska Power Association, prepare the plan. The Nebraska Power Association, composed of representatives from each utility, collects individual utility IRPs (submitted voluntarily), then prepares and files the long-range power plan. The Nebraska Power Association receives the most comprehensive IRPs from the state's eight largest utilities.

- Cooperatively Owned Utilities: Tri-State Generation and Transmission Association, a G\&T headquartered in Colorado, participates in the long-range power planning process.

The specific filing requirements are delineated in Nebraska Statute 70-1023 - 70-1027. The long-range power supply plan submitted to the Nebraska Power Review Board by the Nebraska Power Association must include the following:

- An annual load and capability report, including statewide utility load forecasts and the resources available to satisfy the loads over a 20-year period (70-1025)

- Research and conservation report, including information on research and development, energy conservation, and load management programs, renewable energy sources, and cogeneration. (70-1026) 
AGENCY:

CONTACTS:

SUMMARY OF REQMT:

TYPE OF REQUIREMENT:

ENABLING AUTHORITY:

EFFECTIVE DATE:

APPLICABIITY:

SPECIFIC REQUIREMENTS:
New Mexico Public Utility Commission

Stuart Hamilton, Utility Compliance Specialist (505) 827-6953; fax (505) 827-6973, and John Curl, Economic Manager, (505) 827-6960

The proposed rule requires that electric utilities under the commission's jurisdiction file a 20-year IRP every 3 years.

Rule (proposed)

To be determined

To be determined. The rule-making process started in March 1991, and the commission released a proposed rule in March 1994. As of early 1995, New Mexico utilities were still awaiting a commission decision.

Proposed rule would apply to all electric utilities under the commission's jurisdiction.

- Cooperatively Owned Utilities: All cooperatively owned utilities would be affected except for those requesting a variance.

IRPs submitted in accordance with this proposed rule would include the following:

- Documentation: a nontechnical description of the preferred and alternative plans, the 3-year action plan, and technical documentation of the plans

- Electric energy and demand forecasts for the ensuing 20-year period and historic data for the previous 10-years

- Uncertainty analysis

- Supply- and demand-side resource assessments

- Consideration of environmental impacts

- An integrated resource plan consisting of a preferred plan, a short-term action plan (3-year period), and an explanation and justification of the plans

- Public participation. 
AGENCY:

CONTACT:

SUMMARY OF REQMT:

TYPE OF REQUIREMENT:

EFFECTIVE DATE:

ENABLING AUTHORITY:

APPLICABILITY:

SCHEDULE:
Oklahoma Corporation Commission

Jim Crosslin, Research Coordinator, Research Section (405) 521-6874; fax (405) 521-3336

To be determined

Rule

To be determined. The commission issued a Notice of Inquiry in 1994 and the rule making is in progress.

To be determined

This regulation will apply to electric utilities under commission jurisdiction.

- Cooperatively Owned Utilities: G\&Ts are not regulated by the commission. The commission is investigating whether the proposed regulation will apply to all 31 distribution cooperatives, particularly those distribution cooperatives that have voted themselves exempt from commission jurisdiction.

To be determined. One utility has submitted an IRP voluntarily. 


\section{AGENCIES:}

CONTACT(S):

SUMMARY OF REQMT:

TYPE OF REQUIREMENTS:

ENABLING AUTHORITY:

EFFECTIVE DATE:

APPLICABILITY:

SPECIFIC REQUIREMENTS:
South Carolina Public Service Commission (SCPSC) and South Carolina State Energy Office (SEO)

Dr. James E. Spearman, Assistant Director of Research, (803) 737-5122; fax (803) 737-5199, and Randy Erskine, Engineer, Electric Department, (803) 737-5115 (SCPSC); Jay Flanagan, Director, State Energy Office

(803) 734-3364; fax (803) 734-2727

All electric utilities (IOUs) under the commission's jurisdiction must file a detailed 15-year IRP every 3 years. These plans must be updated annually.

Legislation; rule

SC Energy Supply and Efficiency Act S.C. Code No. 58-37-10; Docket No. 87-223-E, Order No. 91-885, and Order No. 93-845 (Generic), Docket No. 93-430-E, Order Nos. 93-950 and 94-348 (Lockhart Power)

July 1, 1992 (legislation); October 21, 1991 and September 10, 1993 (Generic); October 14, 1993 and April 21, 1994, (SCPSC Orders)

The commission's IRP Order affects South Carolina's four IOUs. Lockhart Power, the smallest of the IOUs, is subject to less extensive IRP requirements, delineated in Docket No. 93-430E.

- Cooperatively Owned Utilities: Twenty-three cooperatively owned utilities are subject to IRP regulations if they acquire ownership of additional generating capacity greater than $12 \mathrm{MW}$.

The specific IRP and DSM requirements are delineated in South Carolina Code Nos. 58-37-10, 58-37-20, 58-37-30, and 58-37-40. The plan filed by Santee Cooper must be developed in consultation with electric cooperatives and municipally owned electric utilities purchasing power and energy from the authority, and must include the effect of demand-side management activities of these cooperatives and municipals.

Electric cooperatives may submit an IRP to the SEO that complies with REA regulations (see Table 5-South Carolina Code No. 58-37-10B) or pattern it after the IRP process developed by the commission (Docket No. 87-223-E, Order No. 93-845), which specifies that the plan include: 
- An integrated resource plan that outlines long- and short-term objectives, evaluates the cost-effectiveness and reliability of supply- and demand-side options, justifies the methodologies used, and explains the underlying assumptions and provides documentation (B1-2, B3, B6)

- A 15-year demand and energy forecast that includes explicit treatment of DSM resources and an uncertainty analysis, and uses forecasting methodologies that include "end-use" modeling techniques (B9) and South Carolina Code 58-37-10

- An assessment of supply-side resources required to support the IRP (B11)

- A demand-side resource assessment (B12)

- Risk assessment (B10)

- A maintenance and refurbishment program for existing units (B15)

- Consideration of environmental costs: costs are to be monetized whenever possible. Costs that cannot be monetized must be addressed on a qualitative basis (B8).

In addition, the commission directs utilities to solicit customer input in the IRP planning process (B4). 


\section{AGENCY:}

CONTACT:

SUMMARY OF REQMT:

TYPE OF REQUIREMENTS:

ENABLING AUTHORITY:

EFFECTIVE DATE:

APPLICABILITY:

SPECIFIC REQUIREMENTS:
Vermont Public Service Board

Kari Dolan, Utilities Analyst, Economics Division, (802) 828-2358; fax (802) 828-3351

The Vermont board requires all electric utilities under its jurisdiction to file IRP plans every 3 years.

Legislation and Public Service Board Order

Statute 30 V.S.A. \$218(c); Docket \#5270 (Phases I-IV for larger utilities, including IOUs); Docket \#5270 (Phase V) (small utilities)

Vermont statute went into effect in 1991; Board Order issued on April 16, 1990 (for larger utilities), and March 13, 1991 (Phase V)

This Order applies to all electric utilities under the board's jurisdiction.

- Cooperatively Owned Utilities: There are only two cooperatives in Vermont: Washington Electric Cooperative, Inc., and Vermont Electric Cooperative, Inc., both of which are subject to the IRP order.

30 V.S.A. 218(c) requires all of the state's electric and gas utilities to conduct IRP. Docket No. 5270 (Phase V) indicates that IRP plans be consistent in detail and content with the Vermont Department of Public Service Twenty-Year Electric Plan, March 1994, and follow the pace and schedule outlined in Docket No. 5270. The plan recommends that IRPs include the following:

- Demand-side resource assessment

- Supply-side resource assessment and acquisition plan: Takes into account capacity and fuel source of current generating facility, operating cycle, contractual provisions and lengths of new contracts, and other uncertainties such as environmental and safety risks

- Base-case load forecasting for a 20 -year period

- An integrated resource plan

- Impact of transmission and distribution (for example, electromagnetic interference effects and development of competitive marketplace for wholesale electricity)

- Uncertainty analysis. 
The board recommends that utilities seek public input concerning IRP planning and make information available for public use. 


\section{AGENCY:}

CONTACT:

SUMMARY OF REQMT:

TYPE OF REQUIREMENT:

ENABLING AUTHORITY:

EFFECTIVE DATE:

APPLICABILITY:

SPECIFIC REQUIREMENTS:
Virginia State Corporation Commission

Rob Lacy, Utilities Research Manager for Economics, (804) 371-9050, fax (804) 371-9935

Utilities under commission jurisdiction must submit 20-year IRPs biennially.

Legislation; commission policy revision

Code of Virginia, Title 56-235.1; Revised 20-Year Data Request

1978 (Virginia code); May 1986 (policy revision)

The commission's IRP data request applies to all electric utilities under the jurisdiction of the commission that own generating facilities and whose total annual Virginia jurisdictional customers exceed 50,000 .

- Cooperatively Owned Utilities: The commission regulates 13 distribution cooperatives but does not have regulatory authority over G\&Ts.

The specific IRP requirements are delineated in Sections I-IX of the Commission's Electric Utility Resource Planning Information Requirements, 1933-2012. The biennial IRP plan must include the following:

- Peak load and energy forecasts: Section III, Section VI, and Appendix I indicate detailed forecasting information requirements, including historical (for the previous 3 years) and forecasted (for the next 20 years) data, and complete documentation of the assumptions, data, and model logic used in developing the forecasts.

- A report on load management and conservation programs expected to be in effect during the 20 -year period (Section IV)

- Demand- and supply-side resource assessments (Section V): The commission requires utilities to discuss major factors affecting current and future resource supplies, including system load characteristics, operation and maintenance requirements of proposed and existing plants, the impact of forecast uncertainty on resource plans, and system reliability criteria and adequacy of projected capacity.

- Explanation of major changes in 20-year forecast and methodologies since previous IRP filing (Section VII) 
- A 20-year integrated resource plan (Section VIII)

- Evaluation of utility's progress toward achieving goals established in previous IRP (Section IX). 
AGENCY:

CONTACT(S):

SUMMARY OF REQMT:

TYPE OF REQUIREMENTS:

ENABLING AUTHORITY:

EFFECTIVE DATE:

APPLICABILITY:

SPECIFIC REQUIREMENTS:
Wisconsin Public Service Commission

Paul C. Newman, Assistant Administrator, Electric Division, (608) 267-5112; fax (608) 266-3957

The commission requires all utilities involved in the generation, distribution, and sale of electricity to individually or collectively submit a 10-year IRP (the "Advanced Plan") biennially. They are all required to jointly develop a statewide plan.

Legislation; rule

Wisconsin Statute Chapter 196.491; Commission Administrative Code, Chapter 111

1975 (legislative requirement); 1976 (PSC Administrative Code)

This regulation applies to all electric utilities under the commission's jurisdiction that generate, distribute, and sell electricity.

- Cooperatively Owned Utilities: All G\&T and distribution cooperatives owning or planning to own high-voltage lines (greater than 1 mile and in excess of $100 \mathrm{kV}$ ) or generating capacity in excess of $300 \mathrm{MW}$ are subject to the regulation. This affects only 1 cooperative, Dairyland Power Cooperative (29 member cooperatives).

Utilities develop a 10-year "Advance Plan" (joint IRP). Utility task forces devoted to specific subject areas (e.g., supply-side, load forecast, externalities, and cogeneration) prepare individual sections of the joint IRP. The specific IRP requirements are delineated in Wisconsin

Administrative Code, Chapter 111. The biennial IRP plan must include:

- Statewide forecast of demand and energy requirements: Sections 111.12 and 111.22 provide detailed guidelines for forecasting peak demand and energy requirements over a 20-year period. The commission requires that each utility provide weekly and annual load duration curve information, forecast the impact of policy on these curves, describe the methodology and data used to derive the forecasted information, and identify any underlying assumptions. Section 111.225 indicates that utilities with a current or planned generating capacity of at least $50 \mathrm{MW}$ must cooperatively develop a forecast of annual 
and monthly coincident demand and load duration curves for the state of Wisconsin.

- Description and assessment of DSM programs: Sections 111.27 and 111.28 establish DSM program information requirements. These include identifying and describing ongoing planned conservation programs, and assessing the probability of success for each program.

- Plans for altering system capacity: Section PSC 111.13 indicates that utilities must provide information on adjustments to existing generating capacity (for example, the addition of generating facilities and the removal of facilities from service) planned for the following 15-year period. In Sections $111.135,111.14,111.15,111.23$, $111.24,111.25$, and 111.26 the commission requires utilities to provide detailed information on alternative generation systems, sites, and transmission routes considered, explain the reasons for selecting the method, fuel type, and site proposed in 111.13, list the environmental impacts associated with the proposed method and the means by which these effects can be minimized or avoided.

- Description of utility research activities and their effect on electric utility operation (Sections 111.16 and 111.27)

- Public review of advance plans: Section 111.31 directs the commission to make advance plans available for public review. The section includes detailed guidelines for publicizing the availability of the plans. 
AGENCY:

CONTACT:

SUMMARY OF REQMT:

TYPE OF REQUIREMENT:

ENABLING AUTHORITY:

EFFECTIVE DATE:

APPLICABILITY:

SPECIFIC REQUIREMENTS:
National Rural Electric Cooperative Association

Rob Church, Principal, (202) 857-9577

Member cooperatives of NRECA have adopted an IRP resolution. The resolution emphasizes that rural electric systems must continue to use IRP and states the need for cooperation and coordination amongst the various entities involved in IRP.

Member Resolution

Continuing Resolution \#53

1992

The resolution applies to over 900 cooperative utilities across the U.S.

Continuing Resolution \#53 reads as follows:

\section{INTEGRATED RESOURCE PLANNING}

Rural electric systems must continue to plan to meet the energy service needs of their members in a manner which effectively integrates supply-side and demand-side resources. Since integrated resource planning for rural electric systems requires the concerted efforts of member consumers, distribution systems, power suppliers, statewide organizations, and regulatory agencies we urge continued cooperation and coordination in the development of rate design, policies and programs.

We urge all segments of our program to continue to use integrated resource planning to assist in providing reliable electrical services at the lowest overall cost by carefully integrating both supply-side and demand-side resources.

This resolution was developed through the cooperative policy development process, which is summarized below (taken from NRECA Rural Electric Sourcebook, 1990, p. 81).

The cooperative policy development process begins each May with the identification of key areas of importance to 
the rural electric program by the NRECA Issues

Committee. The committee (which is appointed by NRECA's board of directors) is comprised of ten members, one from each of the NRECA regions. The committee serves as a forum for identifying concerns, issues, and trends occurring in their respective regions, and develops recommendations that form the basis for new or amended member resolutions. The Issues Committee presents its final recommendations to the NRECA board of directors and to the NRECA membership prior to the start of the regional meetings.

These.recommendations then go to the regional Resolution Committees. These committees consist of an equal number of members (usually only one) from each state. The regional Resolution Committees each draw up recommendations based on input by the membership of directors and managers of local systems and others. These recommendations are then acted upon during the business sessions of the ten regional meetings, held throughout the nation in the fall of each year. Also at the regional meeting, the members of each region elect their representatives to the national standing committees.

At the annual meeting, usually held in February of each year, the final steps in policy development are taken. Members of the 12 standing committees meet to review recommendations and develop resolutions based on those passed at the 10 regional meetings as well as in response to other membership suggestions. Eleven of the standing committees deal with specific subject matter areas; the tweifth, the Resolutions Committee, serves as an overall review committee to put resolutions in final form for presentation to voting delegates during the meeting's business session. 


\section{Appendix C}

\section{G\&T Cooperative Survey Instrument}

The attached survey instrument, "Integrated Resource Planning at Rural Electric Cooperatives," fulfills two purposes:

1. Gathering information on public utility IRP activity and assistance needs for use in the development of DOE's IRP advancement strategy for public utilities; and

2. Satisfying the Energy Policy Act requirement for a survey of cooperative IRP practices.

Because the survey instrument was used for multiple purposes, the survey results presented in this report are limited to information obtained through Sections $A, B$, and $C$ of the instrument. Results for the other survey sections are presented in A Profile of Publicly-Owned Utility Integrated Resource Planning, prepared by Garrick \& Associates under subcontract to NREL. 


\section{INTEGRATED RESOURCE PLANNING AT RURAL ELECTRIC COOPERATIVES}

This questionnaire gathers information about your utility's integrated-resource planning (IRP) activities and interests. The information will help the U.S. Department of Energy to meet the Energy Policy Act's requirement to survey electric cooperative IRP practices and policies and to define a strategy to "increase the use of integrated resource planning." Please answer all questions. Unless instructed otherwise, please circle the number of your answer. If you wish to make comments, use the margins or a separate sheet of paper. If you have any questions, contact Cynthia Garrick at (303) 697-1991.

\section{A. Your Utility's Resource Planning Activities}

Integrated resource planning (IRP) is a method of utility planning in which both supply- and demand-side options are evaluated using comparable terms and methods to determine a combination of utility activities that will yield reliable and adequate energy services at the lowest cost. Please answer the following questions regarding your utility's involvement in the following IRP activities. Note that the REA has already provided some information regarding your planning activities (e.g., load forecasting).

A-1 How often does your utility evaluate supply-side resource options?

1. On an on-going basis

2. Annually

3. Every 2 years

4. Every 3 years

5. Other

A-2 What method(s) are used for supply-side planning and analysis? (Circle all that apply)

1. Levelized bus-bar cost

2. Screening curves analysis

3. Manual evaluation of reliability and cost

4. Automated reliability and cost analysis

5. Hybrid manual and automated analysis

6. Other

A-3 How often does your utility evaluate demand-side resource options?

1. On an on-going basis

2. Annually

3. Every 2 years

4. Every 3 or 4 years

5. Every 5 years or more

6. Other

A-4 Which cost-effectiveness tests are used in the utility's demand-side resource evaluation? (Circle all that apply)

1. Participant test

2. Ratepayer impact measure (RIM) test

3. Utility cost test

4. Total resource cost (TRC) test

5. Societal test

6. Other methods
A-5 What approaches does your utility use to consider social or environmental costs and benefits (e.g., air quality, etc.) associated with supply- and demand-side resource options? (Circle all that apply)

1. Preparation of REA Borrower Environmental Report (BER)

2. Qualitative treatment of "externalities" within IRP analysis (e.g., EIS/listing, scoring, or ranking)

3. Use of environmental and/or social adders

4. Direct quantification or monetization(e.g., cost of control or damage costing)

5. Other

A-6 How often does your utility conduct an integrated evaluation of supply- and demand-side resources?

1. On an on-going basis

2. Annually

3. Every 2 years

4. Every 3 or 4 years

5. Every 5 years or more

6. Other

A-7 What methods are used to integrate supply- and demand-side resource options? (Circle all that apply)

1. Sequential selection, with supply-side considered first

2. Sequential selection, with demand-side considered first

3. Simultaneous supply- and demand-side resource selection, using consistent criteria

4. Other 
A-8 What methods does your utility employ to analyze the uncertainties and risks associated with different electricity resource options? (Circle all that apply)
1. Scenario analysis
2. Sensitivity analysis
3. Portfolio analysis
4. Probabilistic analysis
5. Don't analyze risks and uncertainties
6. Other

A-9 What public involvement approaches does your utility use as part of resource planning and decision-making? (Circle all that apply)

1. Involvement of utility's governing board

2. Involvement of member systems (e.g., advisory group or task force)

3. Involvement of end-use consumers (e.g., workshops, focus groups, surveys)

4. Involvement of outside parties (e.g., public interest groups, etc.)

5. Other

A-10 What is the cost of your utility's integrated resource planning efforts (do not include resource acquisition/ implementation costs)? dollars/year full-time equivalent employees

Other costs

\section{B. IRP Preparation}

B-1 Indicate the relative importance to your utility of the following reasons for doing IRP.
1. To support utility business objectives Very
(Circle your answer)
2. To address environmental considerations Very
Somewhat
Somewhat
Very
Somewhat
4. To meet existing and/or anticipated federal PMA requirements............. Very
Somewhat
5. To meet existing and/or anticipated state PUC requirements
Very
6. To develop the least-cost future resources
Very
Somewhat
Somewhat
7. To become more competitive
Very
Somewhat
Not at All
Not at All
Not at All
Not at All
Not at All
Not at All

8. Other

B-2 Do any of the following factors significantly influence your utility's IRP analyses?

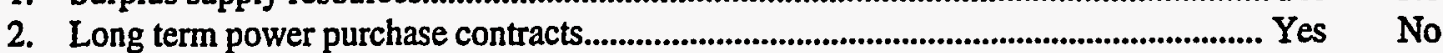

3. Long term all-requirements contracts with member systems........................................... Yes No

4. Transmission limitations........................................................................................................... Yes No

5. Limited financial \& personnel resources................................................................................. Yes No

6. Unavailable/unreliable data.............................................................................................. Nes No

7. Lack of supplier \& distributor coordination......................................................................... Yes No

8. Inconsistent regulations................................................................................................... Yes No

9. Other

\section{Member System Involvement}

C-1 To what extent has or will your G\&T involve its member systems in the following resource planning activities?

1. Demand-side assessment

2. Supply-side assessment.

3. Incorporation of social and/or environmental costs.

4. Integrated evaluation of supply- and demand-side options

5. Uncertainty/risk assessment.

6. Public involvement for resource planning

7. Implementing the resource plan.
(Circle your answer)

Very Somewhat Very Very Very Very .Very Very
Somewhat

Somewhat

Somewhat

Somewhat

Somewhat

Somewhat
Not at All

Not at All

Not at All

Not at All

Not at All

Not at All

Not at All 


\section{Resource Planning Assistance}

In developing its IRP advancement strategy, the Department of Energy is interested in identifying areas where it can provide assistance to rural electric cooperatives. Potential types of assistance include, but are not limited to:

1. Information (e.g., publications, workshops)

2. IRP tools (e.g., software, guidebooks)

3. Technical assistance (e.g. studies, consultations)

4. Financial assistance (e.g., loans, grants)

5. IRP data development (i.e., developing key resource planning data)

D-1 Please rank the five types of IRP assistance listed above in terms of your utility's desire to obtain such assistance during the next five years. (Please write the number of each assistance type on appropriate line below)
\#1 Priority:
\#2 Priority:
\#3 Priority:
\#4 Priority:
\#5 Priority:

Please answer questions D-2 through D-6 to indicate your utility's interest in obtaining various types of IRP assistance.

D-2 How interested would your utility be in the following types of IRP-related information?

(Circle your answer)

1. Publications

Very Somewhat

2. Audiovisual materials.

Very Somewhat

Very Somewhat

3. Workshops and seminars

Very Somewhat

4. Correspondence courses

Very Somewhat

Not at All

Not at All

Don't Know

All Don't know

5. Electronic bulletin boards.

Don't Know

6. Other

D-3 How interested would your utility be in tools (e.g., workbooks, software) to address the following topics?

(Circle your answer)

1. Load forecasting.

Very Somewhat Not at All

2. DSM program selection Very Somewhat Very Somewhat

3. - Externalities costing (e.g., environmental impacts)

Very Somewhat

4. Integrated supply- \& demand-side resource evaluation

Very Somewhat

6. Integration of wholesale and retail impacts

Very Somewhat

Not at All Don't Know

Not at All Don't Know

Not at All Don't Know

Not at All Don't Know

7. Other

D-4 How interested would your utility be in the following types of IRP-related technical assistance?

(Circle your answer)

1. Information hotlines \& clearinghouses........................................ Very Somewhat Not at All Don't Know

2. Circuit rider*............................................................................. Very Somewhat Not at All Don't Know

3. Peer consultation............................................................................ Very Somewhat Not at All Don't Know

4. On-site assistance........................................................................ Very Somewhat Not at All Don't Know

5. Other

* An IRP circuit rider is a resource planning expert shared by several utilities in a region. 
D-5 How interested would your utility be in the following types of IRP-related financial assistance?

(Circle your answer)

1. Loans

Very Somewhat

Not at All Don't know

2. Cost shared funding

Very Somewhat

Very Somewhat

Not at All

3. Grants.

Very Somewhat

Not at All

4. Collective funding by group of utilities

Not at All

Don't Know

6. Awards for IRP performance.

Very Somewhat

Not at All

7. Other

D-6 How interested would your utility be in obtaining improved data in the following areas?

(Circle your answer)

1. Transmission \& distribution options/economics. Very Somewhat

Very Somewhat

Not at All

2. Regional power purchase options/costs

Very Somewhat

3. DSM impacts (e.g., KW, KWH, \& economic)

Very Somewhat

4. Externality costs (e.g., environmental impacts)

Very Somewhat

5. Customer facility \& end-use characteristics

Very Somewhat

Not at All

Not at All

Not at All

Not at All

Not at All

Don't Know

Don't Know

6. Customer attitudes \& behavior

7. Other

D-7 Questions D-2 through D-6 presented various types of IRP assistance which could be of interest to your utility. What other types of IRP-related assistance are you interested in?

D-8 How likely would your utility be to obtain IRP assistance from the following organizations if each offered IRP services to cooperatives?

(Circle your answer)

1. National utility organization (e.g., NRECA, EPRD). .Very Somewhat Not at All

2. Federal power agency (e.g., BPA, SEPA, SWPA, TVA, WAPA) Very Somewhat

3. Rural Electrification Administration Very Somewhat

4. Regional or state utility group (e.g., statewide associations) Very Somewhat Not at All Not at All

Not at All Don't Know Don't Know

5. Private organization (e.g., consultant, information service) Very Somewhat

Not at All Don't Know

6. Other

\section{E. Your Utility's Profile}

E-1 Your utility's average wholesale energy rates.

1. Less than $2 \phi / K W H$

2. $2 \phi / \mathrm{KWH}$ to $4 \phi / \mathrm{KWH}$

3. $4 \phi / K W H$ to $6 \phi / \mathrm{KWH}$

4. $6 \phi / \mathrm{KWH}$ to $8 \notin / \mathrm{KWH}$

5. Greater than $8 \notin / \mathrm{KWH}$

6. This information is not available for release (i.e., confidential)

E-2 Your utility's average wholesale capacity rates.

1. Less than $\$ 3 / \mathrm{KW}$-month

2. $\$ 3 / \mathrm{KW}$ to $\$ 6 / \mathrm{KW}$-month

3. $\$ 6 / \mathrm{KW}$ to $\$ 10 / \mathrm{KW}$-month

4. $\$ 10 / \mathrm{KW}$ to $\$ 14 / \mathrm{KW}$-month

5. Greater than $\$ 14 / \mathrm{KW}$-month

6. This information is not available for release (i.e., confidential)
E-3 Your utility's 1993 annual system sales.

1. Less than $50,000 \mathrm{MWH}$

2. 50,000 to $100,000 \mathrm{MWH}$

3. 100,001 to $500,000 \mathrm{MWH}$

4. 500,001 to $1,000,000 \mathrm{MWH}$

5. Greater than $1,000,000 \mathrm{MWH}$ 
The following information was obtained directly from the Rural Electrification Administration for each of the G\&T survey respondents.

\section{INTEGRATED RESOURCE PLANNING AT G\&T COOPERATIVES}

Utility name

Utility location (City, State)

How often does the utility develop a multi-year load forecast?
1. Annually
2. Every 2 years
3. Every 3 or 4 years
4. Every 5 years or more
5. Never

Does the utility develop a range of demand forecasts (e.g., high, medium, and low forecasts)
1 Yes, always
2. Sometimes
3. No
4. Don'tknow

What forecasting method(s) are used? (Circle all that apply)
1. Time-Trend
2. Time-Series
3. Expert Opinion/Delphi
4. Identity
5. End-Use
6. Econometric
7. Don't know
8. Other

To what extent does the G\&T involve its distribution members in the following resource planning activities?

(Circle answer)

Multi-year load forecasting Very Somewhat

Not at All

Utility's current electrical supply situation.

1. Capacity

2. Energy. Deficit Deficit

(Circle answer)

Balance Surplus

Balance Surplus

Average annual load growth in service area.

1. Negative Load Growth

2. 0 to $1.0 \%$

3. 1.1 to $2.0 \%$

4. 2.1 to $4.0 \%$

5. $4.1 \%$ or greater

Source of "peak load" (not baseload) power used by utility?

1. Utility's own generation

2. A power supply organization in which you have ownership (e.g., joint action agency)

3. A federal power agency (e.g., BPA, SEPA, SWPA, TVA, WAPA)

4. An investor-owned utility

5. Other

Is purchased power the utility's most expensive supply-side resource?

1. Yes

2. No (Skip next question)

Total number of electric utility employees.

1. Less than 50

2. 50 to 200

3. 201 to 500

4. 501 to 1000

5. Greater than 1000 


\section{Appendix D}

\section{Distribution Cooperative Survey Instrument}

The attached survey instrument, "Integrated Resource Planning at Rural Electric Cooperatives," fulfills two purposes:

1. Gathering information on public utility IRP activity and assistance needs for use in the development of DOE's IRP advancement strategy for public utilities; and

2. Satisfying the Energy Policy Act requirement for a survey of cooperative IRP practices.

Because the survey instrument was used for multiple purposes, the survey results presented in this report are limited to information obtained through Sections A and B of the instrument. Results for the other survey sections are presented in A Profile of Publicly-Owned Utility Integrated Resource Planning, prepared by Garrick \& Associates under subcontract to NREL. 


\section{INTEGRATED RESOURCE PLANNING AT RURAL ELECTRIC COOPERATTVES}

This questionnaire gathers information about your system's integrated-resource planning (IRP) activities and interests. The information will help the U.S. Department of Energy to meet the Energy Policy Act's requirement to survey electric cooperative IRP practices and policies and to define a strategy to "increase the use of integrated resource planning." Please answer all questions. Unless instructed otherwise, please circle the number of your answer. If you wish to make comments, use the margins or a separate sheet of paper. If you have any questions, contact Cynthia Garrick at (303) 697-1991.

\section{A. Your Power Supplier}

A-1 Please indicate which of the following sources provides the majority of your rural electric system's power supply. (Circle only one answer)

1. A power supply organization in which you have an ownership interest (e.g., G\&T)

2. A federal power agency (e.g., BPA, TVA, etc.)

3. An investor-owned utility

4. Other (e.g., system's own generation)

A-2 Please identify your power supplier

\section{B. Your System's Resource Planning Activities}

Integrated resource planning ( $(R P)$ is a method of utility planning in which both supply-and demand-side options are evaluated using comparable terms and methods to determine a combination of utility activities that will yield reliable and adequate energy services at the lowest cost. Please indicate the nature of your system's involvement in the following IRP activities. Circle all answers which apply to your system.

B-1 Does your system prepare its own IRP, independent of a power supplier?

1 Yes

2. No

B-2 Describe your system's load forecasting activities.

1. Develop our own load forecasts

2. Participate in developing power supplier's load forecasts

3. Our system is included in load forecasts done solely by power supplier

4. No load forecasting activities

B-3 Describe your system's supply-side resource evaluation activities.

1. Perform our own supply-side resource evaluations

2. Participate in power supplier's supply-side evaluations

3. Our system is included in supply-side evaluations done solely by power supplier

4. No supply-side evaluation activities
B-4 Describe your system's demand-side resource evaluation activities.

1. Perform our own demand-side resource evaluations

2. Participate in power supplier's demand-side evaluations

3. Our system included in demand-side evaluations done solely by power supplier

4. No demand-side evaluation activities

B-5 Describe how your system considers social or environmental costs and benefits (e.g., air quality, etc.) associated with supply- and demand-side resource options.

1. Consider these costs and benefits on our own

2. Participate in power supplier's consideration of such costs and benefits

3. Environmental/social costs and benefits considered solely by power supplier

4. No consideration of these costs and benefits 
B-6 Describe your system's integrated supply- and demand-side resource evaluation activities.

1. Conduct our own integrated resource evaluations

2. Participate in power supplier's integrated resource evaluations

3. Our system is included in integrated resource evaluations done solely by power supplier

4. No integrated resource evaluation activities

B-7 Describe your system's activities to analyze the uncertainties and risks associated with different electricity resource scenarios.

1. Perform our own risk assessments for various resource options

2. Participate in power supplier's risk assessment activities

3. Our system is considered in risk assessments done solely by power supplier

4. No risk assessment activities
B-8 What public involvement approaches does your system use as part of resource planning and implementation?

1. Involvement of system's governing board

2. Involvement of end-use consumers (e.g., workshops, focus groups, surveys)

3. Involvement of outside parties (e.g., public interest groups, etc.)

4. Other

B-9 Do any of the following factors significantly influence your system's analyses and resulting plans?
1. Surplus supply resources.
(Circle your answer)
2. All-requirements power purchase contracts .Yes
3. Long term power sales contracts Yes
No
4. Transmission limitations. Yes
No
5. Limited financial \& personnel resources Yes No
6. Unavailable/unreliable data. ..Yes No
7. Lack of supplier \& distributor coordination .Yes
8. Inconsistent regulations Yes
9. Other

\section{Your System's Supply- and Demand-Side Resources}

C-1 Which of the following are used to meet the electrical needs of your system's consumers? (Circle all that apply)

1. Power purchases from another utility (e.g., G\&T, PMA, IOU, etc.)

2. Purchases of customer generation

3. Purchases of independent power producer generation

4. Utility-owned peaking unit (e.g., gas turbine)

5. Utility-owned baseload unit

6. Utility-owned renewables (e.g., hydroelectric plant, wind turbines, biomass facility)

7. Customer-owned renewables (e.g., remove solar photovoltaic systems)

8. Other

C-2 Please complete the following matrix to indicate the various types of demand-side programs which your system currently operates, and the customer classes which these programs are offered to. Put an " $\mathrm{X}$ " in the boxes below to indicate your current DSM programs.

\section{DSM Program}

1. Peak clipping (e.g., direct load control)

2. Valley filling (e.g., propane to electric fuel substitution)

3. Load shifting (e.g., load control, TOU rates)

4. Strategic conservation

5. Strategic load growth

6. Other

\section{Residential Commercial Industrial Agricultural}

$\begin{array}{lllll}\square & a & a & \square \\ 0 & \square & & \square & \square \\ \square & \square & a & \square \\ \square & \square & \square & \square \\ \square & \square & \square & \square\end{array}$


In developing its IRP advancement strategy, the Department of Energy is interested in identifying areas where it can provide assistance to rural electric systems. Potential types of assistance include, but are not limited to:

1. Information (e.g., publications, workshops)

2. IRP tools (e.g., software, guidebooks)

3. Technical assistance (e.g. studies, consultations)

4. Financial assistance (e.g., loans, grants)

5. IRP data development (i.e., developing key resource planning data)

D-1 Please rank the five types of IRP assistance listed above in terms of your system's desire to obtain such assistance during the next five years. (Please write the number of each assistance type on appropriate line below)

\#1 Priority:

\#2 Priority:

\#3 Priority:

\#4 Priority:

\#5 Priority:

Please answer questions D-2 through D-6 to indicate your system's interest in obtaining various types of IRP assistance.

D-2 How interested would your system be in the following types of IRP-related information?

(Circle your answer)

1. Publications

Very Somewhat

Not at All Don't Know

2. Audiovisual materials

Very Somewhat

Not at All Don't Know

3. Workshops and seminars

Very Somewhat

4. Correspondence courses

Very Somewhat

Not at All Don't Know

5. Electronic bulletin boards

Very Somewhat

Not at All Don't Know

6. Other

D-3 How interested would your system be in tools (e.g., workbooks, software) to address the following topics?

(Circle your answer)

1. Load forecasting.

Very Somewhat

Not at All Don't Know

2. DSM program selection. Very Somewhat

Not at All Don't Know

3. Externalities costing (e.g., environmental impacts)

Very Somewhat

Not at All Don't Know

4. Integrated supply- \& demand-side resource evaluation

Very Somewhat

5. Impact \& process evaluation of DSM programs.

Very Somewhat

6. Integration of wholesale and retail impacts

Very Somewhat

Not at All Don't Know

Not at All Don't Know

7. Other

Not at All Don't Know

D-4 How interested would your system be in the following types of IRP-related technical assistance?

(Circle your answer)

1. Information hotlines \& clearinghouses

Very Somewhat

Not at All Don't Know

2. Circuit rider* Very Somewhat

Not at All

3. Peer consultation

Very Somewhat

Not at All

Don't Know

4. On-site assistance.

.Very Somewhat

5. Other

* An IRP circuit rider is a resource planning expert shared by several utilities in a region.

D-5 How interested would your system be in the following types of IRP-related financial assistance?

(Circle your answer)

1. Loans

Very Somewhat

Not at All

2. Cost shared funding.

Very Somewhat

Not at All

Very Somewhat

Not at All

Don't Know

3. Grants.

Very Somewhat

Not at All

Don't know

4. Collective funding by group of utilities

Very Somewhat

Not at All

Don't Know

6. Awards for IRP performance

7. Other 
D-6 How interested would your system be in obtaining improved data in the following areas?

(Circle your answer)

1. Transmission \& distribution options/economics Very Somewhat

Not at All Don't Know

2. Regional power purchase options/costs

Very Somewhat

Not at All

Very Somewhat

Not at All

Don't Know

3. DSM impacts (e.g., KW, KWH, \& economic)

Very Somewhat

Not at All

Don't Know

4. Externality costs (e.g., environmental impacts)

Very Somewhat

Not at All

6. Customer attitudes \& behavior.

Very Somewhat

Not at All

Don't Know

7. Other

D-7 Questions D-2 through D-6 presented various types of IRP assistance which could be of interest to your system. What other types of IRP-related assistance are you interested in?

D-8 How likely would your system be to obtain IRP assistance from the following organizations if each offered IRP services to cooperatives?

(Circle your answer)

1. National utility organization (e.g., NRECA, EPRI).

Very Somewhat

Not at All Don't Know

2. Federal power agency (e.g., BPA, SEPA, SWPA, TVA, WAPA) Very Somewhat

3. Rural Electrification Administration................................................ Very Somewhat

4. G\&T cooperative......................................................................... Very Somewhat

4. Regional or state utility group (e.g., statewide associations)......... Very Somewhat

5. Private organization (e.g., consultant, information service).............Very Somewhat

Not at All Don't Know

Not at All Don't Know

Not at All Don't Know

Not at All Don't Know

6. Other

\section{E. Your System's Profile}

E-1 Your system's average retail energy rates for general service commercial consumers.

1. Less than $2 \phi / \mathrm{KWH}$

2. $2 \phi / \mathrm{KWH}$ to $4 \phi / \mathrm{KWH}$

3. $4 \phi / \mathrm{KWH}$ to $7 \phi / \mathrm{KWH}$

4. $7 \notin / \mathrm{KWH}$ to $10 \notin / \mathrm{KWH}$

5. Greater than $10 \notin / \mathrm{KWH}$

E-2 Your system's average retail demand rates for general service commercial consumers.

1. Less than $\$ 4 / \mathrm{KW}$-month

2. $\$ 4 / \mathrm{KW}$ to $\$ 8 / \mathrm{KW}$-month

3. $\$ 8 / \mathrm{KW}$ to $\$ 12 / \mathrm{KW}-$ month

4. $\$ 12 / \mathrm{KW}$ to $\$ 16 / \mathrm{KW}$-month

5. Greater than $\$ 16 / \mathrm{KW}$-month
E-3 Average annual load growth in your service area.

1. Negative load growth

2. 0 to $1.0 \%$

3. 1.1 to $2.0 \%$

4. 2.1 to $4.0 \%$

5. $4.1 \%$ or greater

E-4 Total number of electric system employees.

1. Less than 20

2. 20 to 50

3. 51 to 100

4. 101 to 200

5. Greater than 200

1993 Meters and Sales. (Please complete the table)

\begin{tabular}{|l|l|l|}
\hline Customer Class & No. of Meters & kWh Sales \\
\hline Residential & & \\
\hline Commercial & & \\
\hline Industrial & & \\
\hline Agricultural & & \\
\hline Other & & \\
\hline
\end{tabular}

As part of this study, we will also be contacting a limited number of cooperative utilities by telephone. If we do call you, we will ask a few brief questions about your system's planning approaches and needs. The information that we obtain from these discussions will benefit cooperative utilities across the U.S. If you are interested in participating in a telephone interview, please provide your name and telephone number.

Name: System: Telephone: 


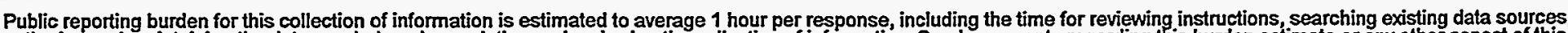

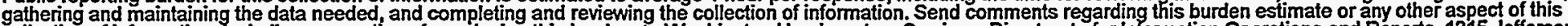

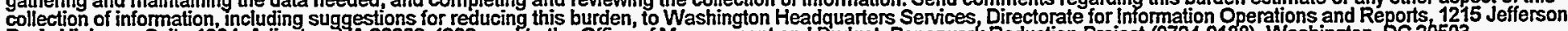

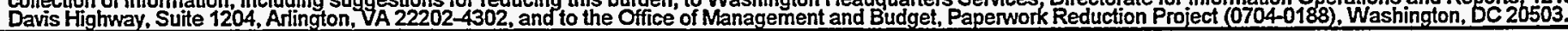
1. AGENCY USE ONLY (Leave blank)
2. REPORT DATE
November 1995
3. REPORT TYPE AND DATES COVERED Subcontractor report

4. TITLE AND SUBTITLE

Rural Electric Cooperatives IRP Survey

5. FUNDING NUMBERS

AS115504

6. AUTHOR(S)

Cynthia J. Garrick

Subcontract AAW-3-13353-01

7. PERFORMING ORGANIZATION NAME(S) AND ADDRESS(ES)

Garrick \& Associates

8. PERFORMING ORGANIZATION

5198 Willow Springs Drive

*sirison, Colorado 80465

9. SPONSORING/MONITORING AGENCY NAME(S) AND ADDRESS(ES)

National Renewable Energy Laboratory

1617 Cole Boulevard

Golden, CO $80401-3393$

10. SPONSORING/MONITORING AGENCY REPORT NUMBER

TP-461-7284

\section{SUPPLEMENTARY NOTES DE95009223}

12a. DISTRIBUTION/AVAILABILITY STATEMENT National Technical Information Service

U.S. Department of Commerce

UC

5285 Port Royal Road

Springrield, VA 22161

13. ABSTRACT (Maximum 200 words)

This report presents the results of a survey of integrated resource planning (IRP) practices of U.S. rural electric cooperatives. A discussion of the IRP policies that influence these practices is also included. Analysts surveyed generation and transmission cooperatives (G\&Ts) and distribution cooperatives. They also obtained information from the Rural Electrification Administration and federal and state agencies. The study found that IRP is widely practiced in the rural electric co-op sector by G\&Ts and other power suppliers. It also found that distribution co-ops owning and governing G\&Ts participate in IRP as well. The report concluded that the cooperative utility sector-with its nonintegrated organization and complex relationships among cooperative systems-offers unique challenges and opportunities for IRP. The report states that these challenges and opportunities can be met through the continued development and application of appropriate IRP practices and policies.

14. SUBJECT TERMS
integrated resource planning; cooperatives; rural electric cooperatives

NUMBER OF PAGES 70

16. PRICE CODE

17. SECURITY CLASSIFICATION OF REPORT unclassified
18. SECURITY CLASSIFICATION OF THIS PAGE unclassified
19. SECURITY CLASSIFICATION OF ABSTRACT unclassified
20. LIMITATION OF ABSTRACT UL 
